\title{
Modelling and mapping of regional disparities associated with female genital mutilation/cutting prevalence among girls aged 0-14 Years in Senegal: Evidence from Senegal (SDHS) Surveys 2005-2017
}

Ngianga-Bakwin Kandala

Paul Komba

Chibuzor Christopher Nnanatu

Glory Atilola

Lubanzadio Mavatikua

See next page for additional authors

Follow this and additional works at: https://knowledgecommons.popcouncil.org/departments_sbsr-rh

Part of the Demography, Population, and Ecology Commons, Family, Life Course, and Society

Commons, Gender and Sexuality Commons, International Public Health Commons, and the Medicine and Health Commons

How does access to this work benefit you? Let us know!

\section{Recommended Citation}

Kandala, Ngianga-Bakwin, Paul Komba, Chibuzor Christopher Nnanatu, Glory Atilola, Lubanzadio Mavatikua, Zhuzhi Moore, and Dennis Matanda. 2020. "Modelling and mapping of regional disparities associated with female genital mutilation/cutting prevalence among girls aged 0-14 Years in Senegal: Evidence from Senegal (SDHS) Surveys 2005-2017," Evidence to End FGM/C: Research to Help Girls and Women Thrive. New York: Population Council. 


\section{Authors}

Ngianga-Bakwin Kandala, Paul Komba, Chibuzor Christopher Nnanatu, Glory Atilola, Lubanzadio Mavatikua, Zhuzhi Moore, and Dennis Matanda 


\section{Evidence to End FGM/C}

Research to Help Girls and Women Thrive

\section{MODELLING AND MAPPING OF FGM/C AND RISK FACTORS AMONG GIRLS \\ 0-14 YEARS IN SENEGAL}

EVIDENCE FROM SENEGAL DEMOGRAPHIC AND HEALTH SURVEYS (SDHS), 2005-2017

January 2020 


\section{MODELLING AND MAPPING OF FGM/C AND RISK FACTORS AMONG GIRLS 0-14 YEARS IN SENEGAL:}

EVIDENCE FROM SENEGAL DEMOGRAPHIC AND HEALTH SURVEYS (SDHS), 2005-2017

NGIANGA-BAKWIN KANDALA

PAUL KOMBA CHIBUZOR CHRISTOPHER NNANATU GLORY ATILOLA LUBANZADIO MAVATIKUA UNIVERSITY OF NORTHUMBRIA AT NEWCASTLE, UK

ZHUZHI MOORE INDEPENDENT CONSULTANT, POPULATION COUNCIL

DENNIS MATANDA POPULATION COUNCIL, NAIROBI, KENYA 
Evidence to End FGM/C: Research to Help Girls and Women Thrive generates evidence to inform and influence investments, policies, and programmes for ending female genital mutilation/cutting in different contexts. Evidence to End FGM/C is led by the Population Council, Nairobi in partnership with the Africa Coordinating Centre for the Abandonment of Female Genital Mutilation/Cutting (ACCAF), Kenya; the Global Research and Advocacy Group (GRAG), Senegal; Population Council, Nigeria; Population Council, Egypt; Population Council, Ethiopia; MannionDaniels, Ltd. (MD); Population Reference Bureau (PRB); University of California, San Diego (Dr. Gerry Mackie); and University of Washington, Seattle (Prof. Bettina Shell-Duncan).

POPULATION COUNCIL

Ideas. Evidence. Impact.
The Population Council confronts critical health and development issues-from stopping the spread of HIV to improving reproductive health and ensuring that young people lead full and productive lives. Through biomedical, social science, and public health research in 50 countries, we work with our partners to deliver solutions that lead to more effective policies, programmes, and technologies that improve lives around the world. Established in 1952 and headquartered in New York, the Council is a nongovernmental, nonprofit organisation governed by an international board of trustees. www.popcouncil.org

Suggested Citation: Kandala Ngianga-Bakwin, Komba Paul, Nnanatu Chibuzor Christopher, Atilola Glory, Mavatikua Lubanzadio, Moore Zhuzhi, and Matanda Dennis. 2020. "Modelling and Mapping of Regional Disparities Associated with Female Genital Mutilation/Cutting Prevalence Among Girls Aged 0-14 Years in Senegal: Evidence from Senegal (SDHS) Surveys 20052017." Evidence to End FGM/C: Research to Help Girls and Women Thrive. New York: Population Council.

This is a working paper and represents research in progress. This paper represents the opinions of the authors and is the product of professional research. This paper has not been peer reviewed, and this version may be updated with additional analyses in subsequent publications. Contact: Prof. Ngianga-Bakwin Kandala N-B.Kandala@warwick.ac.uk or kandalabakwin@yahoo.com

Please address any inquiries about the Evidence to End FGM/C programme consortium to:

Dr Jacinta Muteshi, Project Director, imuteshi@popcouncil.org

Funded by:

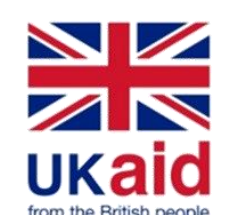

This document is output from a programme funded by UK Aid from the UK government for the benefit of developing countries. However, the views expressed and information contained in it are not necessarily those of, or endorsed by the UK government, which can accept no responsibility for such views or information or for any reliance placed on them. 


\section{Table of Contents}

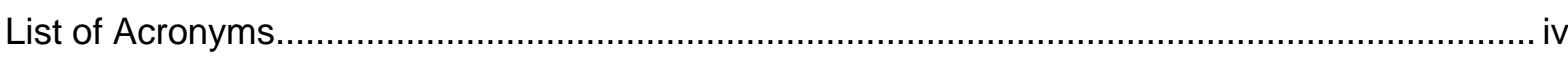

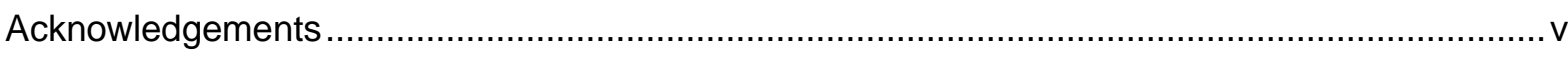

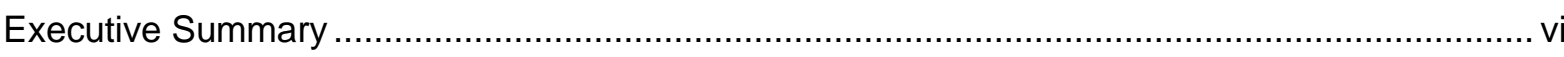

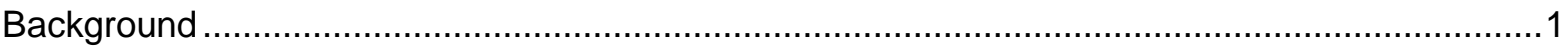

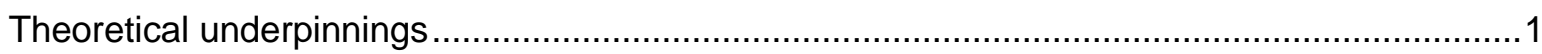

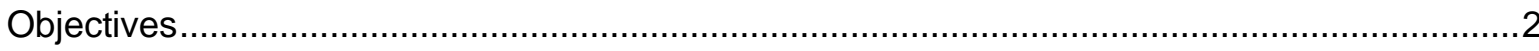

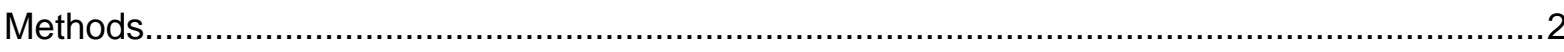

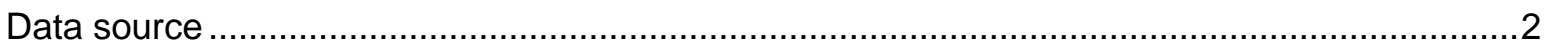

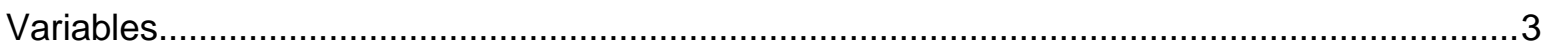

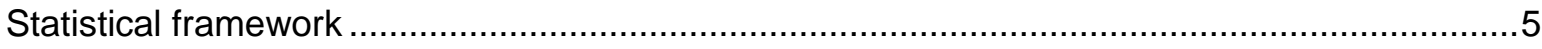

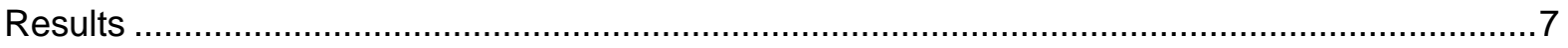

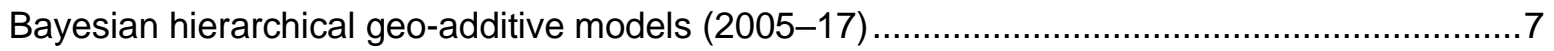

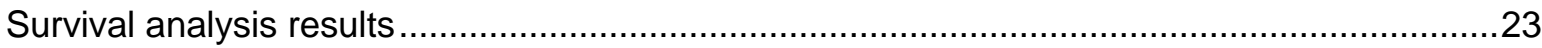

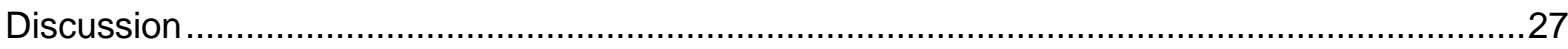

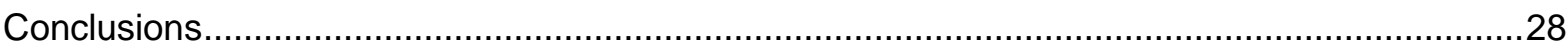

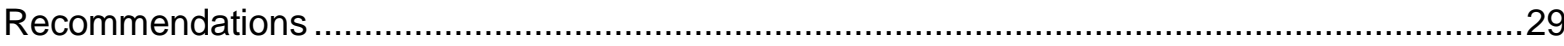

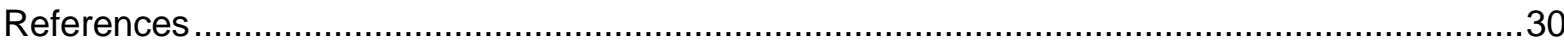

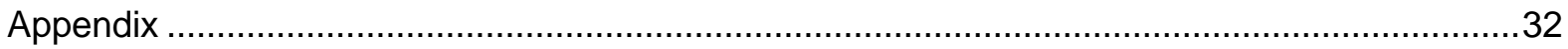




\section{List of Acronyms}

ANSD Agence Nationale de la Statistique et de la Démographie (Sénégal)

DHS Demographic and Health Survey

FGM/C Female Genital Mutilation/Cutting

IAC Inter African Committee

MCMC Markov Chain Monte Carlo

MRF Markov Random Field

SDGs Sustainable Development Goals

SDHS Senegal Demographic and Health Survey 


\section{Acknowledgements}

The authors would like to express their profound thanks to reviewers who provided critical comments for the improvement of this study report. We thank ICF Macro for making it possible for researchers in the field of FGM/C to access the data required to carry out this study. We also wish to thank Dr. Jacinta Muteshi and her team who provided guidance and support for this project. We express our profound gratitude to Dr. Francis Obare, Dr. Caroline W. Kabiru, and Prof. Bettina Shell-Duncan for their thoughtful reviews of the initial versions of this report as well as to Christina Tse for her editorial support. 


\section{Executive Summary}

\section{Background}

Between 2005 and 2017, Senegal experienced a slight national decline in the prevalence of female genital mutilation/cutting (FGM/C) among women aged 15-49 years and girls younger than 15 years. However, significant differences in prevalence exist as a result of multifarious risk factors. Along with its nongovernmental partners, the government has committed substantial resources designed to tackle the practice and achieve Target 5.3 of the Sustainable Development Goals (SDGs). Our previous research in Senegal described the national trends in $\mathrm{FGM} / \mathrm{C}$, showing where, when, and why FGM/C is practised in Senegal. However, no recent study exists to analyse the geographical patterns of $\mathrm{FGM} / \mathrm{C}$ and the effect of individual- and community-level risk factors on the likelihood of cutting among girls younger than 15 years. The present report sought to provide a more consistent evidence base on the patterns of $\mathrm{FGM} / \mathrm{C}$ and the impact of multilevel factors on geographical variations in the risk of girls' cutting. Specifically, this study examined the spatial distribution of FGM/C risks among girls who are younger than 15 years and identified individual- and community-level characteristics associated with the probability for such girls facing cutting in Senegal. This evidence base is necessary for well-informed targeting of prevention strategies.

\section{Methodology}

Data for this study were extracted from the 2005, 2010-11, 2015, and 2017 Senegal Demographic and Health Surveys (SDHS) and comprised 43,155 girls. The study adopted a Bayesian hierarchical modelling approach to develop multivariate explanatory models for FGM/C risks in girls younger than 15 years. The approach also served to model and map geographical variations in prevalence of FGM/C. We simultaneously evaluated the influence of potential risk factors in a Bayesian geo-additive regression framework. Under such a framework, an assessment of residual risk from unobserved factors was conducted with respect to the geographical location of an individual. We also employed survival analytical techniques to determine a girl's survival time (age) to cutting and how this varied based on their mothers' individual- and community-level characteristics.

\section{Key findings}

Results showed that $\mathrm{FGM} / \mathrm{C}$ in Senegal exhibited distinct geographical patterns, with higher probability of girls being cut in the regions of Matam, Kolda, Tambacunda, Zingunchior, and Kedougou. Girls in the western and central regions (including Dakar, Fatick, Thies, and Diourbel) had lowest likelihood of being cut. We also found that FGM/C risk remained high across time in several regions at various time points after accounting for the influence of individual- and community-level factors. Spatial clustering of FGM/C risk were observed across the regions of Sedhiou and Kolda in 2010; Matam and Zinguichor in 2015; and Saint Louis, Tambacounda, and Kolda in 2017. We also observed that individual- and community-level risk factors contributed to FGM/C among girls younger than 15 years. Among individual-level factors, we found that place of residence and mother's ethnicity were the main risk factors. Girls in rural areas were more likely to be cut than those in urban locations. In 2017, the likelihood of a girl being cut was $50 \%$ higher for girls in rural areas compared to their counterparts in urban locations. Over time, several high-prevalence regions remained "hot spots" with a consistently high FGM/C risk over the 12-year period. The prevalence of FGM/C was consistently higher in Kolda and significantly lower in Kedougou. A shift was observed for Sedhiou region, which moved from a significantly higher FGM/C prevalence area in 2005 to a significantly low FGM/C prevalence in 2017. Tabacounda moved from a lower prevalence region in 2005 to higher prevalence region in 2017.

The strong influence of mother's ethnicity on the likelihood of cutting in girls was consistently observed 
across the four survey years, especially among daughters of women from Poular, Mandingue, Soninke, and Diola ethnic groups after adjusting for the influence of other factors. The key communitylevel risk factors included adherence to social norms as measured by the FGM/C status of a girl's mother, her support for continuation of the practice, and whether the mother believed FGM/C was a religious requirement. We found that daughters of cut mothers were at a higher risk of being cut. This was the case despite reduction in the influence of the mother's FGM/C status on daughter's FGM/C status over time. The likelihood of cutting a girl was also found to increase in line with the proportion of women who were subjected to FGM/C within her community. One important variation, however, was that women who supported continuation of the practice were less likely to cut their girls in 2017 . Further, we found that the proportion of mothers who cut for religious reasons was high over time.

Although there was a positive association between mother's age and the probability of cutting her daughter in 2005, the influence of mother's age declined substantially in 2010 and 2017. In 2015, however, the risk of girls being cut was lower among older women. Across the survey years, strong positive association between a girl's age and her likelihood of being cut was observed. Findings from the survival analysis showed that girls born to Soninke mothers were cut at much younger age (1 year old) compared with their counterparts from Diola ethnic group whose median age at cutting was 3 years.

\section{Conclusions}

The study assessed the risk factors and spatial correlates of FGM/C risk among girls younger than 15 years. We found that the risk of FGM/C was high among specific ethnic groups, and when the girl was located in a rural rather than urban area. These results hold true when the girl's mother expressed support for the continuation of the practice, had undergone FGM/C, or believed that FGM/C was a religious requirement. We noted a persistent geographical variation in the risk of girls being cut across the western regions of Senegal. Across ethnicities, variation was also found with respect to a girl's age at cutting. An in-depth understanding of how these factors influence FGM/C risk among young girls across ethnic groups and regions with high FGM/C prevalence may therefore be an important next step.

\section{Recommendations}

Our overall findings are based on residual geographical pattern risks of FGM/C and have taken account of the influence of social norms and other risk factors. The results can inform the design and implementation of community-based interventions by pinpointing regions with high risk of $\mathrm{FGM} / \mathrm{C}$ among young girls. The results also underscore the need for targeted behaviour change interventions at both the individual and community level to address the risks associated with FGM/C in girls. Such interventions must involve relevant stakeholders, including decisionmakers and community, political, and religious leaders, in order to achieve definitive abandonment across all regions. Further research is warranted to explore the reason why girls in Matam and other eastern parts of Senegal have a higher probability of being cut. Further still, an in-depth study needs to consider time to cutting and whether the seasonality of FGM/C may constitute increased risk for girls' cutting. Finally, future research could examine how the risks of cutting compare within the same birth cohort in the 2005-17 SDHS. Particular attention should also be focused on the potential underreporting of the practice given increased attention to the human rights violation of $\mathrm{FGM} / \mathrm{C}$ and the impact of the law banning the practice on the prevalence of FGM/C. 


\section{Background}

Female genital mutilation/ cutting (FGM/C) constitutes a real threat, not only to the health of women and girls, but also to their human rights. The Senegalese government, along with its partners, has responded to this threat at several levels. For example, the country has committed resources to repress the practice in conformity with Target 5.3 of the Sustainable Development Goals (SDGs). Despite these efforts, only a slight decline in prevalence of the practice has been observed at the national level and risk factors and geographical variations in these risks remain persistent (Kandala and Shell-Duncan 2019).

Scholars have highlighted the possibility that social norms could be driving FGM/C in Senegal (Kandala and Shell-Duncan 2019). In addition, research efforts have been directed to increased understanding of contextual determinants of $\mathrm{FGM} / \mathrm{C}$ and the distribution of the practice across communities and regions over time (Achia 2014; Yaya and Ghose 2018; Kandala and Shell-Duncan 2019). However, no study has so far assessed the linkage between geographical location, individualand community-level factors, and FGM/C among girls, using the most recent datasets available for Senegal. The limited understanding of how individual- and community-level factors as well as geographic attributes affect a girl's risk of FGM/C thus remains a major obstacle to the total eradication of the practice (Kandala and Komba 2015). We sought to fill this gap in the literature by using Bayesian spatial modelling to explore the link between these factors and the probability of cutting among girls younger than 15 years. In this respect, the study will be a relevant addition to understanding the degree of risk in the girls' cutting and its variation in Senegal (Figure 1).

Figure 1. Map of Senegal showing the administrative regions

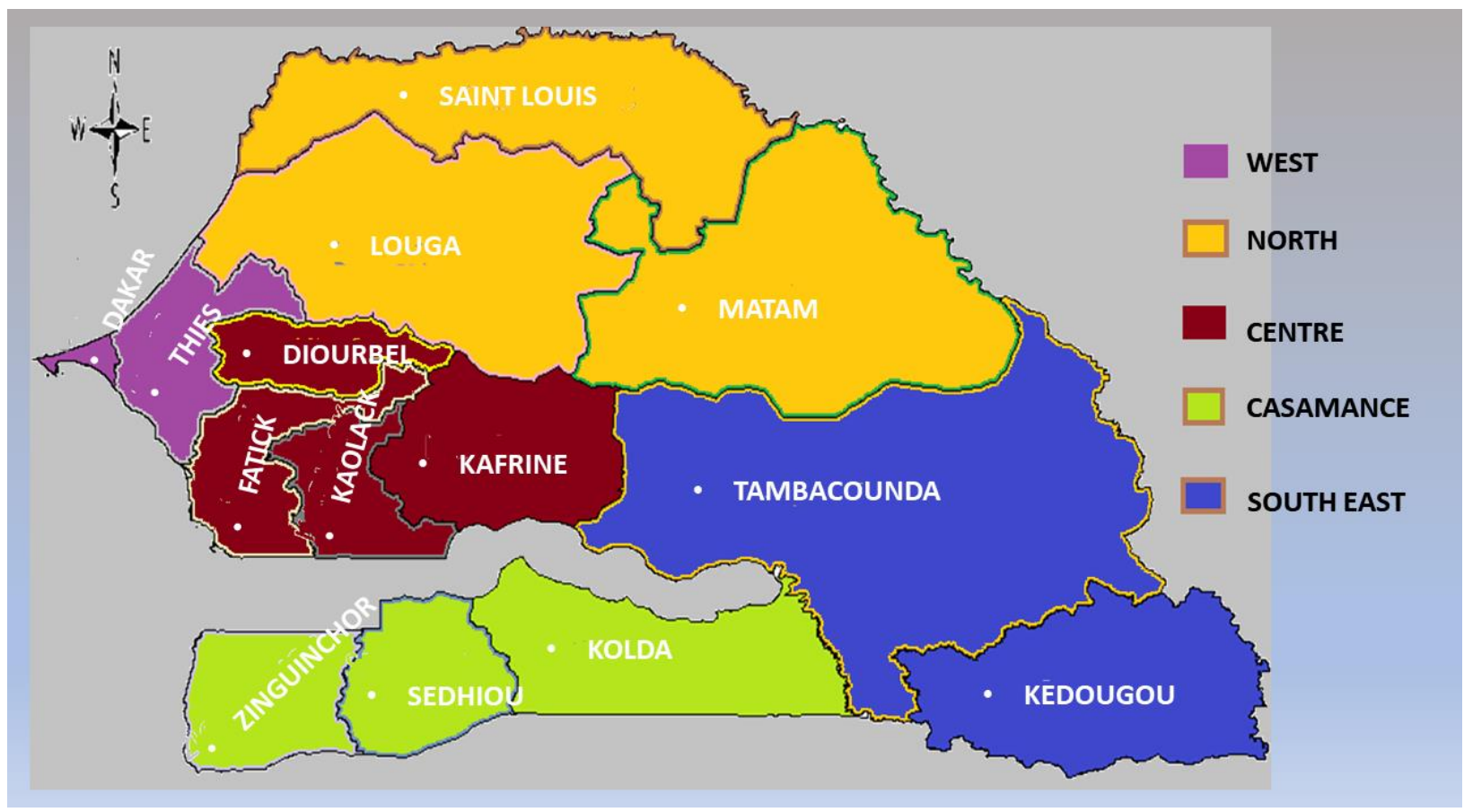

Source: Authors

\section{Theoretical underpinnings}

In our analyses, we operationalised proxy variables stemming from three prevailing theories on FGM/C: social norms theory, the modernisation theory, and feminist theory. The social norms theory was initially proposed to account for the persistence of FGM/C by Mackie (1996). It states that FGM/C persists because of social norms maintained through various interdependent expectations regarding 
marriageability (Mackie 1996; Mackie and LeJeune 2009). Another variant of this view, known as intergenerational peer convention theory, posits that FGM/C serves as a signal to other circumcised women that a girl or woman has been groomed to respect the authority of her circumcised elders and is therefore worthy of inclusion in their social network (Shell-Duncan et al. 2011). In this view, the risk of being circumcised increases when a higher proportion of women in the community have been cut, where record numbers of women support continuation of the practice or believe that FGM/C is required as a matter of religion. It follows that people residing close to one another will interact and have mutual expectations about what counts as appropriate social behaviour. In such practising communities, a higher number of girls may be subjected to $F G M / C$ as per their mothers' expectations through community enforcing mechanisms. These expectations are more pronounced with respect to social norms. The interconnectedness of social actors makes it difficult to secure change of behaviour among individual households who may contemplate to opposing or renouncing the practice. The difficulty is compounded further given the existence of social costs related to deviating from the norms. Studies by Mackie (1996) as well as those by Mackie and LeJeune (2009) have shown, however, that change of behaviour was possible if those intervening in abandonment efforts reached a critical mass of households who were willing and ready to abandon $\mathrm{FGM} / \mathrm{C}$ as a group rather than as single individuals. Bellamere, Novak, and Steinmetz (2015) found that focusing on social convention theory is not enough because decisions on whether a girl should be cut or not are made within the households and at the individual level.

Modernisation theory, on the other hand, posits that there is low FGM/C prevalence when more women are economically empowered. Specifically, higher rates of women's participation in modern life forms-including participation in the labour market, higher educational attainment, and greater exposure to media conveying anti-FGM/C norms-are associated with low risks of FGM/C among girls (Cislaghi and Heise 2018). Feminist theory argues that FGM/C is held in place because women have limited opportunities and lack autonomy in household and community decision making. The focus is on changing the broader social conditions that serve to uphold gender inequalities and promote FGM/C (Yount 2002; Abusharaf 2000).

\section{Objectives}

In this study we analysed the influence of individual- and community-level factors on variation in the risk of cutting girls aged 0-14 in Senegal. Specifically, we pursued two objectives. First, we sought to assess the role that geographical location as well as other latent factors play on FGM/C prevalence. The second objective was to map the hotspots of risk and to understand the effects of factors specific to the unobserved geographical location on the observed prevalence.

\section{Methods}

\section{Data source}

The data from four nationally representative Senegal Demographic and Health Surveys (SDHS) provided an excellent framework to analyse trends in the likelihood of cutting among girls aged 0-14 as data have been collected continuously every year since 2012 .

This analysis is based on data available from the 2005, 2010-11, 2015, and 2017 SDHS rounds of the Senegal Demographic and Health Surveys (SDHS). Each round is a nationally representative survey of women of reproductive age (15-49 years) and their children who are younger than four years. The SDHS samples are drawn through stratified clustered sampling with draws of clusters in regions for each survey. The design of each survey, organisation, sample size, and sampling design, questionnaires, and implementation are described in the respective survey reports (ANSD/Sénégal 
and ICF 2016, 2018; ANSD/Sénégal and International 2012; Ndiaye and Ayad 2006)

Over the years, Demographic and Health Surveys (DHS) have employed a standardised scientific approach to population-based surveys that has been well documented. In order to obtain a representative sample of the target population, sampled units are randomly selected from an existing frame comprising a list of all sampling units. The existence of a sampling frame allows for a probabilitybased selection approach. Sampling is implemented in a stratified two-stage cluster design. A random selection of community clusters (known as enumeration areas/primary sampling units) is carried out at the first stage. The second stage involves a systematic selection of households from a complete listing of all households in each selected cluster. Members of selected households are eligible to participate in the survey. In the 2005, 2010-11, 2015, and 2017 SDHS, respondents were drawn from $377,391,214$, and 400 clusters, respectively. The overall sample sizes for our analysis are reported in Table 1.

The $\mathrm{FGM} / \mathrm{C}$ module provides information about the prevalence of the practice in women and their living daughters. Women are asked about their own experience of $\mathrm{FGM} / \mathrm{C}$, and whether they support its continuation. Prior to 2010, women were also asked whether at least one living daughter had undergone $\mathrm{FGM} / \mathrm{C}$. In 2010, questions on FGM/C were standardised and women were asked about the $\mathrm{FGM} / \mathrm{C}$ status of all living daughters who were younger than 15 years at the time of the survey.

Table 1. Sample size of women aged 15-49 years and girls aged 0-14 years for each of the Senegal DHS surveys from 2005 to 2017

\begin{tabular}{|lcc|}
\hline Year & Women $\mathbf{1 5 - 4 9}$ years & Girls 0-14 years \\
2005 SDHS & 14,602 & 11,878 \\
$2010-11$ SDHS & 15,688 & 9,740 \\
2015 SDHS & 8,851 & 7,529 \\
2017 SDHS & 16,787 & 14,008 \\
\hline
\end{tabular}

* Note: In the 2005 Senegal DHS, FGM/C questions were asked about the most recently cut daughters of any age; for this analysis, sample size is limited to most recently cut girls aged 0-14. In the 2010-11 Senegal DHS, the FGM/C questions were asked for all daughters aged 0-10. In the 2015 and 2017 Senegal DHS, the FGM/C questions were asked for all daughters aged 0-14 years.

\section{Variables}

\section{Primary outcome}

The primary outcome variable for this study was the FGM/C status of girls younger than 15 years. The variable was defined as a binary outcome, coded as 1 if the daughter was cut and 0 if otherwise.

Given the cross-sectional nature of the SDHS, there is a possibility that girls who are younger than 15 years who were not cut at the time of the survey may undergo the procedure in the future. We conducted survival analysis to account for these censored observational units.

Nested data in survey studies is common. Here, the data structure is retrospective birth, health, and FGM/C information, typically about more than one child from each sampled woman. Children's FGM/C and health information is nested within families. In our analyses, we therefore adjusted for nonindependence with mixture models that employ unobserved predictors in a Bayesian hierarchical structure (see Statistical Framework section). 


\section{Explanatory variables}

The main explanatory variables are shown in Table 2:

Table 2. List of explanatory variables

\begin{tabular}{|c|c|c|c|}
\hline Factor & Variables & $\begin{array}{l}\text { Level of definition } \\
\text { and measurement }\end{array}$ & $\begin{array}{l}\text { Categories (for } \\
\text { categorical } \\
\text { variables) }\end{array}$ \\
\hline \multirow[t]{5}{*}{ Demographic } & $\begin{array}{l}\text { Age of mother and her } \\
\text { daughter at the time of the } \\
\text { survey }\end{array}$ & Continuous & \\
\hline & Place of residence & Binary & $\begin{array}{l}\text { Urban (Ref) } \\
\text { Rural }\end{array}$ \\
\hline & $\begin{array}{l}\text { Religious affiliation of } \\
\text { mother }\end{array}$ & Categorical & $\begin{array}{l}\text { Christian (Ref) } \\
\text { Muslim, Animist }\end{array}$ \\
\hline & $\begin{array}{l}\text { Household wealth index } \\
\text { (Quintile) }\end{array}$ & Categorical & $\begin{array}{l}\text { Middle (Ref) } \\
\text { Poorer, Poorest, } \\
\text { Richer, Richest }\end{array}$ \\
\hline & Mother's ethnicity & Categorical & $\begin{array}{l}\text { Wolof (Ref) } \\
\text { Idiola, Mandingue, } \\
\text { Non-Senegalese, } \\
\text { Other, Poular, Serer } \\
\text { and Soninke }\end{array}$ \\
\hline \multirow[t]{5}{*}{ Social norms } & $\begin{array}{l}\text { FGM/C status of the mother } \\
\text { ("Mother cut?") }\end{array}$ & Binary & $\begin{array}{l}\text { No (Ref) } \\
\text { Yes }\end{array}$ \\
\hline & $\begin{array}{l}\text { Support for FGM/C } \\
\text { continuation }\end{array}$ & Categorical & $\begin{array}{l}\text { Be stopped (Ref) } \\
\text { Continued, } \\
\text { Depends/Don't } \\
\text { know }\end{array}$ \\
\hline & $\begin{array}{l}\text { Proportion of mothers cut in } \\
\text { the community }\end{array}$ & proportion & \\
\hline & $\begin{array}{l}\text { Proportion of pro-FGM/C } \\
\text { support among mothers in } \\
\text { community }\end{array}$ & proportion & \\
\hline & $\begin{array}{l}\text { Proportion of mothers who } \\
\text { cut for religious reasons }\end{array}$ & proportion & \\
\hline Religious beliefs & $\begin{array}{l}\mathrm{FGM} / \mathrm{C} \text { is required by } \\
\text { religion }\end{array}$ & Binary & $\begin{array}{l}\text { No (Ref) } \\
\text { Yes }\end{array}$ \\
\hline $\begin{array}{l}\text { Women's decisionmaking } \\
\text { on own earnings }\end{array}$ & $\begin{array}{l}\text { Expenditure of mother and } \\
\text { father's earnings jointly } \\
\text { decided or alone }\end{array}$ & Categorical & $\begin{array}{l}\text { Alone (Ref) } \\
\text { Husband/partner; } \\
\text { With } \\
\text { husband/partner; } \\
\text { Missing (Not } \\
\text { Available) } \\
\end{array}$ \\
\hline $\begin{array}{l}\text { Women's and partner's } \\
\text { educational Status }\end{array}$ & $\begin{array}{l}\text { Level of education of mother } \\
\text { and her partner's }\end{array}$ & Categorical & $\begin{array}{l}\text { Secondary (Ref) } \\
\text { No education, } \\
\text { Primary, Higher }\end{array}$ \\
\hline & & & $\begin{array}{l}\text { Higher (Ref) } \\
\text { No education, } \\
\text { Primary, Secondary }\end{array}$ \\
\hline Gender norms & $\begin{array}{l}\text { Household decisionmaking } \\
\text { on health care }\end{array}$ & Categorical & $\begin{array}{l}\text { Alone (Ref) } \\
\text { Husband/partner; } \\
\text { With } \\
\text { husband/partner; } \\
\text { Missing (Not } \\
\text { Available) }\end{array}$ \\
\hline
\end{tabular}




\begin{tabular}{|c|c|c|c|}
\hline Factor & Variables & $\begin{array}{l}\text { Level of definition } \\
\text { and measurement }\end{array}$ & $\begin{array}{l}\text { Categories (for } \\
\text { categorical } \\
\text { variables) }\end{array}$ \\
\hline & $\begin{array}{l}\text { Mother's justification } \\
\text { (acceptance) of wife beating } \\
\text { if a wife goes out, neglects } \\
\text { the children; argues with the } \\
\text { husband; denies her } \\
\text { husband sex; or denies her } \\
\text { husband food }\end{array}$ & Binary & $\begin{array}{l}\text { No (Ref) } \\
\text { Yes }\end{array}$ \\
\hline Media exposure & $\begin{array}{l}\text { Frequency of reading the } \\
\text { newspaper, listening to the } \\
\text { radio and watching } \\
\text { television }\end{array}$ & Categorical & $\begin{array}{l}\text { No (Ref) } \\
\text { Less than once a } \\
\text { week, At least once } \\
\text { a week }\end{array}$ \\
\hline \multirow[t]{2}{*}{$\begin{array}{l}\text { Geographic location and } \\
\text { mobility }\end{array}$} & Region of residence & Categorical & $\begin{array}{l}\text { Dakar (Ref) } \\
\text { Diourbel, Fatick, } \\
\text { Kaffrine, Kaolack, } \\
\text { Kedougou, Kolda, } \\
\text { Louga, Matam, } \\
\text { Saint Louis, } \\
\text { Sedhiou, } \\
\text { Tambacounda, } \\
\text { Thies and } \\
\text { Zinguichor }\end{array}$ \\
\hline & $\begin{array}{l}\text { Number of years mother } \\
\text { had lived continuously in } \\
\text { current location of residence }\end{array}$ & Categorical & $\begin{array}{l}0 \text { (Ref) } \\
1-10 \text { years, } \\
11-20 \text { years, } \\
21 \text { or more years }\end{array}$ \\
\hline
\end{tabular}

Note: Ref $=$ Reference category for analyses of categorical variables

\section{Statistical framework}

\section{Bayesian geo-additive generalised linear mixed models}

\section{Model formulation and specifications}

We considered a class of Bayesian geo-additive models to address the objectives of the study. This class of flexible regression models provides a unified framework to investigate the role of geographical locations in the likelihood and prevalence of $F G M / C$ in a manner that allows the effects of various factors operating at individual-, household-, and community-levels to be fully accounted for in a coherent regression framework. This framework also enabled the assessment of the influence of nonlinear continuous covariates such as age, on the likelihood of a girl being cut.

The unobserved spatial effects of the geographical location were quantified using the estimated posterior mean spatial effects maps and the associated $95 \%$ posterior probability maps. All models were estimated within a Markov Chain Monte Carlo (MCMC) framework. These were then implemented in $\mathrm{R}$ version 3.5.0 using the $\mathrm{R}$ interface to BayesX known as R2BayesX (Belitz et al, 2009, 2012; Umlauf et al. 2015).

The modelling techniques are described in more detail elsewhere (Kandala et al. 2009, Kandala et al. 2018). However, a brief framework of the model is given below. It is a common practice in the literature to model the outcome variable $\mathrm{FGM} / \mathrm{C}$ with a strictly linear predictor,

$$
\eta_{i}=x^{\prime} \beta+w_{i}^{\prime} \gamma+\epsilon_{i}
$$


where the response variable $y$ has mean $E[y \mid]=.\mu$ and is linked to a linear predictor $\eta$ by $\mu=h(\eta)$, where $\gamma$ are unknown parameters to be estimated and the response function $h$ is usually known, and $\epsilon_{i} \sim N\left(0, \sigma^{2}\right)$ for $i=1, \ldots, n$. The standard linear regression model requires a linear relationship between the response variable and the independent variables, normally distributed residuals, minimal correlation between the covariates, and constant variance of the error terms (homoscedasticity).

In several practical situations, such as ours, there are a number reasons why the standard regression model cannot be used. First, our data contain continuous covariates, such as age of girl and mother and it may not be appropriate to assume that these have a strictly linear effect on the outcome. Second, evidence has shown that our observations (girl's FGM/C status) are spatially and temporally correlated, thus, in light of this, the independence assumption is no longer valid. We need a model that adequately captures this interdependence among covariates while simultaneously considering the unobserved location-specific autocorrelation and heterogeneity.

We replace the strictly linear predictor in (1), with a geo-additive semi-parametric predictor $\mu_{i}=h\left(\eta_{i}\right)$ such that

$$
\eta_{i}=f_{1}\left(x_{i 1}\right)+\cdots+f_{p}\left(x_{i p}\right)+f_{\text {spat }}\left(s_{i}\right)+w_{i}^{\prime}
$$

where, $f_{1}(),. \ldots, f_{p}($.$) are nonlinear smooth functions of the metrical covariates (e.g., respondent's age)$ and $f_{\text {spat }}\left(s_{i}\right)$ is the effect of the spatial covariate, $s_{i}=\{1, \ldots, S\}$ representing the regions in Senegal, in which case $S=14$. Note that the model in (2) can be extended to include the interaction $f(x) z$ between a continuous covariate $x$ and a binary component of $z$, leading to varying coefficient models, and/or adding a nonlinear interaction $f_{1,2}\left(x_{1}, x_{2}\right)$ of two continuous covariates, $x_{1}$ and $x_{2}$. In addition, we extend (2) to separately account for spatial autocorrelation and spatial heterogeneity by splitting up the total spatial effect component $f_{\text {spat }}($.$) into a spatially correlated (structured) effect f_{\text {str }}($.$) and$ a spatially uncorrelated (unstructured) effect $f_{\text {unstr }}($.$) as in (3) below$

$$
\boldsymbol{f}_{\text {spat }}\left(\boldsymbol{s}_{i}\right)=\boldsymbol{f}_{\text {str }}\left(\boldsymbol{s}_{i}\right)+\boldsymbol{f}_{\text {unstr }}\left(\boldsymbol{s}_{i}\right) \text {. }
$$

For full Bayesian inference, we chose Markov Random Field (MRF) priors for the structured spatial effects and zero mean Gaussian priors for the unstructured spatial effects. Because of its flexibility and ability to draw samples with ease even from very complex nonstandard posterior distributions, MCMC techniques were used for full Bayesian inference.

\section{Model Estimation}

To evaluate risk factors of FGM/C among Senegalese girls aged 0-14 years, we fitted Bayesian geoadditive logistic regression models to datasets extracted from the four SDHS waves. We estimated three nested models using each dataset. In the first model (Model I), we assessed the unadjusted association between the independent variable of interest and the likelihood of $F G M / C$ among Senegalese girls younger than 15 years. In essence, Model I did not consider the possible confounders including the unobserved effects due to geographical location. In the second model (Model II), we took into account geographical location. However, other potential confounders such as age, place of resident, wealth, religion, and ethnicity, were not taken into account in Model II. The third model (Model III) incorporated these confounders as well as unobserved effects of space.

In this report for the sake of clarity, we refer to the unadjusted model as Model I, the spatially adjusted model as Model II, and the fully adjusted model as Model III. These models were fitted to the dataset from each survey. In addition, we fitted a Bayesian hierarchical space-time logistic regression model to pooled datasets from 2010 to 2017 SDHS to assess the cumulative effects of the risk factors over 
time, examine time trends, and account for effects of interactions in time and space. The reason for excluding the 2005 SDHS is due to the creation of new geographical regions in Senegal (Kaffrine, Kedegou and Sedhiou) after the 2005 SDHS, thus data from the 2005 SDHS are not consistent with the others and as a result inappropriate to be combined. The reason for fitting the three models is to allow us to quantify the influence of a factor in the presence of other confounders.

In order to test the social norms theory, we used a woman's FGM/C status and her support for the continuation of the practice as proxy measures of social norms. Similarly, a woman's justification of wife beating, and level of a woman's decision-making power within her household were used as proxy measures for gender norms. In addition, proxy measures of women's agency include a woman and her husband/partner's highest level of educational attainment. For media exposure, we used a woman's frequency of reading the newspaper, listening to the radio, and watching television as the proxy measures.

\section{Survival analysis}

We conducted survival analysis to account for the fact that girls who were not yet cut at the time of the survey could still face the risk of being cut in the future or not cut at all. This technique allows right censoring of the time until failure $(\mathrm{FGM} / \mathrm{C})$ among the girls younger than 15 years who were uncut at the time their mothers were interviewed. For our purposes here we used only the 2017 SDHS, which is the most recent survey for which data are available to assess how risk factors (mainly sociodemographic factors) influenced the time at which girls were cut. Reference to "time" means time from birth to the period at which data were available. Here, the event or failure is coded 1 if a girl was cut or 0 if the girl was uncut. Explanatory variables used included mother's education, religion, ethnicity, household socioeconomic status, region of residence, as well as type of place of residence (ruralurban). At any given point in time, the data included observations in one of the following three categories: 1) Those who have been cut, 2) those who have not been cut but might be cut at some point in the future, and 3) those who have not been cut and will not be cut.

\section{Results}

\section{Bayesian hierarchical geo-additive models (2005-17)}

Detailed results of the four survey time points (2005-17 SDHS) are presented in Tables A1-A4 in the appendix. Posterior estimates of unobserved effects of geographical locations are presented as maps (Figure 2-Figure 5). Results from pooled datasets for 2010 and 2017 are shown in Table A5 in the Appendix, while the maps of posterior risk are shown in Figure 6.

The posterior risk maps of estimated effects of geographic location on the likelihood of FGM/C are presented along with the corresponding $95 \%$ posterior probability. On the maps, low-risk regions are shaded green while high- risk regions are shaded red. For the posterior probability maps, black coloured regions are areas of significantly high risk, white colours are areas of significantly low risk, while nonsignificant areas are shown in grey colour.

\section{SDHS}

The results of the Bayesian geo-additive models fitted to the 2005 SDHS data examining the likelihood of a girl undergoing FGM/C are presented in Table A1. Key socio-demographic determinants of FGM/C among Senegalese girls aged 0-14 years in 2005 included mother's ethnicity, place of residence, and religious affiliation. In the unadjusted model, the likelihood of experiencing FGM/C among urban girls was $47 \%$ lower than for rural girls. The difference in likelihood of cutting was reduced to $43 \%$ in the spatially adjusted model (Model II) and $30 \%$ lower when other factors were 
accounted for (Model III). The likelihood of undergoing FGM/C was highest among girls from Matam and Kolda. The likelihood of cutting was generally low among girls in the western regions. Results based on the unadjusted model showed that Muslim girls had 3.82 times greater odds of undergoing $\mathrm{FGM} / \mathrm{C}$ than Christian girls, which reduced to $1.88(1.00,3.97)$ after accounting for all co-founders in the fully adjusted model.

In addition, the mother's household socioeconomic status was significantly associated with whether her daughter was cut. For instance, girls from households in the lowest wealth quintile had a higher likelihood of being cut compared to girls from middle quintile households, in the unadjusted model and spatially adjusted model, respectively. The effect of this quintile, however, dropped to $11 \%$ likelihood when other factors were accounted for. In contrast, girls from households in the highest (with $88 \%$ lower) and fourth (49\% lower) quintiles had a lower likelihood of being cut than those from the middle quintile. In essence, 2005 SDHS results show a negative association between a household's wealth index and the likelihood of FGM/C among girls who belong to the household. Results from the fully adjusted model using 2005 SDHS show that daughters of formerly married women had a $43 \%$ lower likelihood of being cut than daughters of women who were in marital union in the fully adjusted model.

A considerable disparity is observed across the ethnic groups. The unadjusted effect of mother's ethnicity on a girl's FGM/C was generally large across the ethnic groups, followed by a moderate reduction after taking into account the spatial location (Model II) and even significant drops in the fully adjusted model. Girls from the Poular and Soninke ethnic groups had higher odds of being cut than girls from the Wolof ethnic group.

Daughters whose mothers were cut had considerably higher odds of being cut (with estimated effect ranging from 35 times in the unadjusted model to 43 times in the fully adjusted model) than daughters of uncut women. In addition, daughters of women who supported FGM/C continuation were three times more likely to be cut than girls whose mothers supported discontinuation of the practice. Girls whose mothers believed $\mathrm{FGM} / \mathrm{C}$ is required by their religion were more likely to be cut than girls whose mothers believed otherwise.

With respect to education, results showed significantly higher likelihood of cutting among girls whose mothers' partner had no or primary-level education than among those whose mothers' partners had higher levels of education in the unadjusted model and after adjusting for spatial effect. In the fully adjusted model, however, the differences were no longer statistically significant. This indicates that the effect of the (mother's) partner's education level on a girl's likelihood of being cut gradually disappears in the presence of other confounders explaining more variance. With respect to women's education, those with no education were more likely to cut their daughters than those with secondarylevel education, a pattern consistently observed to be significant even after adjusting for known potential confounders.

Results also showed a higher likelihood of cutting in girls whose mothers had informal occupations compared to those whose mothers were formally employed in the unadjusted model. This effect, however, was reduced to $16 \%$ in the fully adjusted model and was nonsignificant. With respect to gender norms, the likelihood of undergoing FGM/C was higher among girls whose mothers justified wife beating for going out and neglecting the children compared to those who did not justify wife beating. Daughters of women who supported wife beating for denying a husband sex and denying him food also had a higher likelihood of undergoing FGM/C compared with daughters of women in the fully adjusted model who did not support wife beating. In the unadjusted model, girls from households where the mother's husband or partner solely made decisions on large household purchases had higher odds of being cut than those where the mother made these decisions alone. However, this association was not significant in the adjusted models. In contrast, girls from households where the mother's husband or partner solely made decisions on the mother's health were less likely to be cut 
that those where the mother made this decision solely.

We also found evidence of a positive association between the duration mothers had stayed in their current location and the likelihood of a girl being cut. For instance, a girl born to a woman who had lived in her current location continuously for between 11 and 20 years was more than three times more likely to be cut than daughters of women who had lived in the current location for less than a year in the space-adjusted model. Overall, results showed that mother's exposure to any media was significantly associated with a lower likelihood of her daughter undergoing FGM/C in the unadjusted and space-adjusted models. However, these were not significant in the fully adjusted model. Posterior risk maps of estimated effects of geographic location on FGM/C prevalence among Senegalese girls in 2005 are presented in Figure 2 below.

Figure 2. Maps showing risk of experiencing FGM/C among girls 0-14 years by region, 2005 SDHS. Shown are posterior risk maps (left) and corresponding 95\% (right) posterior significance maps for unadjusted spatial effect (top)) and fully adjusted model

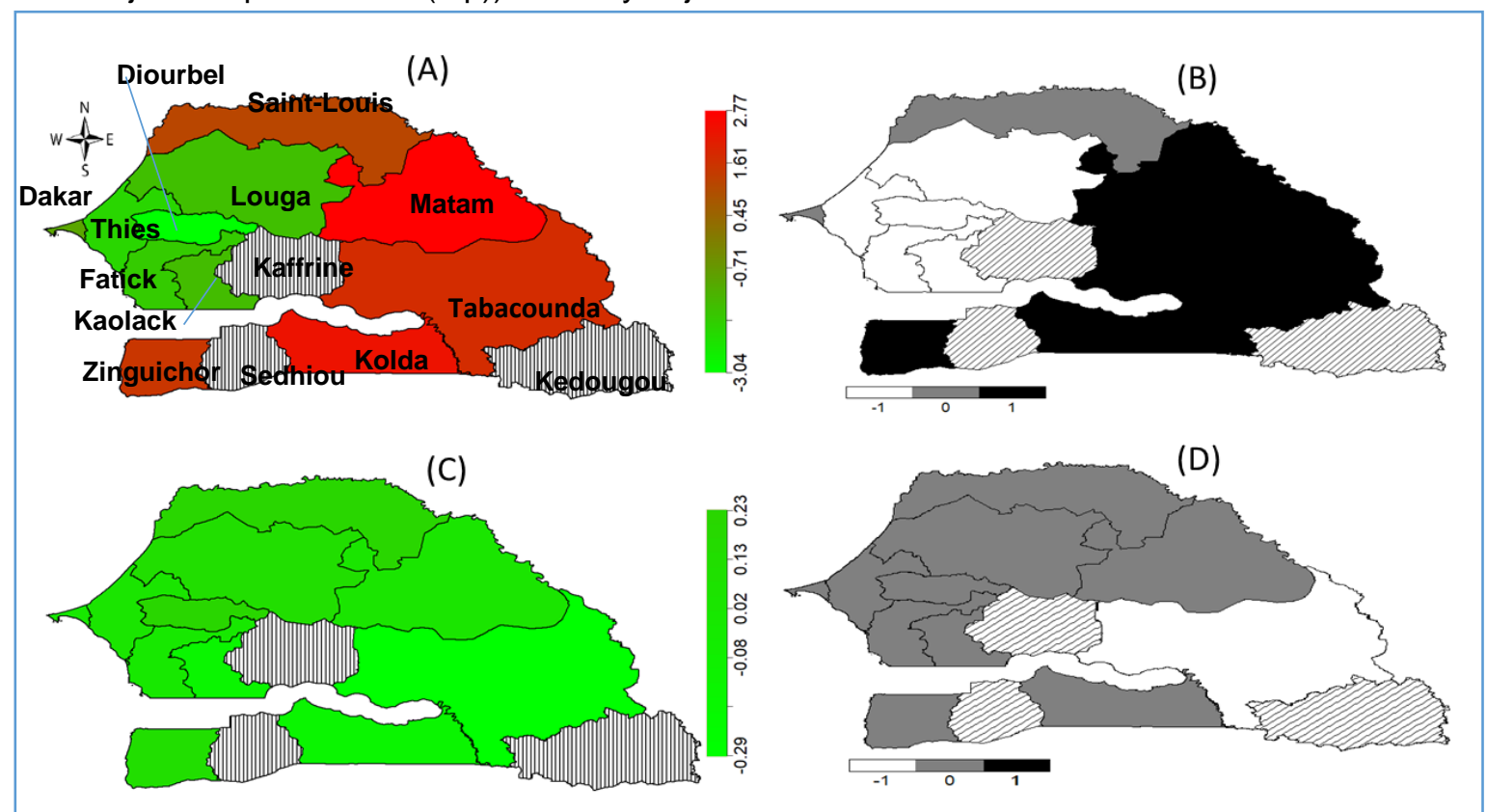

Note: Light green to red corresponds to low risk to high risk. Black colour indicates significantly high-risk regions, white colour indicates significantly low risk regions and grey colour indicates non-significant.

In 2005, the unadjusted spatial location effects showed a significantly high risk of FGM/C in the North East and southern regions such as Matam and Kolda, while a significantly low risk profile was observed in western regions including Diourbel, Louga, and Thies. The model, adjusted for both known risks factors and unknown residual factors (Model III in Table A1), showed that some regions (e.g., Matam) originally identified as high-risk remain so even after accounting for confounding factors. Other regions, however, showed evidence of low risk of FGM/C among girls (Figure 2C-2D).

\section{SDHS}

Similar to 2005 findings, the likelihood of girls undergoing FGM/C was 37\% lower in urban compared to rural areas in the fully adjusted model. With respect to region, the likelihood of cutting was higher among girls from Matam, Tambacounda, and Kolda than among those from Dakar. Muslim girls had a higher likelihood of being cut than Christian girls in the unadjusted and the space-adjusted models.

Daughters of women who had never married were less likely to have been cut than daughters of currently married women; the association was significant in both the unadjusted and the space- 
adjusted models. The likelihood of being cut was significantly lower among girls from households in the highest and fourth wealth quintiles than among those from households in the middle quintile. The association between the household wealth index and cutting status was not significant in the fully adjusted model. With respect to ethnicity, girls from all ethnic groups, except the Serer, were more likely to be cut than Wolof girls. In the fully adjusted model, girls who were Poular were more than two times more likely to be cut than Wolof girls. The remaining associations were not significant. Girls born to cut mothers were 21 times more likely to be cut than daughters of uncut mothers. Meanwhile, girls born to mothers who supported FGM/C continuation were five times more likely to be cut in the fully adjusted model. In the fully adjusted model, the likelihood of a girl being cut was $71 \%$ higher for girls whose mothers believed $\mathrm{FGM} / \mathrm{C}$ was a religious requirement compared to girls whose mothers did not believe FGM/C was a religious requirement. Results from Model I and Model II show that women who had no education or women who attended only primary education were more likely to be cut compared with those whose mothers had secondary schooling. The association between a woman's education and her daughter's likelihood of being cut was non-significant in the fully adjusted model.

With respect to indicators of gender norms, in the fully adjusted model, girls whose mothers justified wife beating for denying husbands sex and food were significantly more likely to be cut than those whose mothers did not justify wife beating. With respect to household decision making, girls from households where the husband/partner solely or jointly with the mother made decisions about large household purchases were less likely to be cut than those where the mother solely made these decisions. The association was only significant in the unadjusted model. Conversely, those where the husband/partner solely or jointly with the mother made decisions about the mother's health were more likely to be cut than those where the mother solely made these decisions. Again, this association was only significant in the unadjusted model. A mixed pattern was observed on the effect of mother's exposure to media with girls whose mothers read newspapers being less likely to be cut than those whose mothers did not read newspapers, while the likelihood of being cut was higher among those whose mothers listened to the radio compared to those whose mothers did not listen to the radio.

Figure 3 below shows the geographical distribution of the risk of undergoing FGM/C across the 14 regions for the model unadjusted for known risk factors $(3 A)$ and the model which accounted for the effects of observed factors at individual and group levels (3B) along with the posterior probability maps (3B and 3D). Similar to 2005, the risk of girls being cut was high in such regions as Matam, Tambacunda, Kolda, Kedougou in the northeastern and southern parts of the country. Regions in the West such as Louga and Dakar showed evidence of moderate risk unlike in 2005 in the unadjusted model. Sedhiou and Kolda were the two high-risk regions where the observed likelihood of FGM/C among girls was significant due to factors not accounted for in the model. Known covariates, however (Appendix Table A2), explained the high likelihood of FGM/C observed across all high-risk regions (including Matam and Tambacounda) and the low likelihood observed in most regions in the west. Evidence of high FGM/C likelihood was also found among girls from the Kolda region and low likelihood among girls in Kaolack (Figure 3C-D) after accounting for known factors. We also noted a change in risk profile from high to low in the Kedougou region in the South East after accounting for known risk factors. 
Figure 3. Maps showing risk of experiencing FGM/C among girls $\mathbf{0 - 1 4}$ years by region, 2010 SDHS. Shown are posterior risk maps (left) of Senegalese 0-14-year-old girls' FGM/C with the corresponding 95\% (right) posterior significance maps for unadjusted spatial effect (top) and fully adjusted model (bottom). Evidence from the 2010 SDHS.

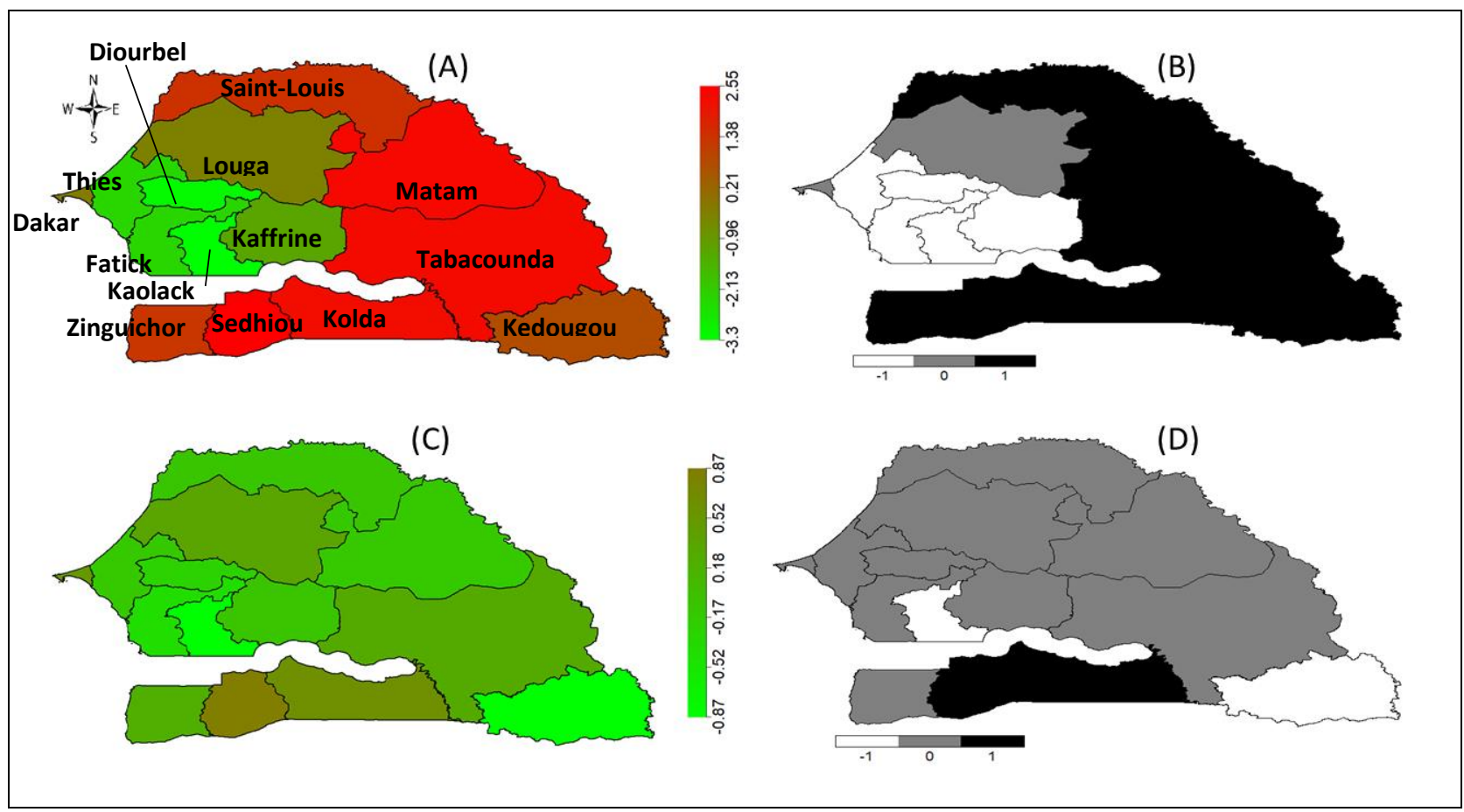

Note: Light green to red corresponds to low-risk to high-risk. Black colour indicates significantly high-risk regions, white colour indicates significantly low-risk regions, and grey colour indicates nonsignificant.

\section{SDHS}

Similar to previous surveys, in 2015, girls born to mothers living in urban areas were less likely than those in rural areas to be cut. In addition, girls from southern (Kolda, Sedhiou, and Zinguichor) and western regions (Kedougou and Matam) were more likely to be cut compared to girls from Dakar. A pattern of association between mother's household wealth index and likelihood of FGM/C in girls aged 0-14 years was similar to that in 2010. Girls from the poorest two quintiles were more likely to be cut than those from households in the middle quintile while those from the wealthiest two quintiles were less likely to be cut than those from the middle quintile. These associations were significant in the unadjusted and space-adjusted model. Girls born to women who were never married had $72 \%$ lower likelihood of being cut than those born to women who were currently married in the space-adjusted model.

With regard to ethnicity, the likelihood of cutting was higher among Soninke than among Wolof girls, while an even higher likelihood of cutting was observed in non-Senegalese girls compared to Wolof girls. Overall, girls from all other ethnic groups, except the Idiola and Serer, had significantly higher odds of being cut than Wolof girls in the fully adjusted model.

With respect to social norms, girls born to cut mothers were more than 13 times more likely to be cut than girls born to uncut mothers after adjusting for other factors. Adjusting for other factors, girls born to mothers who supported the continuation of $F G M / C$ were more than four times more likely to be cut than those whose mothers wanted the practice stopped. The likelihood of cutting was also $52 \%$ higher in girls born to mothers who believed FGM/C is a religious requirement than those who believed otherwise. 
Girls born to mothers whose partner or husband had no formal education were more likely than those with higher than secondary education to be cut. However, the association was only significant in the unadjusted and space-adjusted models. Similar to 2010 , daughters born to women with no or primary education had higher odds of being cut compared to those born to women with secondary educationas shown in the unadjusted and space-adjusted models. The effect of mother's education was not significant in the fully adjusted model.

With respect to household decision making, girls born to women whose husbands/partners solely made decisions on the mother's health were more likely to be cut than those born to mothers who were the sole decisionmakers on their health care. These associations were only significant in the unadjusted models.

The posterior risk map of FGM/C likelihood in 2015 among Senegalese girls aged 0-14 years is presented in Figure 4 along with the 95\% posterior likelihood maps for the unadjusted model and the model which accounted for known risk factors. The unadjusted map showed a positive significant association between unmeasured region-specific factors and high likelihood of FGM/C in regions such as Matam, Tambacounda, Kolda, and Zinguichor across the North and South parts of the country. On the other hand, a pattern of reduced likelihood of FGM/C was found in regions such as Kolda, Sedhiou, and Tambacounda in the South and Saint-Louis in North after known risk factors were accounted for. Latent spatial effects due to region of residence remained significantly associated with increased likelihood of FGM/C in Matam and Zinguichor (Figure 4C-D).

Figure 4. Maps showing the risk of experiencing FGM/C among girls 0-14 years by region, 2015 SDHS. Shown are posterior risk maps (left) of Senegalese 0-14-year-old girls' FGM/C with the corresponding $95 \%$ (right) posterior significance maps for unadjusted spatial effect (top) and fully adjusted model (bottom). Evidence from the 2015 SDHS.

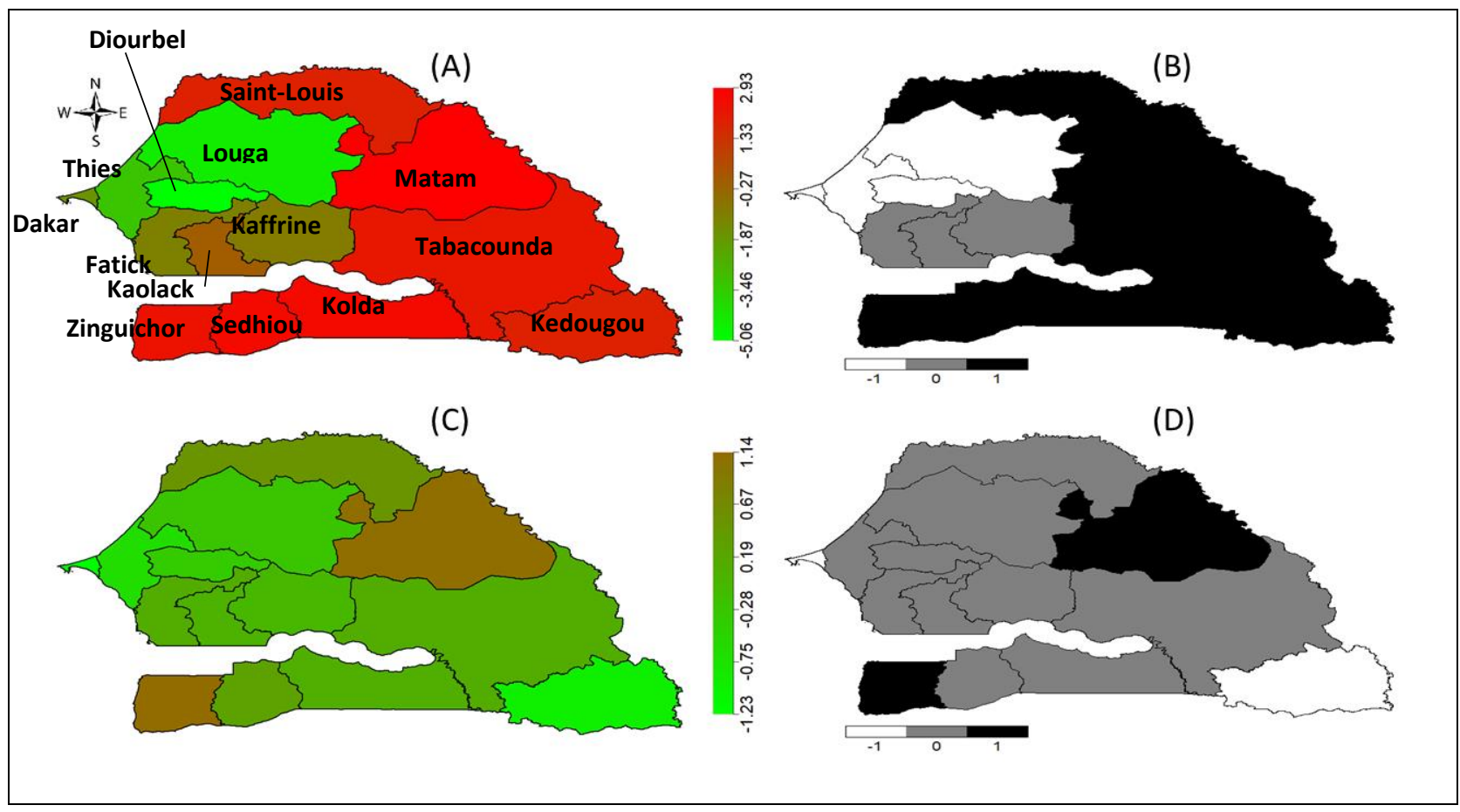

Note: Light green to red corresponds to low-risk to high-risk. Black colour indicates significantly high-risk regions, white colour indicates significantly low-risk regions, and grey colour indicates nonsignificant.

\section{DHS}

The likelihood of cutting was 50\% lower among urban girls than their rural counterparts in 2017 (Table A4). With respect to religion, a Muslim girl was about six times more likely to be cut than a Christian 
girl in the space-adjusted model. The association between religion and FGM/C was not significant in the fully adjusted model. In addition, there was a higher likelihood of FGM/C among girls from households in the poorest two quintiles than among those from households in the middle quintile. This association was significant in the unadjusted and space-adjusted models. The likelihood of cutting was lower among daughters of women who were never married $(80 \%$ lower in the space-adjusted model) compared to daughters of currently married women.

In the fully adjusted model, Diola girls were six times more likely to be cut compared with their Wolof counterparts. Likewise, girls from the Mandingue and Soninke ethnic groups were four times more likely than Wolof girls to be cut in the fully adjusted model.

In relation to social norms, daughters of cut mothers had 14 times greater odds of being cut than daughters of uncut mothers. In addition, girls whose mothers supported the continuation of FGM/C were more than five times more likely to be cut than those whose mothers favoured discontinuation of the practice after accounting for other possible explanatory factors in the full model. Compared to girls born to women whose husband or partner had a higher than secondary education, those born to women whose husband or partner had no education were more than two times more likely to be cut.

Girls born to women who justified wife beating if a wife neglected the children or denied her husband sex were more likely to be cut than those born to women who did not justify wife beating for these reasons. In contrast, daughters of women who justified wife beating if a woman denied her husband food were less likely to be cut than those who were daughters of women who did not justify wife beating for this reason. With respect to household decision making, the likelihood of a girl being cut was $70 \%$ lower when her mother's husband or partner was involved in decisions around large household purchases than when the mother solely made these decisions. In contrast, a girl was $88 \%$ more likely to be cut if her mother's husband or partner solely made decisions on the mother's health than when mothers made this decision solely.

The results of the 2017 SDHS showed that unobserved effects of geographic location on the likelihood of FGM/C among Senegalese girls had a pattern similar to that of 2015 with significantly high likelihood of FGM/C in North and South regions and low likelihood in the West as presented in Figure 5A-B. We only focused on pinpointing regions with high risks to show where interventions should focus and/or where researchers can conduct in-depth analysis of the regions for more targeted interventions. A proper account of known risk factors is important to show which of them may directly or indirectly contribute to geographic variation in risk of FGM/C. The high-risk factors were still observed in SaintLouis, Tabacounda, and Kolda after adjusting for all known risk factors (Figure 5C-D). 
Figure 5. Maps showing risk of experiencing FGM/C among girls 0-14 years by region, 2017 SDHS. Shown are posterior risk maps (left) of Senegalese 0-14-year-old girls' FGM/C with the corresponding 95\% (right) posterior significance maps for unadjusted spatial effect (top) and fully adjusted model (bottom). Evidence from the 2017 SDHS.

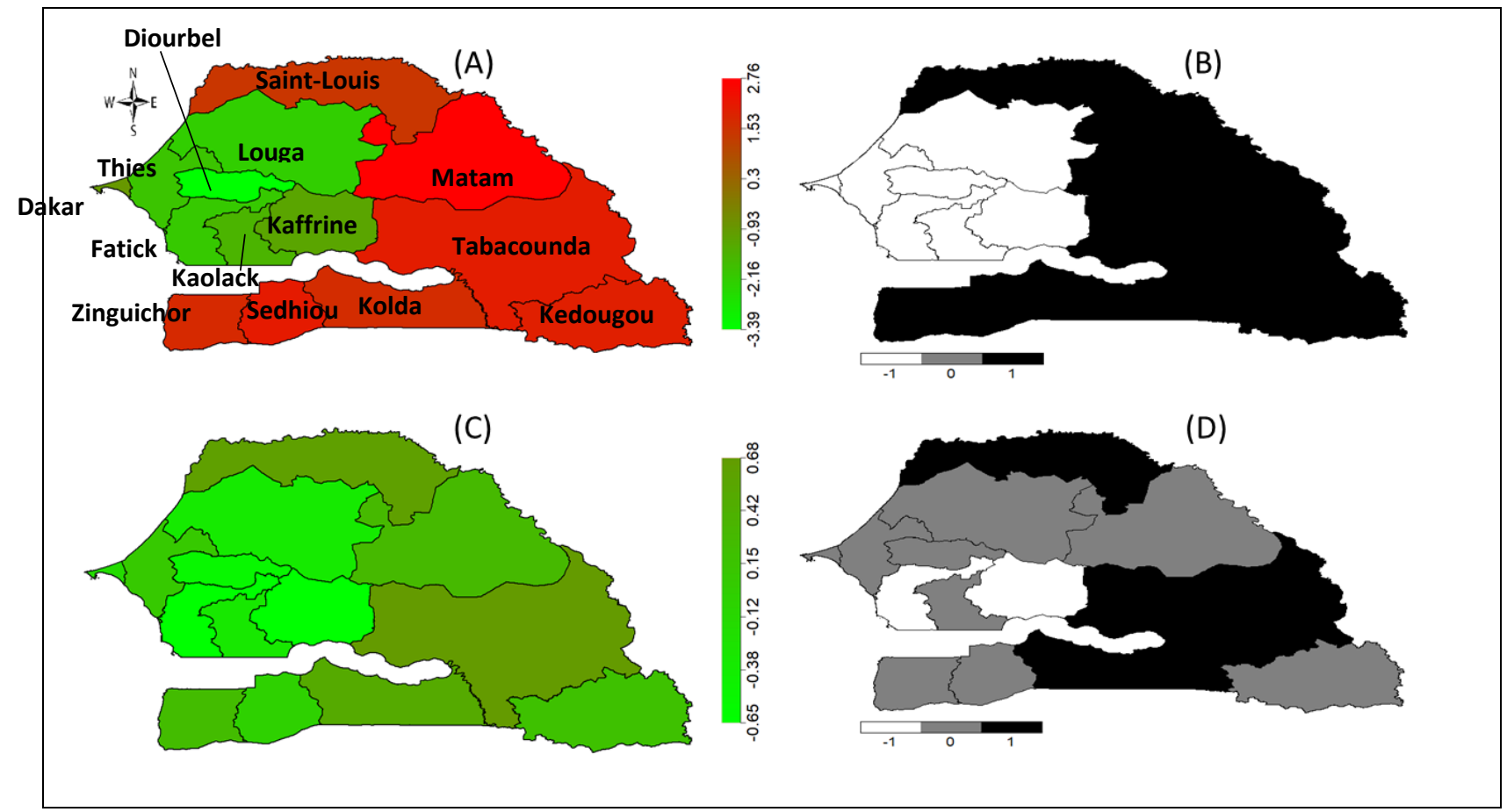

Note: Light green to red corresponds to low-risk to high-risk. Black colour indicates significantly high-risk regions, white colour indicates significantly low-risk regions, and grey colour indicates nonsignificant.

\section{The shift in the prevalence of FGM/C at the regional level during the 12-years period}

Over time, several high prevalence regions remained "hot spots" with a consistently high FGM/C risk during the 12-year period. The prevalence of $\mathrm{FGM} / \mathrm{C}$ was consistently higher in Kolda and significantly lower in Kedougou. A shift was observed for Sedhiou region, which moved from a higher FGM/C prevalence region in 2005 to a low FGM/C prevalence region in 2017. Tabacounda moved from a lower prevalence region in 2005 to higher prevalence region in 2017.

\section{Pooled 2010 to 2017 SDHS}

Using pooled data from 2010 to 2017, we examined the geographic variation in the likelihood of $\mathrm{FGM} / \mathrm{C}$ in order to account for temporal trends as well as potential interaction between region-specific factors and time. The pooled estimate showed a reduction in the likelihood of FGM/C only in one region, namely, Kedougou, as in the previously identified high-risk areas at each separate time point (i.e., 2010-11 SDHS, 2015 SDHS, and 2017 SDHS). However, the likelihood of FGM/C was not significantly associated with unobserved geographic location-specific effects in all regions except in Matam (Figure 6C-D). In other words, risks of FGM/C in Matam are significantly high. 
Figure 6. Maps showing risk of experiencing FGM/C among girls $0-14$ years by region, 2010-17 SDHS. Shown are posterior risk maps (left) of Senegalese 0-14-year-old girls' FGM/C with the corresponding $95 \%$ (right) posterior significance maps for unadjusted spatial effect (top) and fully adjusted model (bottom). Evidence from pooled data from the 2010-11 to 2017 SDHS.

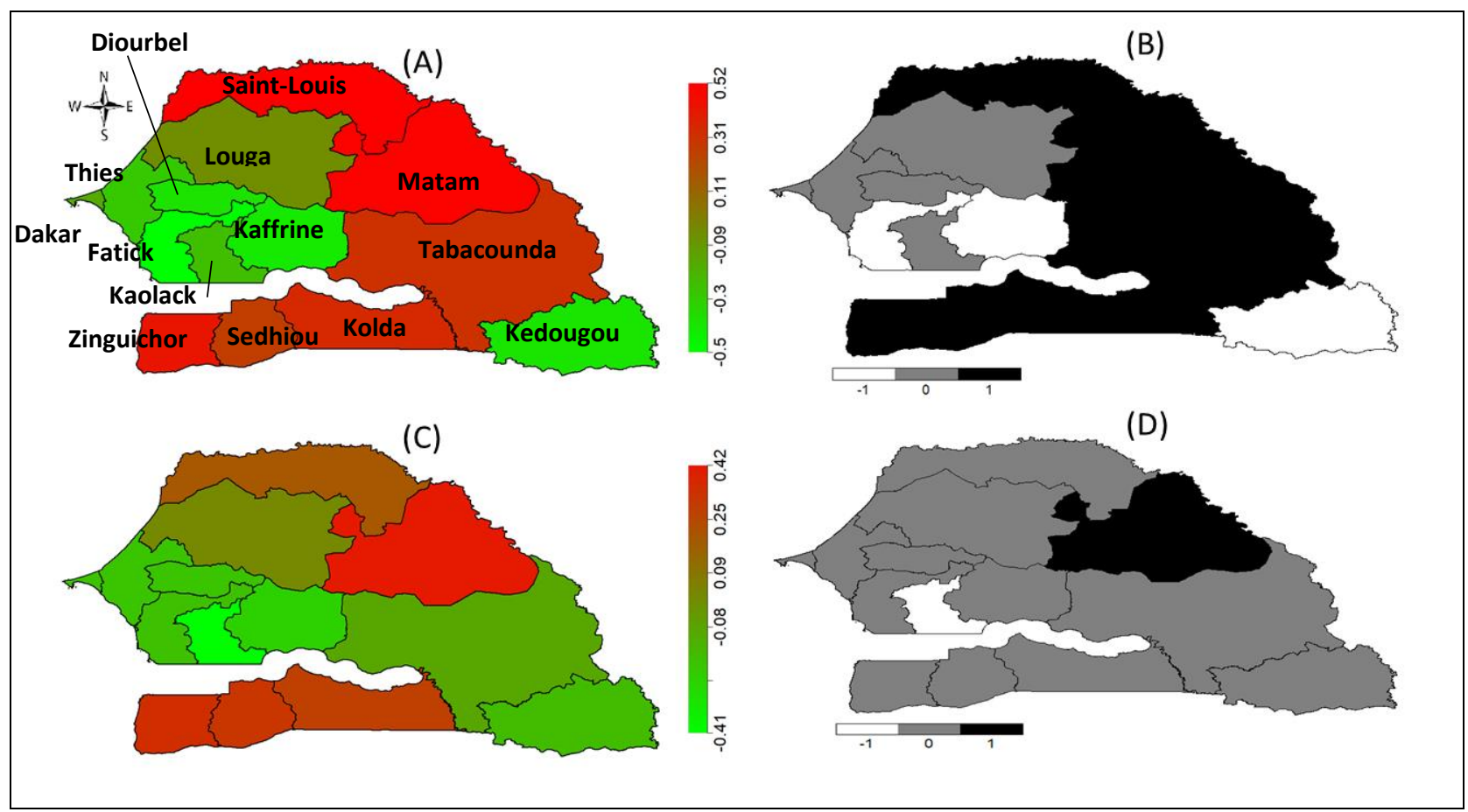

Note: Light green to red corresponds to low-risk to high-risk. Black colour indicates significantly high-risk regions, white colour indicates significantly low-risk regions, and grey colour indicates nonsignificant.

Detailed results of the analysis are given in Appendix Table A5. The pooled data showed that the likelihood of having undergone $\mathrm{FGM} / \mathrm{C}$ was $37 \%$ lower among girls in urban than rural areas between 2010 and 2017. In addition, the likelihood of having undergone FGM/C was 50\% lower among animist girls compared to their Christian counterparts.

The likelihood of cutting was significantly higher among all ethnic groups (except the Serer) compared to Wolof girls. For instance, girls from Soninke had four times greater odds while girls from Diola and Poular had three times greater odds of undergoing FGM/C than Wolof girls. With respect to social norms, daughters of cut mothers were 13 times more likely to be cut than their counterparts born to uncut mothers. We also observed that girls born to mothers who supported the continuation of FGM/C were five times more likely to be cut than those whose mothers supported abandonment. The combined results also showed a $64 \%$ higher likelihood of cutting among daughters of women who believed that $\mathrm{FGM} / \mathrm{C}$ was a religious requirement than among those who had a contrary belief.

Regarding women's employment status and its association with girls' FGM/C status, a daughter of a woman employed at least in the last seven days prior to the surveys had a significantly lower likelihood of being cut than the daughter of a woman who did not work at all. Daughters of women who had an informal occupation and those whose mothers were not working were more likely to be cut compared to girls whose mothers were formally employed. The likelihood of cutting was also higher between 2010 and 2017 among girls whose mothers listened to the radio than girls whose mothers never listened to radio.

Overall, results from the geo-additive semi-parametric modelling (Appendix Tables A1-A5) showed significant variations in $\mathrm{FGM} / \mathrm{C}$ prevalence between regions and across survey years. Matam region had consistently the highest FGM/C prevalence over the years, ranging from $79 \%$ in 2005 to $59 \%$ in 
2017 (Table A6). In contrast, most of the regions in the western part of the country had consistently low FGM/C prevalence, with the Diourbel region having the lowest prevalence across survey years (from $1 \%$ in 2005 to $0.2 \%$ in 2017). Between these two extremes lie other regions with varying trends in $\mathrm{FGM} / \mathrm{C}$ prevalence over time.

Although all regions experienced a decline in FGM/C prevalence from 2005 to 2017, the largest absolute and relative decline occurred in the Kolda (by $36 \%$ ) and Louga (82\%) regions, respectively (Figure 7). The smallest absolute decline in prevalence occurred in Tambacounda region (18\%), followed by Matam (26\%), Zinguichor (27\%), and Saint Louis (30\%). It is, however, important to note that three new regions were created in 2010, namely Kedougou, Kaffrine, and Sedhiou (See hatched regions, on Figure 7; 2005 SDHS maps). An analysis of trends in FGM/C prevalence in these regions between 2010 and 2017 showed a sharp increase in the practice in Kedougou between 2010 and 2015 (from 16\% to 36\%) - a pattern similar to that observed in the southwestern region of Zinguichor. This is a border region where prevalence increased from $22 \%$ in 2010 to $50 \%$ in 2015 . In contrast, between 2015 and 2017, Kedougou experienced an absolute increase of $8 \%$ over the same period.

Figure 7. Observed (top panel) and Predicted (bottom panel) FGM/C prevalence among girls aged 0-14 in Senegal, 2005 to 2017

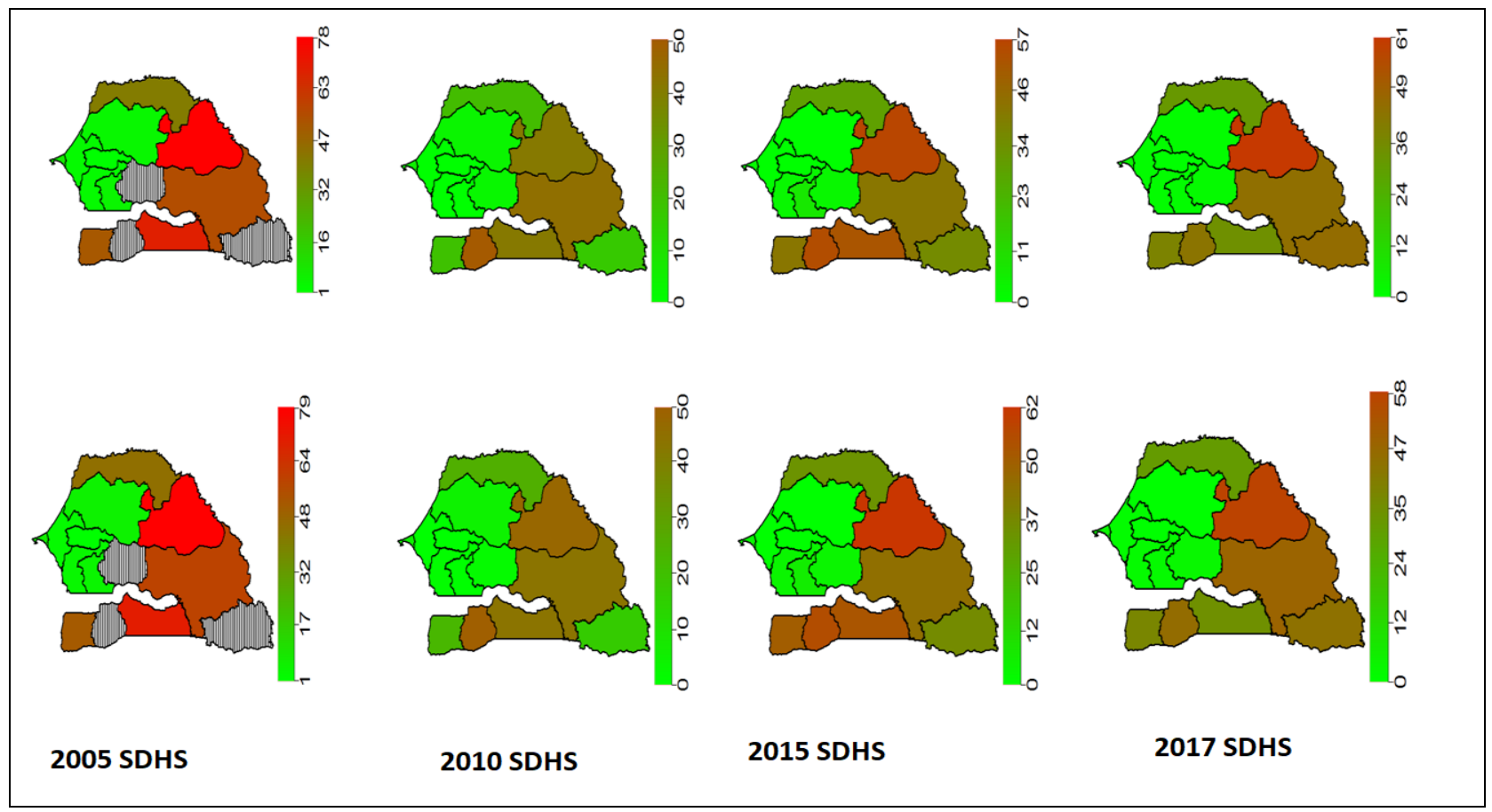

The posterior FGM/C prevalence maps obtained from the fully adjusted model (the model with all the potential confounders simultaneously accounted for) for years 2010, 2015, and 2017 are presented in Figure 8 below. The highest FGM/C prevalence was noted in Matam and Tambacounda in 2015 and 2017. Other regions in the South such as Kolda and Sedhiou experienced a decline between 2015 and 2017. Prevalence remained low across all regions in the west from 2010 and 2017. 
Figure 8. Maps showing FGM/C prevalence among girls --14 following the space-time model, Senegal DHS 2010-17

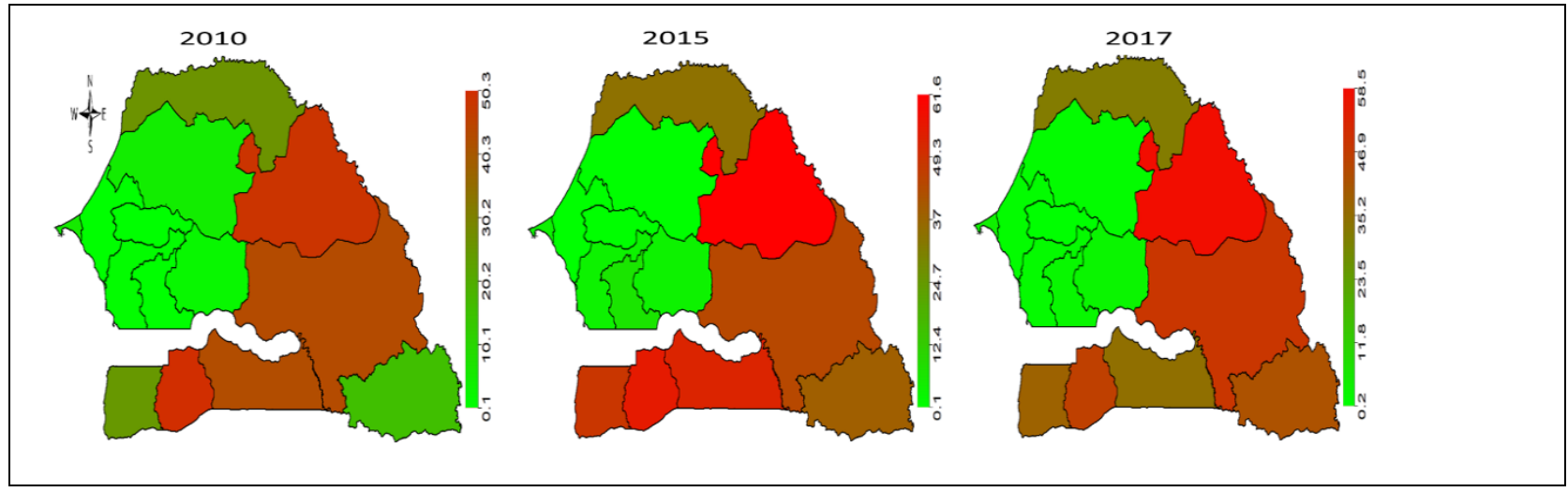

We further examined the relationship between the age of the mother and the likelihood of cutting girls over time. Our interest here was whether, for instance, a 20-year-old mother was more or less likely to have a cut daughter in 2005 than in 2017, and how this changed over time.

Figure 9. Variations in the likelihood of undergoing FGM/C by mother's age based on pooled datasets (left panel) AND time trends in the likelihood of undergoing FGM/C between 2010 and 2017.

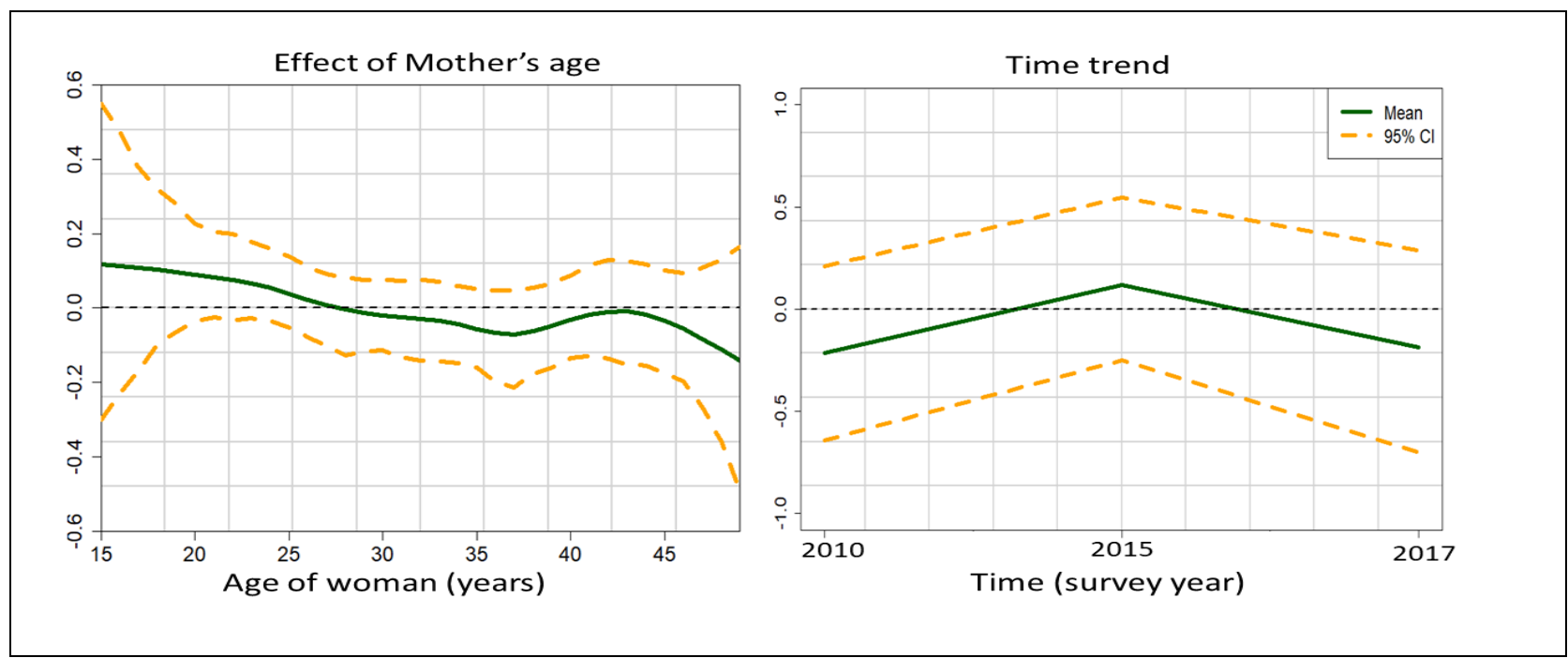

Results of trends showed an increase in the likelihood of undergoing FGM/C between 2010 and 2015 and a decline to the 2010 levels in 2017 (Figure 9). The results further show that daughters of younger mothers (aged 15 to 20 years old) had the highest likelihood of being cut. 


\section{Trends in the likelihood of FGM/C by mother's age}

Figure 10 compares the likelihood of being cut by mother's age, from 2005 to 2017 . The results show that in 2005 , older women were more likely than younger ones to have a cut daughter. However, in 2010, there were no significant variations between the age of the mother and the likelihood of having a cut daughter. There was a negative association between mother's age and the likelihood of cutting girls in 2015 , an indication that younger mothers were more likely to cut their daughters than older ones. Two years later (in 2017), the association between mother's age and the likelihood of cutting her daughter became nonsignificant. Overall, findings suggest diminishing influence of the age of the mother on the likelihood of her daughter being cut.

Figure 10. Trends in the likelihood of FGM/C among girls $0-14$ by mother's age, Senegal 2005 to 2017

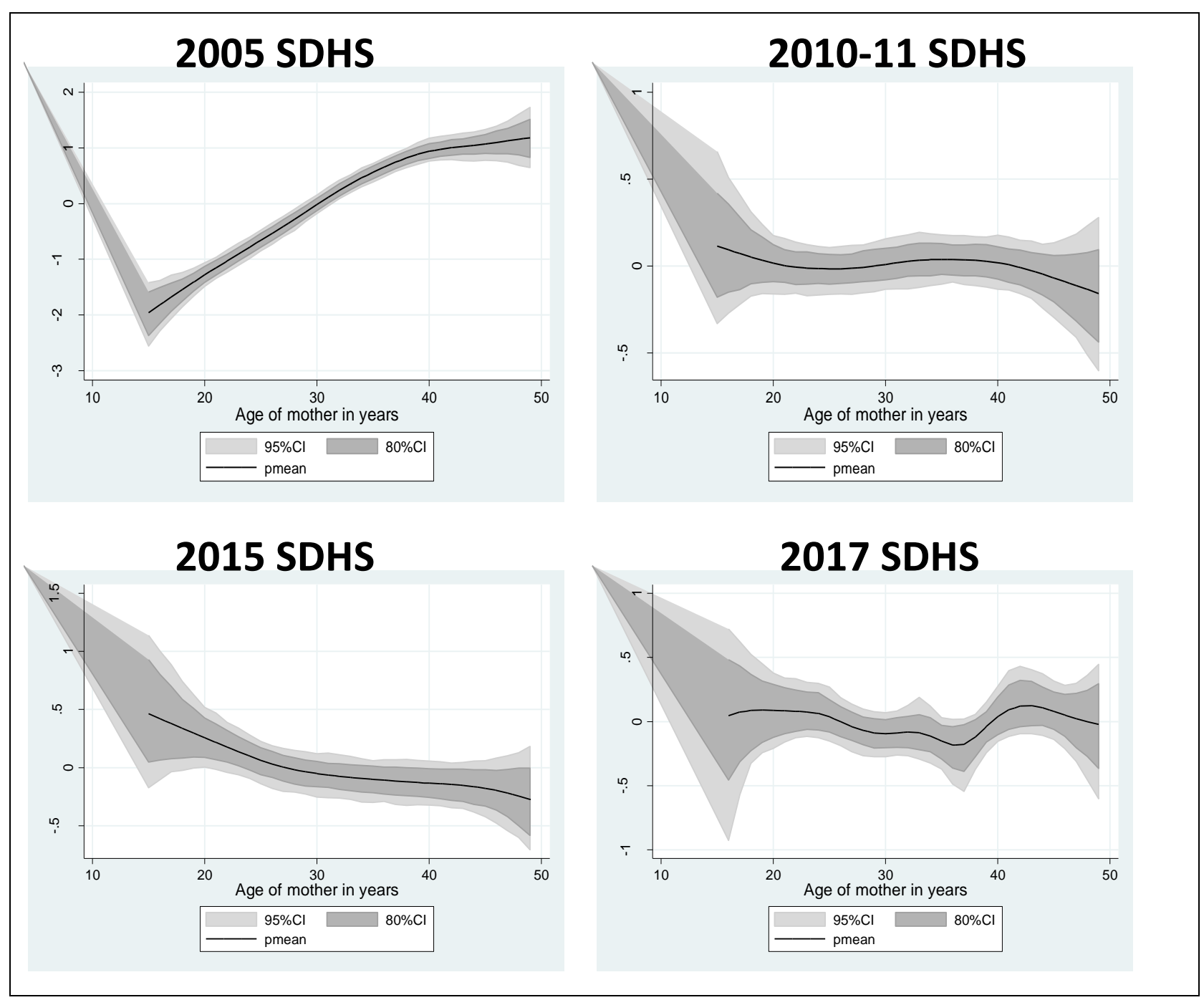




\section{Trends in the likelihood of FGM/C by girl's age}

There was a clear pattern of a positive association between the girl's age and her likelihood of being cut across the four surveys. In particular, the likelihood of undergoing FGM/C increased with a girl's age. The narrow 95\% posterior credible interval of the estimates around the mean showed that the age of a Senegalese girl was strongly associated with her likelihood of undergoing FGM/C (Fig. 11).

Figure 11. Trends in the likelihood of undergoing FGM/C by age of girls, Senegal DHS 2005 to 2017

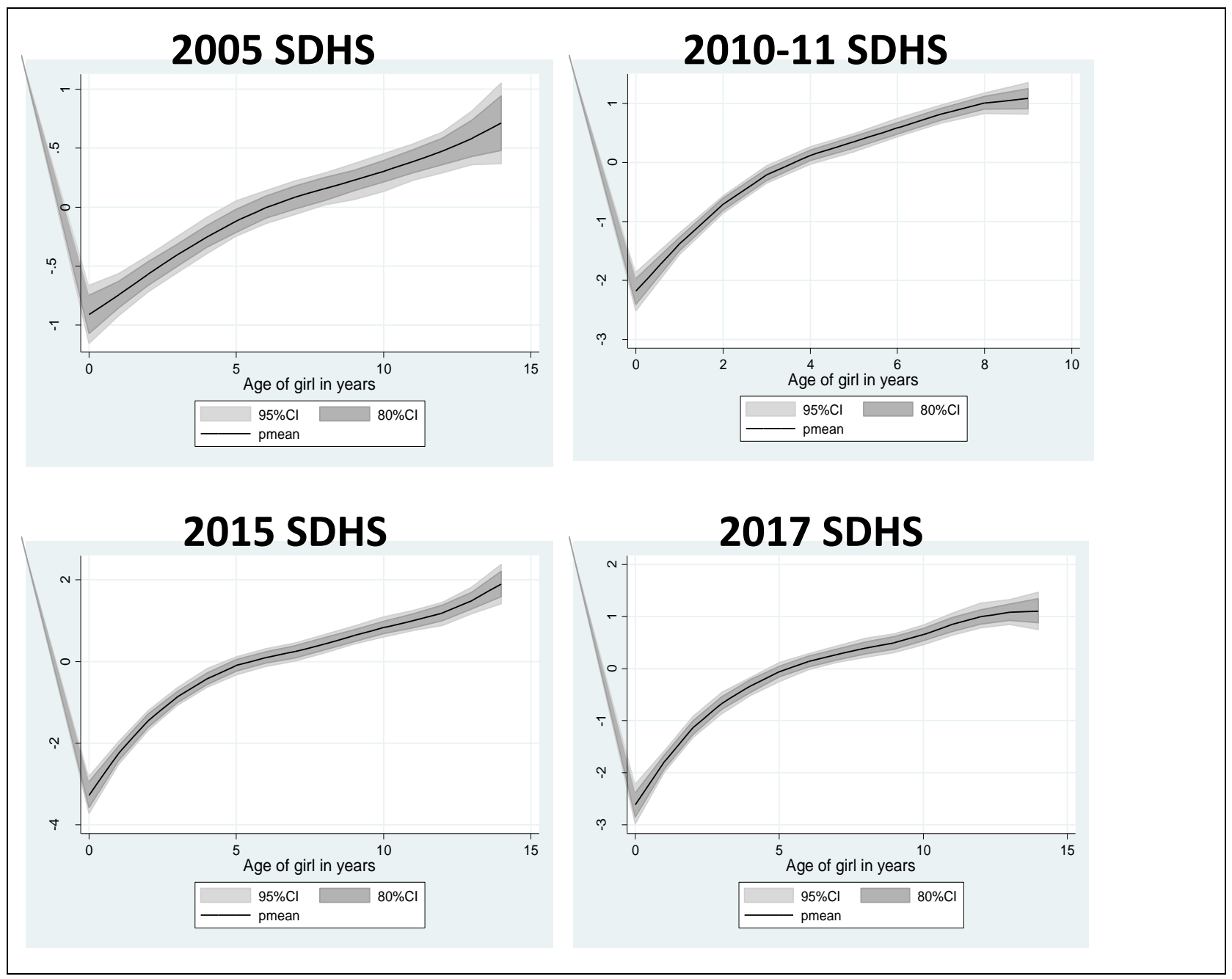


Trends in FGM/C prevalence by norms that perpetuate the practice

An analysis of the association between the proportion of cut women in the community and the likelihood of a girl being cut showed an increased likelihood of cutting as the proportion of cut women in her community increased across the years (Figure 12).

Figure 12. Trends in the likelihood of undergoing FGM/C by prevalence of the practice in the community, Senegal 2005 to 2017

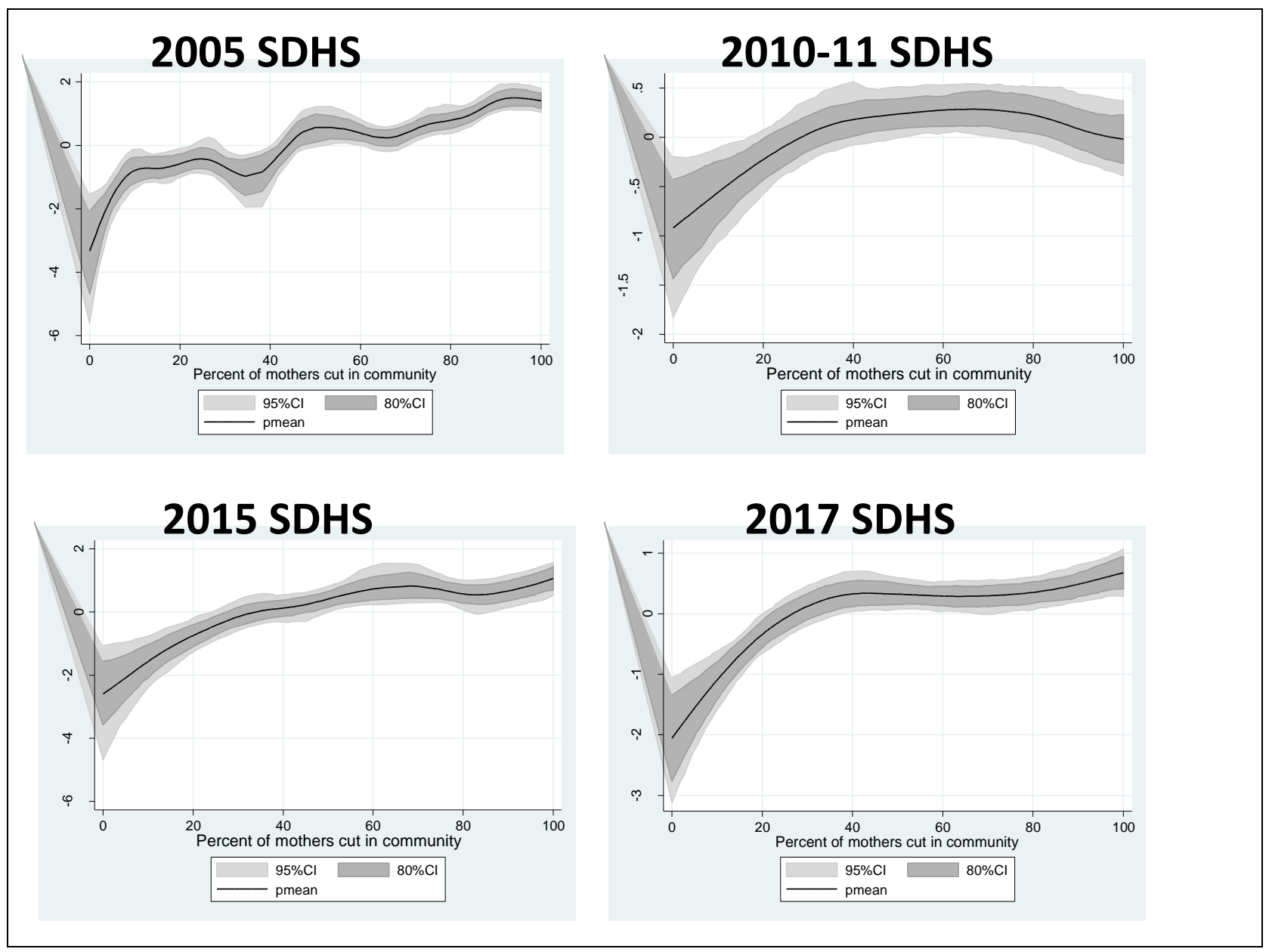


Results from analysis of trends in the likelihood of FGM/C by mother's support for continuation of the practice showed that in 2010 , there was a positive association between the two indicators as the proportion of mothers who supported continuation of the practice in a community increased to $30 \%$ (Figure 13). However, the likelihood of FGM/C declined as the proportion of women in the community who support the practice increased beyond $30 \%$ (Figure 13). There was a positive association between the two indicators in 2015 and a strong negative association in 2017.

Figure 13. Trends in the likelihood of FGM/C by mothers' support for continuation of the practice, Senegal 2010 to 2017

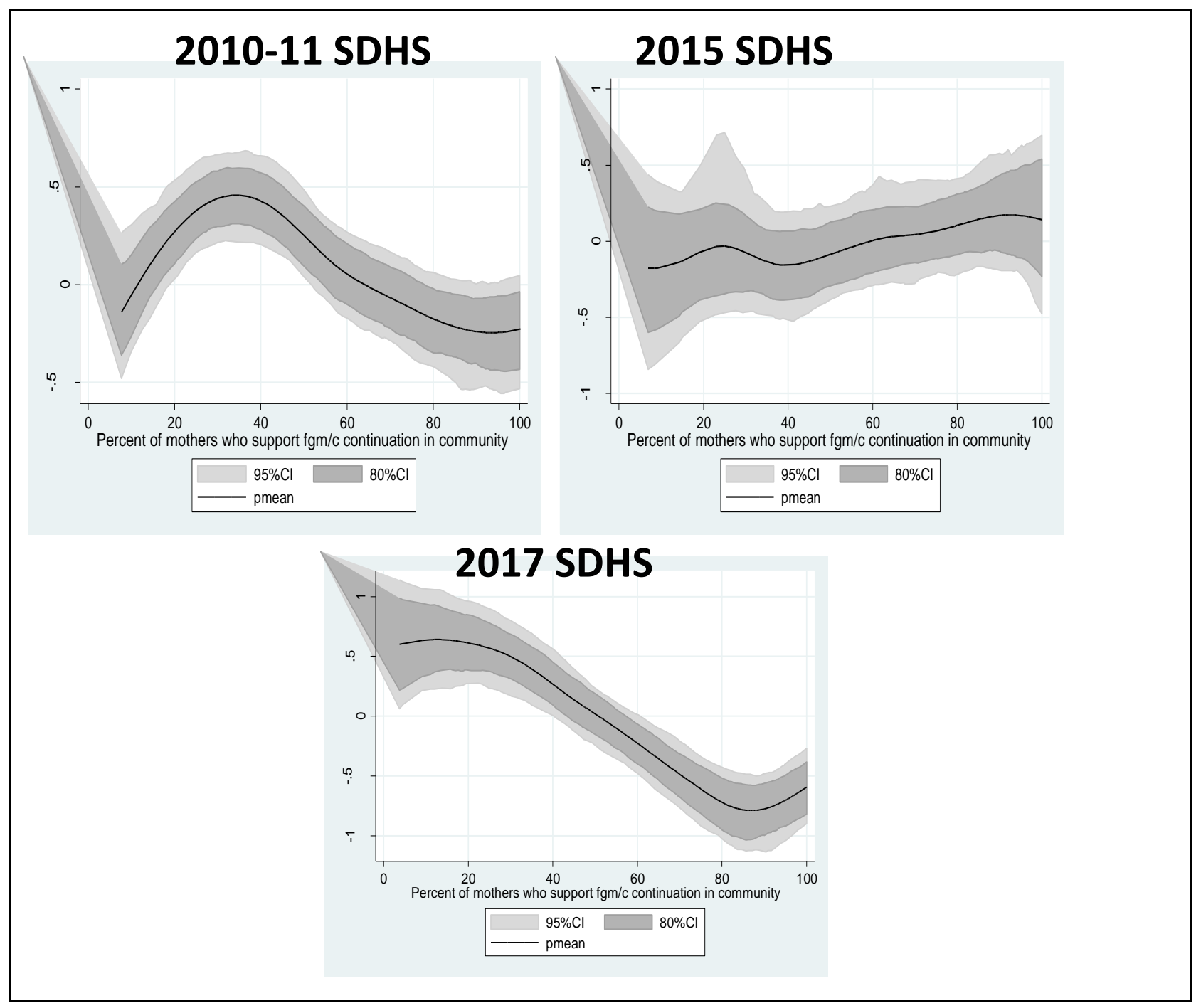


There was a positive association between a mother's belief that FGM/C was a religious requirement and the likelihood of having a cut daughter in 2010 and 2015 but this ceased to be the case in 2017 (Figure 14).

Figure 14. Trends in the likelihood of daughters experiencing FGM/C by mothers' beliefs regarding the practice, Senegal 2010 to 2017

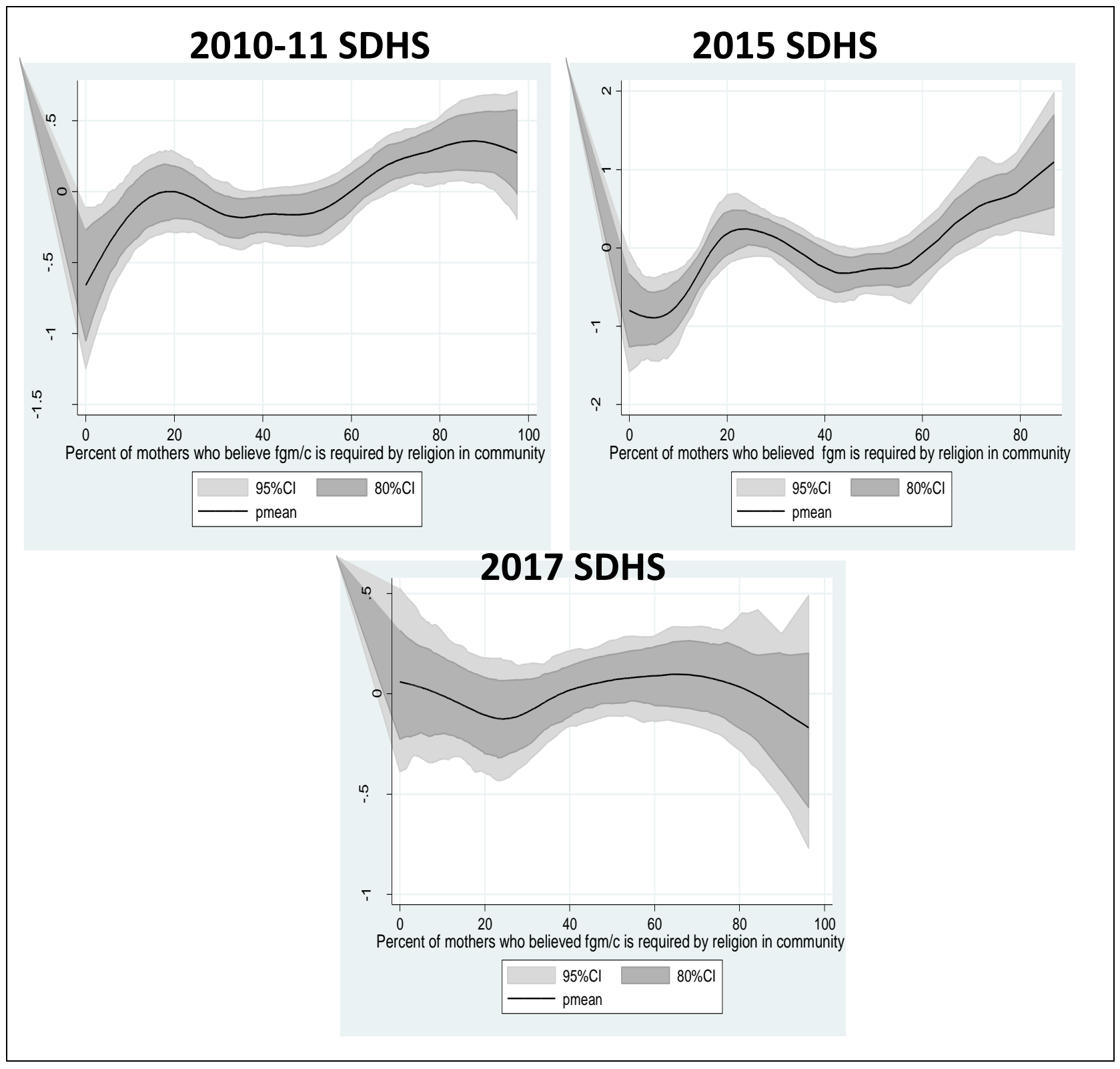




\section{Trends in the likelihood of FGM/C by mother's status}

In 2005 and 2010, there was a positive correlation in the estimated effect of mother's FGM/C status on her daughter's FGM/C status. There was also a downward trend in predicted prevalence in the regions of Saint Louis, Matam, and Tambacounda; with no correlation found between 2010 and 2015. However, within each of same three regions, between 2015 and 2017 only a minimal change in the influence of mother's FGM/C status and predicted prevalence was observed. In 2015-17, within other regions such as Kolda, Zinguichor, and Sedhiou, no correlation was observed between the FGM/C status of the mother and predicted decline in prevalence. Overall, evidence suggests a significant decline in the association between mother's FGM/C status and the likelihood of cutting girls over time (Figure 15).

Figure 15. Trends in the likelihood of daughters experiencing FGM/C by mother's status, Senegal 2005 to 2017

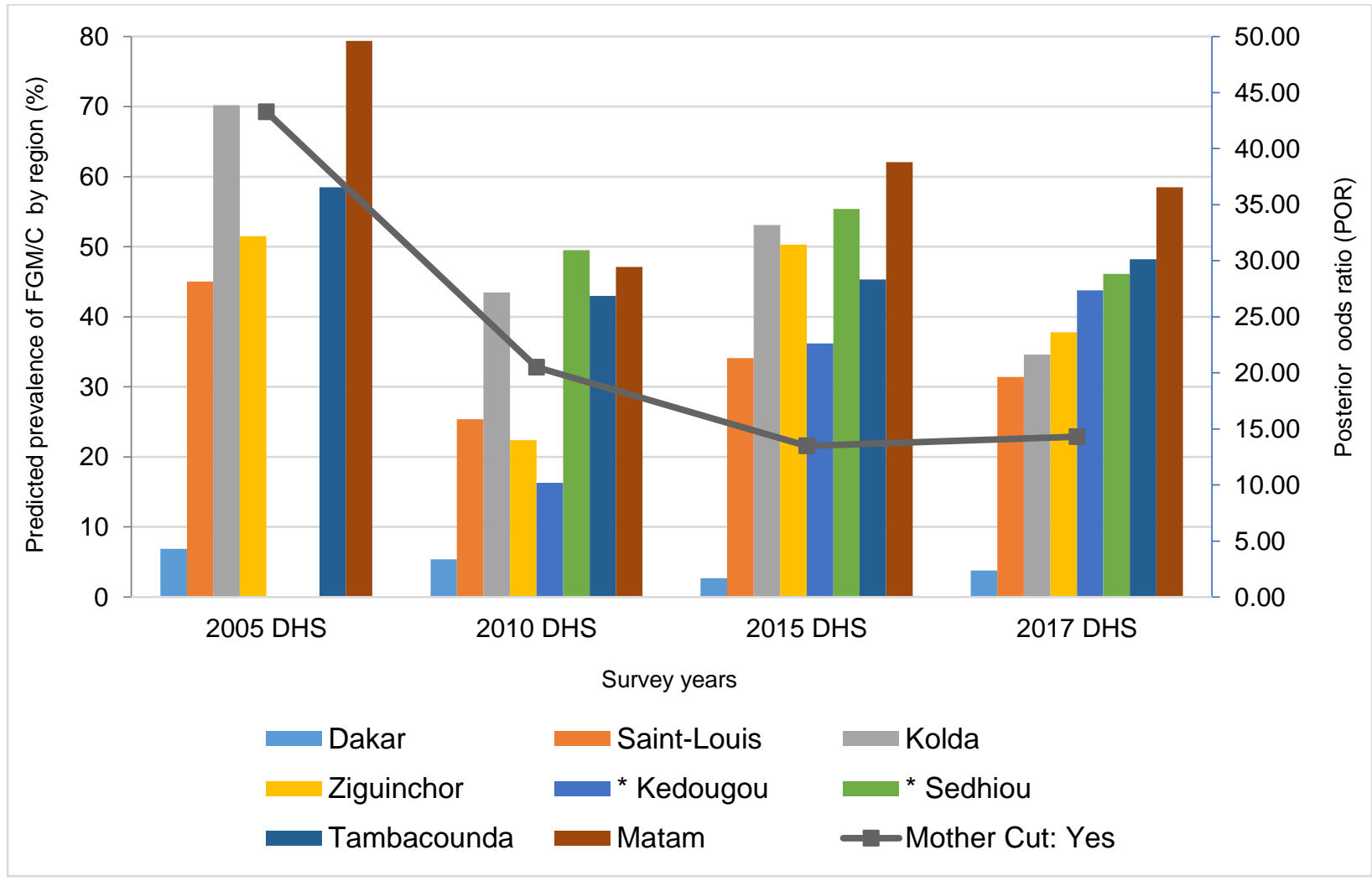

\section{Survival analysis results}

We also estimated time to cutting with respect to some individual-level characteristics using the most recent survey. The idea was to get an overview of recent trends in the practice in terms of time to cutting. In 2017, a total of 14,321 women who had at least one living daughter reported that 1,421 girls underwent FGM/C (median age at cutting: 2 years; interquartile range [IQR]: 1-3 years). This implies that $25 \%, 50 \%$ and $75 \%$ of all the cut girls were cut by ages 1, 2, and 3 years, respectively. Table 3 shows the median survival time to cutting and the IQR in years by socioeconomic background. The median time to cutting was similar in rural and urban communities (2 years). In addition, the average time to cutting among Christian and Muslim girls was 2 years with an IQR of 1-3 years. There were no variations in the time to cutting by mother's educational attainment ( 2 years across all education categories, with an IQ range between age 1 and 3; Table 3). 
Age at cutting of girls varied across ethnic groups. For instance, daughters of women from the Soninke ethnic group were cut within their first year (IQR: 1-2). Girls from Wolof, Poular, and Mandingue ethnic groups had a median time to cutting of 2 years. FGM/C occurred much later in Diola girls, at age 3, compared to girls from other ethnic groups (IQR: $2-5)$.

There were no variations in age at cutting by household wealth quintiles. With respect to region of residence, the age at cutting for daughters in the Louga region was during the first year after birth (IQR: 1-2) and at the age of 2 years in Fatick (IQR: 2-6), Kolda (IQR: 1-3), Matam (IQR 1-3), SaintLouis (IQR: 1-3), Tambacounda (IQR: 1-3), Sedhiou (IQR: 2-3), and Kedougou (1-4). Later age at cutting occurred in girls from Kaolack, Zinguichor, and Kafferine at age 3, and at age 4 in girls from the Thies region (IQR: $3-5)$.

Table 3. Median and interquartile range (IQR) survival time (years) to cutting of girls, Senegal 2017

\begin{tabular}{|c|c|c|c|c|c|}
\hline Predictors & Level & $\begin{array}{c}\text { No. of } \\
\text { subjects } \\
(\mathrm{N}=1421)\end{array}$ & $\begin{array}{l}\text { Median } \\
\text { (years) }\end{array}$ & IQR & Log rank test, p-value \\
\hline Residence & & & & & 0.006 \\
\hline & Rural & 1173 & 2 & $(1,3)$ & \\
\hline & Urban & 248 & 2 & $(1,4)$ & \\
\hline Education & & & & & 0.6615 \\
\hline & No education & 1113 & 2 & $(1,3)$ & \\
\hline & Primary & 229 & 2 & $(1,3)$ & \\
\hline & Secondary & 78 & 2 & $(1,3)$ & \\
\hline & Higher & 1 & - & - & \\
\hline Religion & & & & & 0.528 \\
\hline & Muslim & 1405 & 2 & $(1,3)$ & \\
\hline & Christian & 16 & 2 & $(1,3)$ & \\
\hline Ethnicity & & & & & $<0.0001$ \\
\hline & Wolof & 12 & 2 & $(1,3)$ & \\
\hline & Poular & 707 & 2 & $(1,3)$ & \\
\hline & Serer & 2 & 3 & $(3,3)$ & \\
\hline & Mandingue & 409 & 2 & $(1,3)$ & \\
\hline & Diola & 112 & 3 & $(2,5)$ & \\
\hline & Soninke & 23 & 1 & $(1,2)$ & \\
\hline & $\begin{array}{l}\text { Non- } \\
\text { Senegalese }\end{array}$ & 108 & 2 & $(2,3)$ & \\
\hline Wealth index & & & & & 0.0773 \\
\hline & Poorest & 699 & 2 & $(1,3)$ & \\
\hline & Poor & 412 & 2 & $(1,3)$ & \\
\hline & Middle & 223 & 2 & $(2,3)$ & \\
\hline & Richer & 64 & 2 & $(1,3)$ & \\
\hline & Richest & 23 & 3 & $(2,5)$ & \\
\hline Region & & & & & $<0.0001$ \\
\hline & Dakar & 25 & 3 & $(2,4)$ & \\
\hline & Diourbel & 1 & - & - & \\
\hline
\end{tabular}




\begin{tabular}{|c|c|c|c|c|}
\hline Predictors & $\begin{array}{c}\text { No. of } \\
\text { subjects } \\
(\mathrm{N}=1421)\end{array}$ & $\begin{array}{l}\text { Median } \\
\text { (years) }\end{array}$ & IQR & Log rank test, $p$-value \\
\hline Fatick & 12 & 2 & $(2,6)$ & \\
\hline Kaolack & 15 & 3 & $(2,6)$ & \\
\hline Kolda & 222 & 2 & $(1,3)$ & \\
\hline Louga & 2 & 1 & $(1,2)$ & \\
\hline Matam & 147 & 2 & $(1,3)$ & \\
\hline Saint-Louis & 48 & 2 & $(1,3)$ & \\
\hline Tambacounda & 246 & 2 & $(1,3)$ & \\
\hline Thies & 9 & 4 & $(3,5)$ & \\
\hline Zinguichor & 175 & 3 & $(2,4)$ & \\
\hline Kaffrine & 28 & 3 & $(2,5)$ & \\
\hline Sedhiou & 321 & 2 & $(2,3)$ & \\
\hline Kedougou & 170 & 2 & $(1,4)$ & \\
\hline \multirow[t]{4}{*}{$\begin{array}{l}\text { Mother's support for } \\
\text { FGM/C }\end{array}$} & & & & 0.0464 \\
\hline & 1062 & 2 & $(1,3)$ & \\
\hline & 309 & 2 & $(1,3)$ & \\
\hline & 50 & 2 & $(1,2)$ & \\
\hline $\begin{array}{l}\text { Mother's } \quad F G M / C \\
\text { status }\end{array}$ & & & & 0.2104 \\
\hline Cut & 1396 & 2 & $(1,3)$ & \\
\hline Not cut & 25 & 2 & $(1,3)$ & \\
\hline
\end{tabular}


The Kaplan-Meier (KM) estimator of survival functions, by the key socioeconomic factors associated with age at cutting of girl in Senegal, are presented in Figures 16-18 and Figures A1-A6 in the Appendix. Figure 16 shows that the age at cutting girls was similar in rural and urban areas during the first 2 years of life. Between ages 3 and 8 , girls in rural areas were cut much earlier there than in urban areas (log rank test, $\mathrm{p}=0.006$ ).

Figure 16. Rate of cutting of girls by place of residence (SDHS 2017)

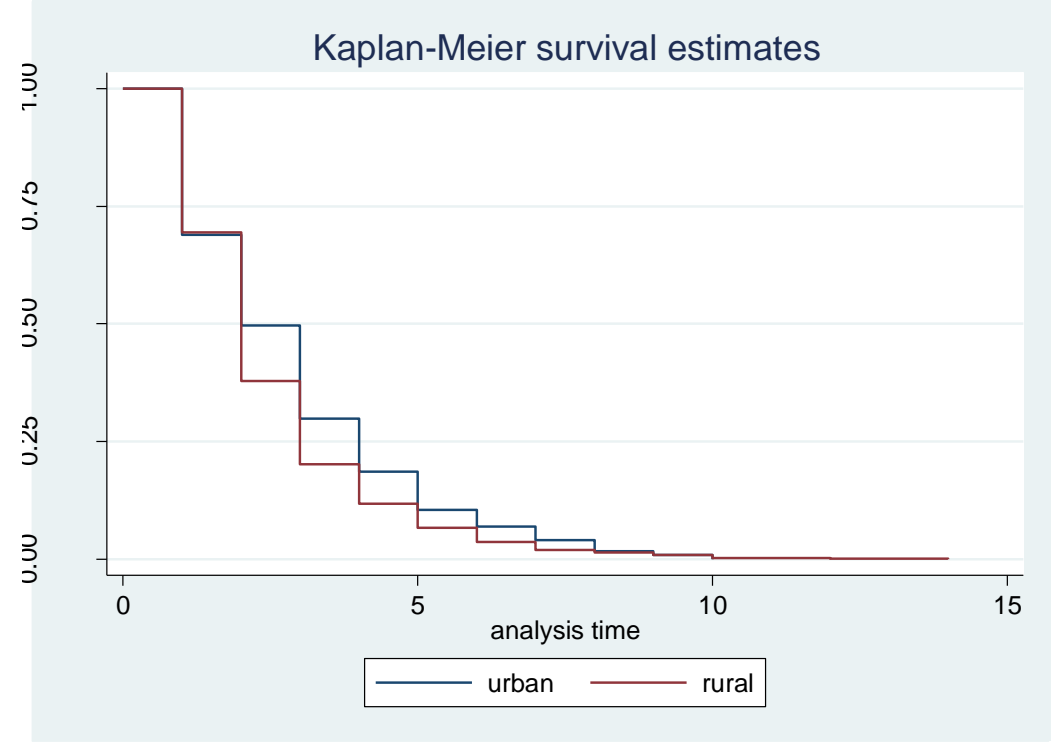

Regional disparity existed in the pattern of time to cutting among girls in Senegal as shown in Figure 17. Women in the southern regions (such as Kolda and Sedhiou in Casamance and Kedougou in the South East) generally tend to cut their girls earlier. However, daughters of women from the western regions including Thies, Kaolack, and Kaffrine, experienced delayed time to cutting (log rank test, $\mathrm{P}<0.001)$. The likelihood of being cut after the age of 10 was minimal in all regions.

Figure 17. Rate of cutting girls by region of residence (SDHS 2017)

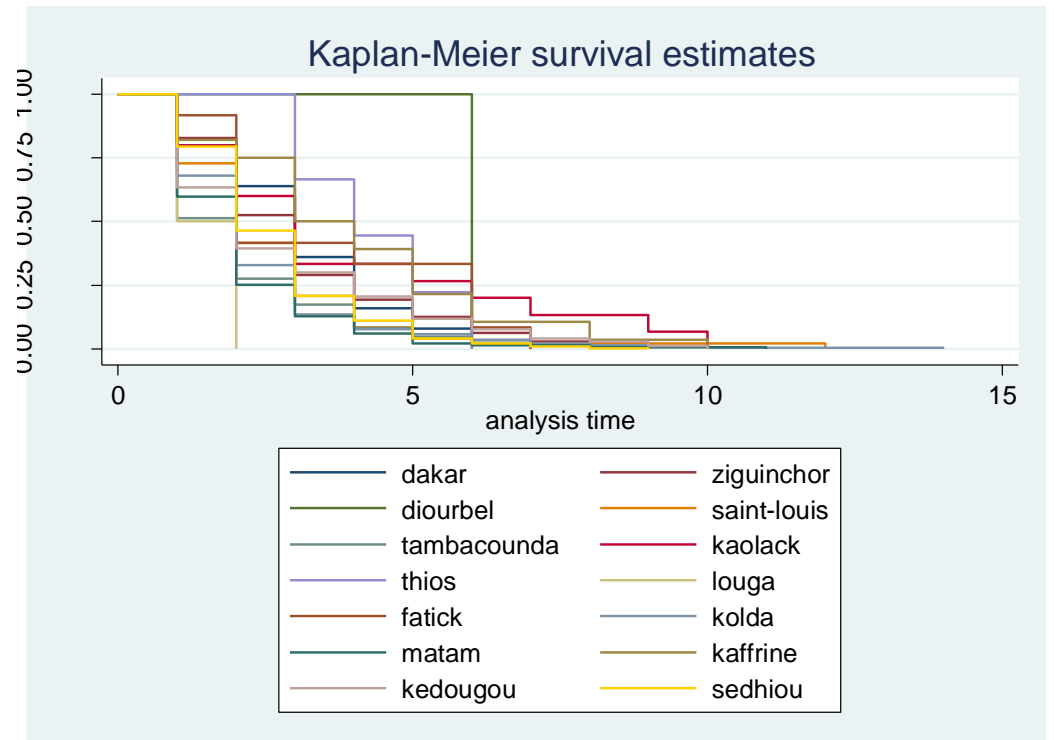

Variations in the rate of cutting by mother's support for FGM/C showed that those who supported the practice cut their daughters within the first 5 years of life at a higher rate than those who did not 
$(p=0.046)$. Beyond five years, the rate of cutting diminishes to near zero, with no major difference between the two groups.

Figure 18. Rate of cutting girls by mother's support for FGM/C (SDHS 2017)

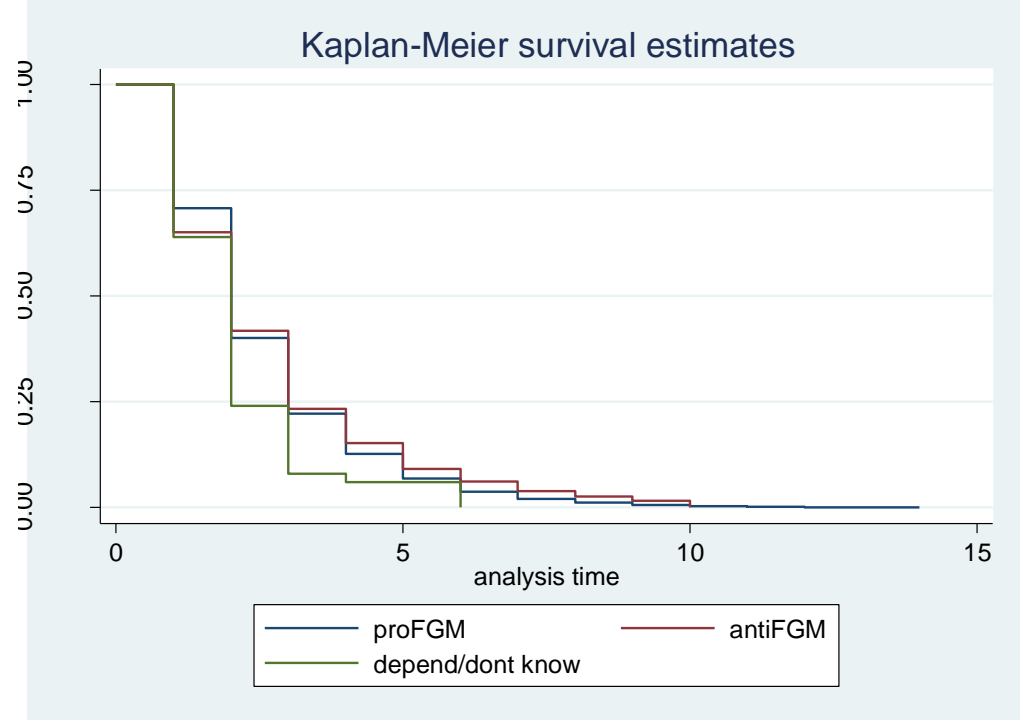

The rate of cutting was similar among daughters of women with no education and those with secondary-level education (Figure A1). Figure A2 (Appendix) shows that between ages 6 and 10 years, Muslim girls were cut at a lower rate than Christian girls while there is no major difference in the rate of cutting between the two groups before age 5 (log rank test, $P=0.528$ ). In Figure A3 in the Appendix, we see that before age 5, Soninke mothers cut their daughters at a lower rate compared with other ethnic groups, while from age 5 onwards, the rate of cutting was similar across all ethnic groups. The rate of cutting at the different ages by wealth index are shown in Figure A4. The highest rate of cutting was found in girls born into the poorest household quintile but the differences by age were not statistically significant (log rank test, $\mathrm{P}=0.077$ ). Mothers who supported the practice cut their daughters at a higher rate than those who did not within the first 5 years of life ( $p=0.046)$ (Figure A5). Figure $A 6$ shows that mothers who underwent FGM/C generally cut their daughters at a higher rate than mothers who did not undergo the practice. This shows that while change may be occurring in space and time, the differences in the rate of cutting by age were not statistically significant (log rank test, $P=0.210$ ).

\section{Discussion}

This study examined the influence of individual and community-level factors on variation in the risk of $\mathrm{FGM} / \mathrm{C}$ among girls who are younger than 15 years in Senegal. We also evaluated how the geographical location of the mothers and other factors affected the observed FGM/C prevalence. We observed a spatial clustering of cut girls, with strong evidence of differences in the prevalence of $\mathrm{FGM} / \mathrm{C}$ by region of residence and across time in the shared underlying $\mathrm{FGM} / \mathrm{C}$ risk factors. These patterns and trends are consistent with known trends in FGM/C prevalence (Kandala and Komba 2015; Kandala and Shell-Duncan 2019). Mothers' FGM/C status is the leading risk factor for being cut in Senegal and is likely to strongly reflect past FGM/C patterns. We also found that the risk of cutting was higher among girls whose mothers supported the continuation of FGM/C and those whose mothers believed that $\mathrm{FGM} / \mathrm{C}$ was a religious requirement. This result is consistent with the social norms theory (Mackie 1996; Mackie and LeJeune 2009). 
We found a high risk of cutting for girls living in Kedougou and Zinguinchor regions between 2010 and 2015. The proximity of these regions to neighbouring countries-Guinea and Guinea Bissau —with a high prevalence of $F G M / C$ may explain the higher risk of FGM/C. Senegal's FGM/C legislation does not ban cross-border cutting, suggesting that mothers can easily move to have their daughters cut before returning to their communities (Kandala and Komba 2015). Similarly, we also found a significant clustering of FGM/C risk in the northeastern regions of Senegal.

We found a declining probability of $\mathrm{FGM} / \mathrm{C}$ among girls in the western regions. For instance, Zinguinchor experienced a 13 percentage-point decline in FGM/C prevalence between 2015 and 2017. Declines were also observed in Kolda (18.5 percentage points) and in Sedhiou (9.3 percentage points). The Wolof have a significantly lower likelihood of practising $F G M / C$, and primarily inhabit the western region.

In 2005, we found that older women were significantly more likely to cut their daughters than younger women. In more recent years, there was no significant difference in the likelihood of cutting based on mother's age. This result suggests that older women may be increasingly less likely to cut their daughters. As noted by Shell-Duncan et al. (2018), older women may have more power to negotiate changes in traditional practices and thus over time are less likely to support FGM/C.

Our fully adjusted model revealed that girls born to women living in rural areas and in poorer households had a higher risk of being cut than their urban and richer household counterparts. These findings provide strong support for predictions from the modernisation theory which posit that a shift to formal employment, higher educational attainment, and increased exposure to media containing anti-FGM/C messages can significantly reduce the risk of FGM/C (Yount 2002; Hayford 2005). Furthermore, our evidence showed that gender norms did not significantly explain the risk of cutting girls. Our findings do not therefore confirm the feminist theory (Abusharaf 2000; Gruenbaum 2001) but another possible explanation for this finding could be that women who are urban and wealthier are less likely to report FGM/C.

This report has both strengths and limitations. Among its strengths was the fact that this was the first study to have analysed successive waves of DHS data including the most recent survey datasets (2017 SDHS). The use of a Bayesian modelling approach represented a major advance in addressing complex spatial autocorrelation and unobserved spatially structured influences on risk of girls' cutting. Secondly, the use of Bayesian hierarchical geo-additive models helped to explain household- and community-level factors as well as the residual influence of geographic location within a unified analytical framework. However, our study also has some limitations. First, our findings apply only to Senegal and cannot be generalised to other contexts where FGM/C is prevalent. Second, reliance on cross-sectional DHS means that we cannot imply causation between individual-/community-level factors and FGM/C. Finally, the data used in the analysis are derived from self-reports. Thus, the precise rates of prevalence may be underreported. Despite these shortfalls, the study offers a robust analysis based on large nationally representative data and provides key insights into the possible effects of individual-level and community-level factors on a girl's likelihood of undergoing FGM/C in Senegal.

\section{Conclusions}

This study applied a Bayesian geo-additive modelling approach to understand the effects of multiple factors on the probability of girls being subjected to FGM/C in Senegal. We conducted a combined analysis of successive DHS data and accounted for nonlinear effects of continuous covariables. Our fully adjusted model revealed that the risk of cutting girls in Senegal was associated with the area of residence, ethnicity, mothers' support for the continuation of FGM/C, mothers own FGM/C status, and 
mothers' belief that $F G M / C$ is a religious requirement. We also found that the risk for $F G M / C$ varied by region. Our findings confirmed the relevance of social norms theory in understanding the risk factors associated with FGM/C among girls in Senegal.

Our results suggest that addressing community-level risk factors is as important as individual-level risk factors. Further, the spatially structured random effects point to areas of excess FGM/C risk that deserve special attention. These findings can inform the targetting of interventions designed to reduce the high likelihood of cutting girls in Senegal.

\section{Recommendations}

Based on our findings, we make six critical recommendations:

- Targeted behaviour-change interventions should be planned and implemented at both individual and community levels to address harmful social norms associated with FGM/C. Such interventions must involve relevant stakeholders including community, political, and religious leaders in order to achieve a definitive abandonment across all regions.

- More resources should be channelled to the rural areas of Senegal to accelerate implementation of abandonment programmes.

- Additional research is needed to examine the reason why Matam and other Eastern parts of Senegal have a higher probability in cutting girls.

- Future research could examine how the risks of cutting compare within the same birth cohort.

- Finally, research should be undertaken to explore how men's participation in household decision making and community-wide interventions may lower likelihood of FGM/C among Senegalese girls. 


\section{References}

Abusharaf, R.M. 2000. "Revisiting feminist discourses on infibulation: Responses from Sudanese feminists," in B. Shell-Duncan and Y. Hernlund (eds.), Female Genital 'Circumcision' in Africa: Culture, Controversy, and Change, 151-166. Boulder, CO: Lynne Rienner.

Achia T.N. 2014. "Spatial modelling and mapping of female genital mutilation in Kenya," BMC Public Health 14: 276. https://doi.org/10.1186/1471-2458-14-276

Agence Nationale de la Statistique et de la Démographie (ANSD/Sénégal) and ICF International. 2012. Enquête Démographique et de Santé à Indicateurs Multiples Sénégal (EDS-MICS) 2010-2011. Calverton, MD : ANSD and ICF International. Retrieved 21 January 2020 from http://dhsprogram.com/publications/publication-fr258-dhs-final-reports.cfm

2016. Senegal Enquête Démographique et de Santé Continue (EDS-Continue) 2015. Rockport, MD : ANSD and ICF. Retrieved 21 January 2020. https://dhsprogram.com/publications/publication-FR320-DHS-Final-Reports.cfm

2018. Senegal: Enquête Démographique et de Santé Continue (EDS-Continue) 2017. Rockville, MD : ANSD and ICF. Retrieved 21 January 2020. https://www.dhsprogram.com/publications/publication-FR345-DHS-Final-Reports.cfm

Belitz, C., A. Brezger, T. Kneib, and S. Lang. 2009. BayesX-software for Bayesian Inference in Structure Additive Regression Models, version 2.0.

2012. Bayes $X$ Software for Bayesian inference in structured additive regression models version 2.0.1, 2012. Retrieved 4 July 2019. http://www.statistik.unimuenchen.de/ bayesX/manual/methodology manual.pdf

Bellamere, M.C, L. Novak, and T.L. Steinmertz. 2015. "All in the family: Explaining the persistence of female genital cutting in West Africa," Journal of Economic Development 116: 252-265.

Cislaghi, B. and L. Heise. 2018. "Using social norms theory for health promotion in low-income countries," Health Promotion International 34(3): 616-623. doi: 10.1093/heapro/day017

Gruenbaum, E. 2001. The Female Circumcision Controversy: An Anthropological Perspective. Philadelphia: University of Pennsylvania Press.

Hayford, S. 2005. "Conformity and change: Community effects on female genital cutting in Kenya," Journal of Health and Social Behavior 46(2): 121-140.

Kandala, N., M.C. Ezejimofor, O.A. Uthman, and P. Komba. 2018. "Secular trends in the prevalence of female genital mutilation/cutting among girls: A systematic analysis," BMJ Global Health 3:e000549.

Kandala, N.B. and P. Komba. 2015. "Geographic variation of female genital mutilation and legal enforcement in sub-Saharan Africa: A case study of Senegal," American Journal of Tropical Medicine and Hygiene 92(4): 838-847.

Kandala, N.B., N. Nwakeze, and N.I. Kandala. 2009. "Spatial Distribution of female genital mutilation in Nigeria," American Journal of Tropical Medicine and Hygiene 81(5): 784-792.

Kandala, N.B. and B. Shell-Duncan. 2019. "Trends in female genital mutilation/cutting in Senegal: What can we learn from successive household surveys in sub-Saharan African countries?" International Journal for Equity in Health 18: 25. doi:10.1186/s12939-018-0907-9

Mackie, G. 1996. "Ending footbinding and infibulation: A convention account," American Sociological Review 61: 999-1017. 
Mackie, G. and J. LeJeune. 2009. Social Dynamics of Abandonment of Harmful Practices: A New Look at the Theory. Innocenti Working Paper No. 2009-06, Florence: UNICEF Innocenti Research Centre.

Ndiaye, S, and M. Ayad. 2006. Enquête Démographique et de Santé au Sénégal 2005. Calverton, MD: Centre de Recherche pour le Développement Humain/Sénégal and ORC Macro. https://dhsprogram.com/pubs/pdf/FR177/FR177.pdf

Shell-Duncan, B. 2001. "The medicalization of female circumcision: Harm reduction or promotion of a dangerous practice?” Social Science and Medicine 52: 1013-1028.

Shell-Duncan, B., A. Moreau, K. Wander, and S. Smith. 2018. "The role of older women in contesting norms associated with female genital mutilation/cutting in Senegambia: A factorial focus group analysis," PLOS ONE 13(7): e0199217. https://doi.org/10.1371/journal.pone.0199217

Shell-Duncan, B., K. Wander, Y. Hernlund, and A. Moreau. 2011. "Dynamics of change in the practice of female genital mutilation in Senegambia: Testing predictions of social convention theory," Social Science and Medicine 73: 1275-1283.

Umlauf, N., D. Adler, T. Kneib, S. Lang, and A. Zeileis. 2015. "Structured additive regression models: An R interface to BayesX," Journal of Statistical Software 63(21): 1-46. doi: 10.18637/jss.v063.i21

Yaya, S. and B. Ghose. 2018. "Female genital mutilation in Nigeria: A persisting challenge for women's rights," Social Sciences 7(12): 244. https://doi.org/10.3390/socsci7120244

Yount, K. 2002. "Like mother like daughter? Female genital cutting in Minia, Egypt," Journal of Health and Social Behaviour 46(2): 121-140. 


\section{Appendix}

Table A1. Odds ratios and $95 \%$ confidence intervals from Bayesian geo-additive multilevel regression analysis, 2005 SDHS

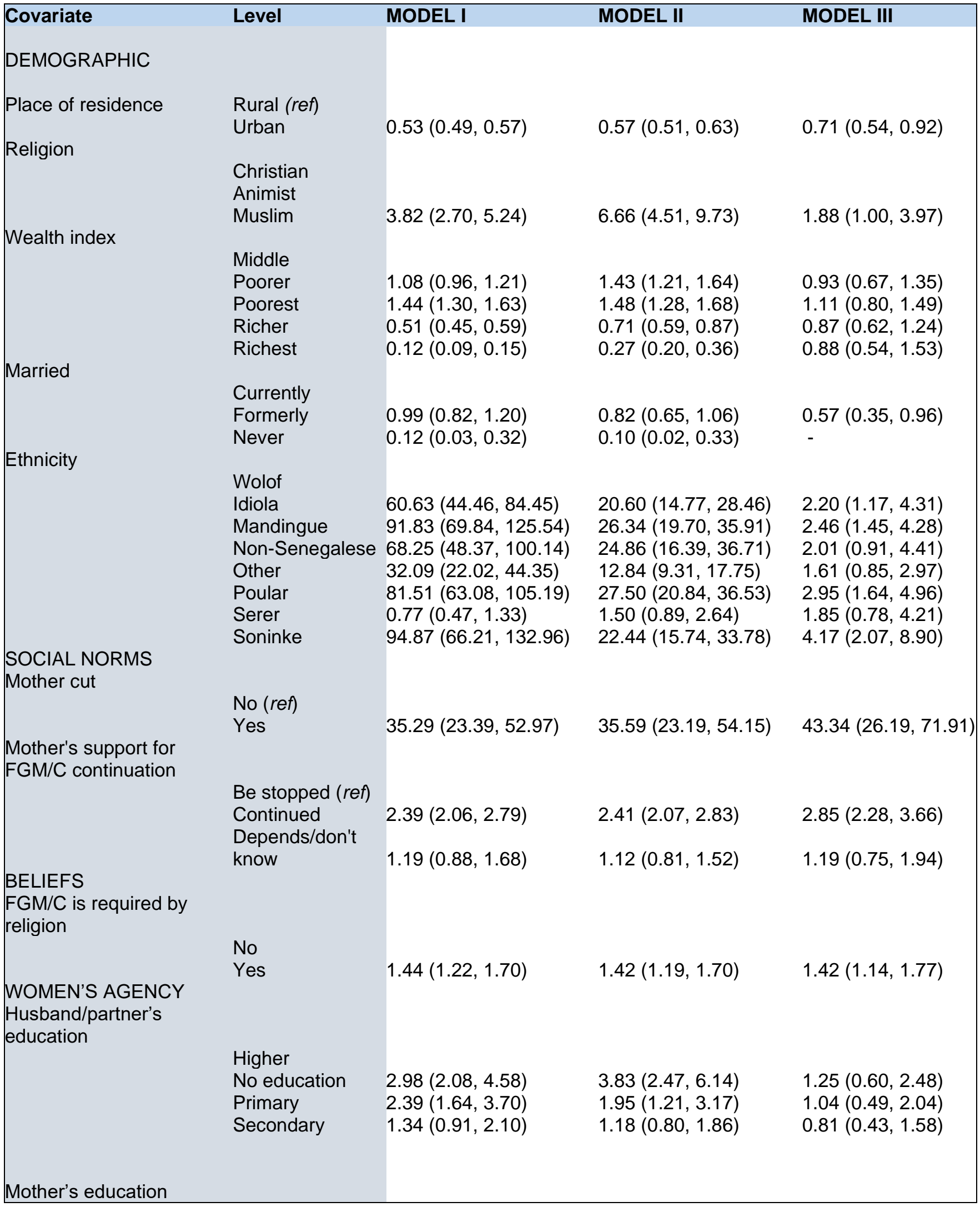




\begin{tabular}{|c|c|c|c|c|}
\hline \multirow{3}{*}{$\begin{array}{l}\text { Covariate } \\
\text { Mother employed in the } \\
\text { last } 7 \text { days }\end{array}$} & Level & MODEL I & MODEL II & MODEL III \\
\hline & $\begin{array}{l}\text { Secondary } \\
\text { No education } \\
\text { Primary } \\
\text { Higher* }^{*}\end{array}$ & $\begin{array}{l}5.03(3.80,6.81) \\
2.49(1.88,3.45)\end{array}$ & $\begin{array}{l}5.23(3.89,7.22) \\
2.15(1.57,3.02)\end{array}$ & $\begin{array}{l}2.10(1.09,4.22) \\
1.04(0.59,1.80)\end{array}$ \\
\hline & $\begin{array}{l}\text { No } \\
\text { Yes }\end{array}$ & & & $0.84(0.58,1.18)$ \\
\hline Mother's occupation & $\begin{array}{l}\text { Formal } \\
\text { Informal } \\
\text { Not working }\end{array}$ & $\begin{array}{l}2.17(1.85,2.51) \\
1.35(1.10,1.69)\end{array}$ & $\begin{array}{l}1.22(0.98,1.50) \\
1.00(0.75,1.31)\end{array}$ & $\begin{array}{l}1.16(0.80,1.67) \\
1.60(0.93,2.76)\end{array}$ \\
\hline $\begin{array}{l}\text { Husband/partner's } \\
\text { occupation }\end{array}$ & $\begin{array}{l}\text { Formal } \\
\text { Informal } \\
\text { Not working }\end{array}$ & $\begin{array}{l}0.94(0.85,1.06) \\
1.73(1.21,2.38)\end{array}$ & $\begin{array}{l}0.83(0.74,0.96) \\
1.36(0.90,2.18)\end{array}$ & $\begin{array}{l}0.73(0.59,0.92) \\
0.80(0.43,1.50)\end{array}$ \\
\hline Who decides? & Alone (ref) & & & \\
\hline Wife's expenditure & $\begin{array}{l}\text { Husband/partner } \\
\text { With } \\
\text { husband/partner } \\
\text { Missing (Not } \\
\text { Available) }\end{array}$ & $\begin{array}{l}0.40(0.26,0.62) \\
0.75(0.52,1.06) \\
0.84(0.70,1.01)\end{array}$ & $\begin{array}{l}0.66(0.35,1.11) \\
0.89(0.55,1.40)\end{array}$ & $\begin{array}{l}1.21(0.50,2.68) \\
1.35(0.69,2.81)\end{array}$ \\
\hline $\begin{array}{l}\text { GENDER NORMS } \\
\text { Female attitude to wife } \\
\text { beating: } \\
\text { Wife beating for going out } \\
\text { is justified. (A"yes" } \\
\text { response would indicate } \\
\text { the respondent agrees it is } \\
\text { justified, while a "no" } \\
\text { would indicate otherwise.) }\end{array}$ & No (ref) & $1.23(1.06,1.42)$ & $0.80(0.67,0.97)$ & $0.74(0.54,0.98)$ \\
\hline $\begin{array}{l}\text { Wife beating for } \\
\text { neglecting the children }\end{array}$ & $\begin{array}{l}\text { No }(r e f) \\
\text { Yes }\end{array}$ & $0.74(0.64,0.85)$ & $0.85(0.71,1.03)$ & $0.78(0.60,1.05)$ \\
\hline $\begin{array}{l}\text { Wife beating for arguing } \\
\text { with the husband }\end{array}$ & $\begin{array}{l}\text { No }(r e f) \\
\text { Yes }\end{array}$ & $1.06(0.93,1.22)$ & $1.26(1.05,1.51)$ & $1.06(0.78,1.43)$ \\
\hline $\begin{array}{l}\text { Wife beating for denying } \\
\text { husband sex }\end{array}$ & $\begin{array}{l}\text { No }(r e f) \\
\text { Yes }\end{array}$ & $0.97(0.85,1.10)$ & $1.11(0.93,1.33)$ & $1.32(1.01,1.66)$ \\
\hline $\begin{array}{l}\text { Wife beating for denying } \\
\text { husband food }\end{array}$ & $\begin{array}{l}\text { No }(r e f) \\
\text { Yes }\end{array}$ & $0.93(0.82,1.06)$ & $1.14(0.96,1.34)$ & $1.19(0.96,1.51)$ \\
\hline $\begin{array}{l}\text { Who makes large } \\
\text { household purchases }\end{array}$ & $\begin{array}{l}\text { Alone (ref) } \\
\text { Husband/partner } \\
\text { With husband/pa }\end{array}$ & $\begin{array}{r}1.33(1.06,1.66) \\
\text { ro.82 }(0.62,1.09)\end{array}$ & $\begin{array}{l}1.08(0.82,1.44) \\
1.05(0.73,1.54)\end{array}$ & $\begin{array}{l}1.38(0.90,2.14) \\
1.13(0.63,2.09)\end{array}$ \\
\hline $\begin{array}{l}\text { Who makes decision on } \\
\text { mother's health } \\
\text { MOBILITY } \\
\text { Number of years mother } \\
\text { lived continuously in her } \\
\text { current location }\end{array}$ & $\begin{array}{l}\text { Alone(ref) } \\
\text { Husband/partner } \\
\text { With } \\
\text { husband/partner }\end{array}$ & $\begin{array}{l}0.50(0.43,0.59) \\
0.84(0.65,1.18)\end{array}$ & $\begin{array}{l}0.74(0.61,0.89) \\
0.88(0.63,1.29)\end{array}$ & $\begin{array}{l}0.57(0.42,0.79) \\
0.52(0.31,0.89)\end{array}$ \\
\hline
\end{tabular}




\begin{tabular}{|c|c|c|c|c|}
\hline \multirow[t]{2}{*}{ Covariate } & Level & MODEL I & MODEL II & MODEL III \\
\hline & $\begin{array}{l}0 \text { years } \\
1-10 \text { years } \\
11-20 \text { years } \\
21 \text { or more years }\end{array}$ & $\begin{array}{l}1.25(0.86,1.87) \\
2.07(1.40,3.11) \\
2.78(1.90,4.13)\end{array}$ & $\begin{array}{l}1.57(1.02,2.56) \\
3.46(2.11,5.77) \\
2.56(1.67,3.98)\end{array}$ & \\
\hline \multicolumn{5}{|l|}{$\begin{array}{l}\text { MASS MEDIA } \\
\text { EXPOSURE }\end{array}$} \\
\hline \multirow{2}{*}{ Read newspaper } & $\begin{array}{l}\text { No } \\
\text { Less than once a } \\
\text { week }\end{array}$ & $0.32(0.25,0.42)$ & $0.35(0.25,0.46)$ & $0.91(0.57,1.51)$ \\
\hline & $\begin{array}{l}\text { At least once a } \\
\text { week } \\
\text { No }\end{array}$ & & $0.25(0.16,0.41)$ & $0.79(0.41,1.59)$ \\
\hline \multirow[t]{2}{*}{ Listen to radio } & $\begin{array}{l}\text { Less than once a } \\
\text { week } \\
\text { At least once a }\end{array}$ & $0.47(0.40,0.57)$ & $0.87(0.67,1.11)$ & $0.98(0.68,1.45)$ \\
\hline & & $0.85(0.73,0.98)$ & $1.33(1.13,1.60)$ & $1.25(0.97,1.67)$ \\
\hline \multirow[t]{2}{*}{ Watch television } & $\begin{array}{l}\text { Less than once a } \\
\text { week }\end{array}$ & $0.68(0.59,0.78)$ & $0.73(0.62,0.87)$ & $0.67(0.52,0.89)$ \\
\hline & week & $0.59(0.54,0.65)$ & $0.63(0.55,0.72)$ & $0.94(0.73,1.24)$ \\
\hline
\end{tabular}

*No women with higher education.

Model I: Unadjusted model

Model II: Adjusted with unobserved spatial location effects.

Model III: Fully adjusted spatial model with all significant potential confounders.

POR $=$ Posterior odds ratio; $95 \% \mathrm{Cl}=95 \%$ credible interval. 
Table A2. Odds ratios from Bayesian geo-additive multilevel regression, 2010 SDHS

\begin{tabular}{|c|c|c|c|c|}
\hline \multirow{3}{*}{$\begin{array}{l}\text { Covariate } \\
\text { DEMOGRAPHIC } \\
\text { Place of residence }\end{array}$} & Level & MODEL I & MODEL II & MODEL III \\
\hline & Rural (ref) & & & \\
\hline & $\begin{array}{l}\text { Urban } \\
\text { Dakar (ref) }\end{array}$ & $0.54(0.48,0.61)$ & $0.54(0.46,0.64)$ & $0.63(0.48,0.79)$ \\
\hline \multirow[t]{13}{*}{ Region } & Diourbel & $0.03(0.01,0.12)$ & $0.02(0.00,0.14)$ & \\
\hline & Fatick & $0.13(0.05,0.27)$ & $0.06(0.00,0.36)$ & \\
\hline & Kaffrine & $0.38(0.20,0.69)$ & $0.14(0.02,0.63)$ & \\
\hline & Kaolack & $0.04(0.00,0.14)$ & $0.02(0.00,0.18)$ & \\
\hline & Kedougou & $2.86(1.84,4.29)$ & $0.76(0.06,4.72)$ & \\
\hline & Kolda & $12.24(8.25,17.98)$ & $2.17(0.19,19.27)$ & \\
\hline & Louga & $0.87(0.54,1.45)$ & $0.34(0.06,1.50)$ & \\
\hline & Matam & $13.17(8.83,20.01)$ & $3.63(0.59,20.05)$ & \\
\hline & Saint Louis & $5.37(3.70,7.78)$ & $1.66(0.07,10.09)$ & \\
\hline & Sedhiou & $16.61(12.03,23.87)$ & $1.03(0.05,28.15)$ & \\
\hline & Tambacounda & $12.93(8.71,18.60)$ & $3.17(0.25,18.05)$ & \\
\hline & Thies & $0.11(0.04,0.25)$ & $0.06(0.01,0.30)$ & \\
\hline & Zuguinchor & $4.70(3.08,6.78)$ & $0.24(0.01,8.05)$ & \\
\hline \multirow[t]{3}{*}{ Religion } & Christian (ref) & & & \\
\hline & Animist & $1.33(0.41,3.66)$ & $0.84(0.28,2.54)$ & $0.43(0.10,1.71)$ \\
\hline & Muslim & $3.33(2.03,5.62)$ & $3.64(2.16,6.29)$ & $0.85(0.38,1.93)$ \\
\hline \multicolumn{5}{|l|}{ Wealth index } \\
\hline & Middle (ref) & & & \\
\hline & Poorer & $1.57(1.37,1.80)$ & $1.35(1.14,1.60)$ & $0.87(0.65,1.22)$ \\
\hline & Poorest & $1.13(0.97,1.34)$ & $1.18(0.96,1.43)$ & $0.82(0.62,1.12)$ \\
\hline & Richer & $0.44(0.35,0.55)$ & $0.66(0.51,0.86)$ & $0.93(0.63,1.36)$ \\
\hline & Richest & $0.18(0.13,0.26)$ & $0.36(0.24,0.51)$ & $0.82(0.47,1.33)$ \\
\hline \multirow[t]{3}{*}{ Married } & Currently (ref) & & & \\
\hline & Formerly & $0.96(0.74,1.27)$ & $0.88(0.64,1.23)$ & \\
\hline & Never & $0.43(0.26,0.71)$ & $0.33(0.19,0.53)$ & \\
\hline \multirow[t]{8}{*}{ Ethnicity } & & & & \\
\hline & $\begin{array}{l}\text { Wolof (ref) } \\
\text { Idiola }\end{array}$ & 47.28 (25.29, 83.52) & $13.63(7.77,24.44)$ & $1.76(0.78,4.64)$ \\
\hline & Mandingue & $109.46(70.76,192.5)$ & $18.55(10.68,32.29)$ & $1.43(0.68,3.42)$ \\
\hline & Non-Senegalese & $71.50(39.66,135.87)$ & $20.73(11.65,36.77)$ & $1.46(0.60,3.37)$ \\
\hline & Other & $43.24(26.49,77.58)$ & $11.40(6.70,19.63)$ & $1.45(0.67,3.28)$ \\
\hline & Poular & $90.35(53.99,165.76)$ & $25.75(16.12,40.90)$ & $2.41(1.22,5.42)$ \\
\hline & Serer & $0.77(0.24,2.37)$ & $1.41(0.51,3.55)$ & $0.38(0.08,1.48)$ \\
\hline & Soninke & $73.25(42.43,138.97)$ & $22.95(13.26,39.36)$ & $2.07(0.85,5.55)$ \\
\hline \multicolumn{5}{|l|}{$\begin{array}{l}\text { SOCIAL NORMS } \\
\text { Mother cut }\end{array}$} \\
\hline & No $(r e f)$ & & & \\
\hline \multirow{3}{*}{$\begin{array}{l}\text { Mother's support } \\
\text { for FGM/C } \\
\text { continuation }\end{array}$} & Yes & $19.91(11.94,37.00)$ & $20.02(11.69,38.52)$ & $20.54(10.93,37.8)$ \\
\hline & $\begin{array}{l}\text { Be stopped } \\
\text { Continued } \\
\text { Depends/Don't }\end{array}$ & $4.26(3.55,5.15)$ & $4.38(3.59,5.23)$ & $5.47(4.40,6.66)$ \\
\hline & know & $1.52(0.94,2.35)$ & $1.52(0.99,2.30)$ & $1.85(1.14,3.03)$ \\
\hline $\begin{array}{l}\text { BELIEFS } \\
\mathrm{FGM} / \mathrm{C} \text { is required }\end{array}$ & & & & \\
\hline
\end{tabular}




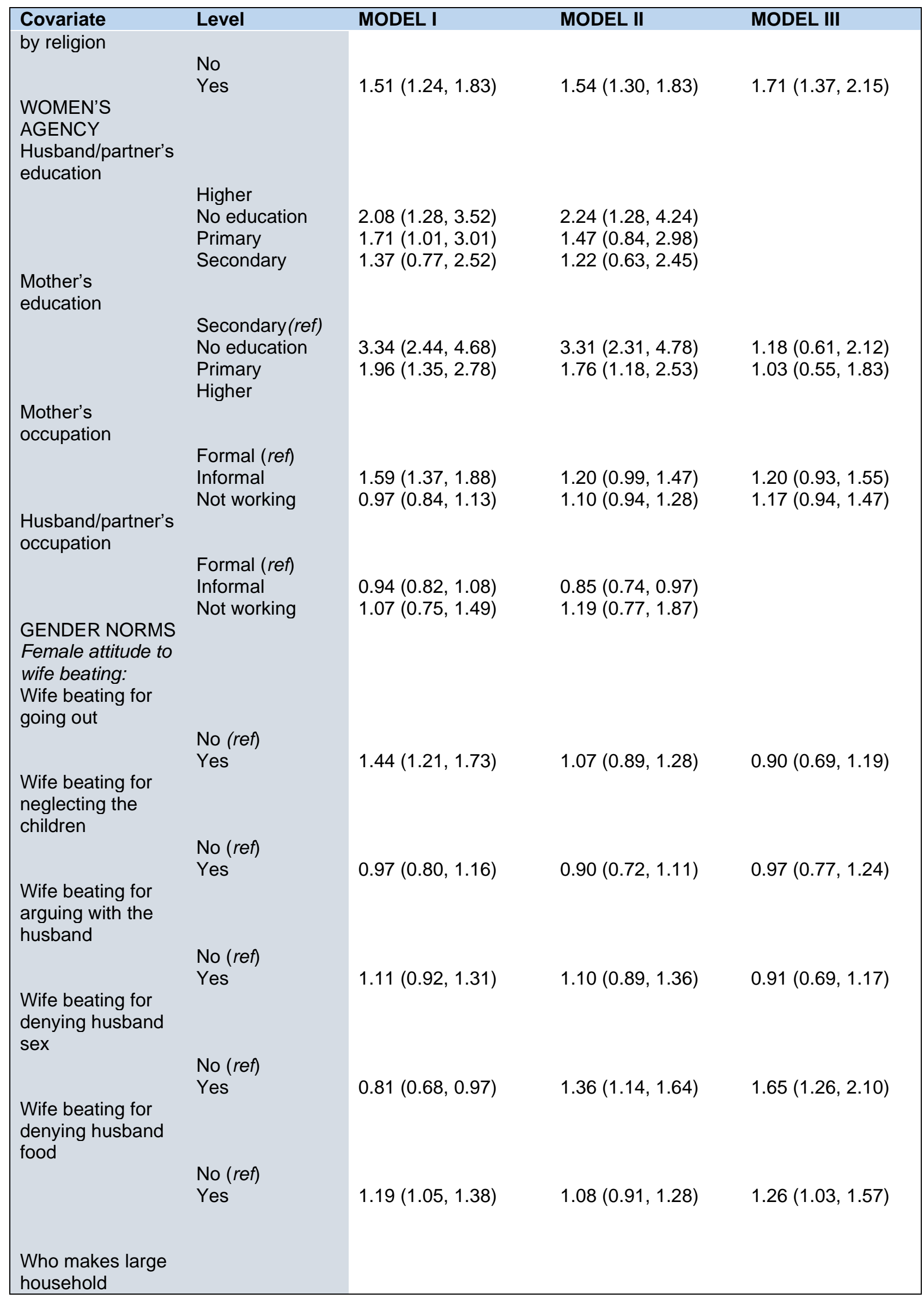




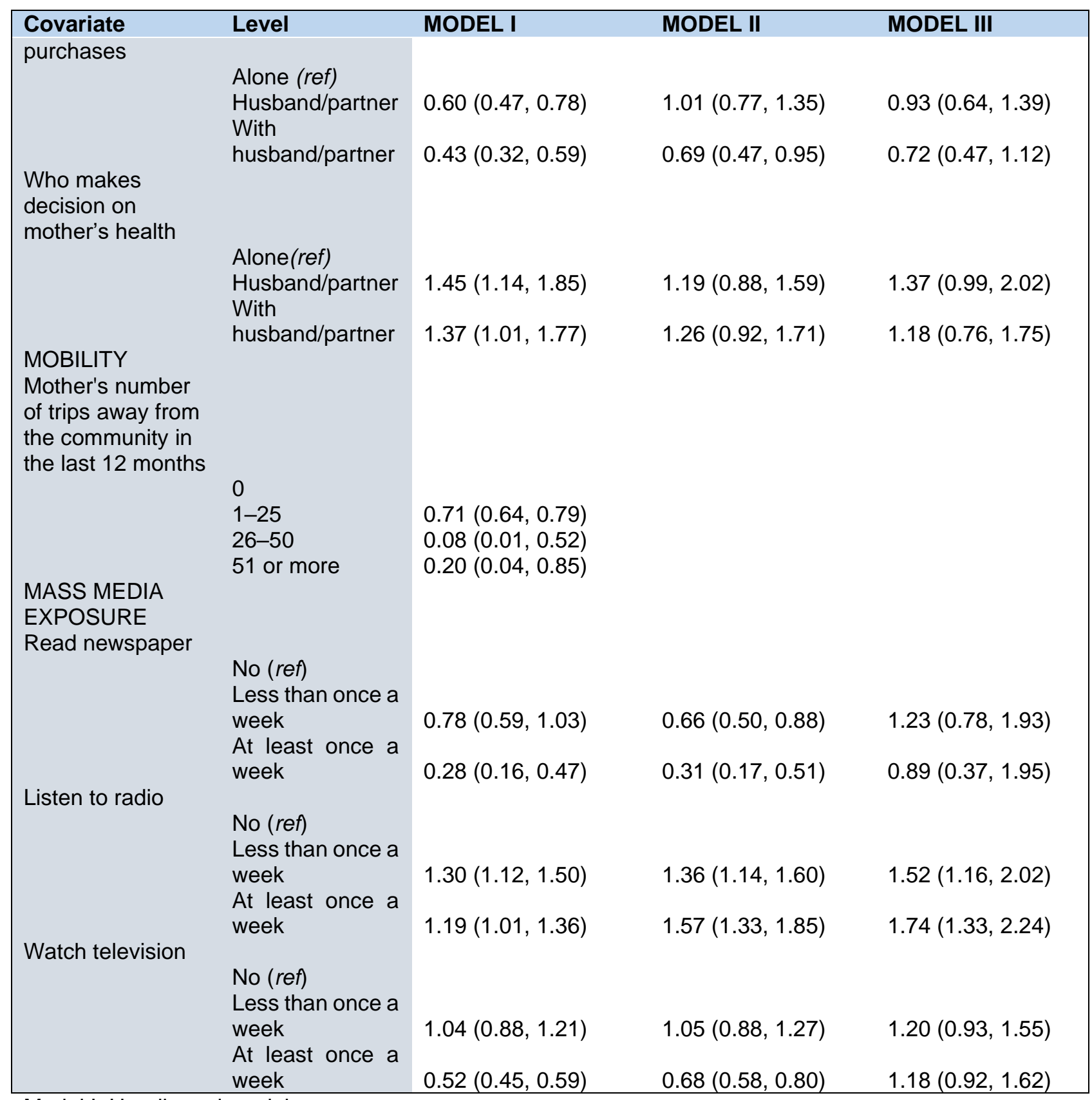

Model I: Unadjusted model

Model II: Adjusted with unobserved spatial location effects.

Model III: Fully adjusted spatial model with all significant potential confounders.

$\mathrm{POR}=$ Posterior odds ratio; $95 \% \mathrm{Cl}=95 \%$ credible interval. 
Table A3. Unadjusted and adjusted posterior odds ratios (POR) and associated $95 \%$ credible intervals $(\mathrm{Cl})$ from Bayesian geo-additive hierarchical logistic regression models, SDHS 2015

\begin{tabular}{|c|c|c|c|c|}
\hline \multirow{2}{*}{$\begin{array}{l}\text { Covariate } \\
\text { DEMOGRAPHIC } \\
\text { Place of residence }\end{array}$} & Level & MODEL I & MODEL II & MODEL III \\
\hline & Rural (ref) & \multirow[b]{2}{*}{$0.49(0.43,0.56)$} & & \\
\hline \multirow{15}{*}{ Region } & Urban & & $0.55(0.47,0.64)$ & $0.82(0.60,1.13)$ \\
\hline & Dakar (ref) & & & \\
\hline & Diourbel $^{*}$ & - & - & - \\
\hline & Fatick & $1.94(0.69,5.04)$ & - & - \\
\hline & Kaffrine & $2.22(0.97,5.98)$ & - & - \\
\hline & Kaolack & 12.87) & - & - \\
\hline & Kedougou & $\begin{array}{l}36.41 \\
85.29)\end{array} \quad$ (17.13, & - & - \\
\hline & Kolda & $\begin{array}{ll}77.84 & (35.58, \\
197.28)\end{array}$ & - & - \\
\hline & Louga* & - & - & - \\
\hline & Matam & $272.75)$ & - & - \\
\hline & Saint Louis & 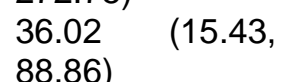 & - & - \\
\hline & Sedhiou & $\begin{array}{l}77.35 \\
188.4)\end{array}$ & - & - \\
\hline & Tambacounda & $\begin{array}{ll}52.68 & \text { (22.4, } \\
131.15) & \end{array}$ & - & - \\
\hline & Thies & $0.19(0.02,0.87)$ & - & - \\
\hline & Zuguinchor & $\begin{array}{l}58.81 \\
147.5)\end{array}$ & - & - \\
\hline \multirow[t]{3}{*}{ Religion } & Christian (ref) & \multirow{3}{*}{$\begin{array}{l}2.77(1.54,5.37) \\
1.87(1.37,2.81)\end{array}$} & & \\
\hline & Animist & & $2.38(1.26,4.2)$ & $0.34(0.11,0.96)$ \\
\hline & Muslim & & $4.40(2.96,6.7)$ & $1.01(0.47,2.15)$ \\
\hline \multirow[t]{5}{*}{ Wealth index } & Middle (ref) & \multirow{6}{*}{$\begin{array}{l}1.42(1.23,1.62) \\
1.36(1.18,1.57) \\
0.34(0.27,0.41) \\
0.17(0.11,0.24)\end{array}$} & & \\
\hline & Poorer & & $1.26(1.05,1.50)$ & $1.17(0.76,1.85)$ \\
\hline & Poorest & & $1.40(1.16,1.73)$ & $1.46(0.99,2.13)$ \\
\hline & Richer & & $0.54(0.41,0.71)$ & $0.83(0.49,1.57)$ \\
\hline & Richest & & $0.34(0.22,0.51)$ & $0.76(0.38,1.71)$ \\
\hline \multirow[t]{3}{*}{ Married } & & & & \\
\hline & $\begin{array}{l}\text { Currently (ref) } \\
\text { Formerly }\end{array}$ & \multirow{2}{*}{$\begin{array}{l}1.11(0.85,1.45) \\
0.50(0.29,0.82)\end{array}$} & $0.97(0.69,1.36)$ & - \\
\hline & Never & & $0.28(0.16,0.49)$ & - \\
\hline \multirow[t]{8}{*}{ Ethnicity } & & & & \\
\hline & $\begin{array}{l}\text { Wolof (ref) } \\
\text { Idiola }\end{array}$ & $\begin{array}{l}104.09 \\
177.40)\end{array}$ & $21.1(8.59,95.36)$ & $2.40(0.77,7.64)$ \\
\hline & Mandingue & $\begin{array}{l}121.22 \\
201.77)\end{array}$ (78.21, & $34.28(16.10,119.20)$ & $3.77(1.76,8.91)$ \\
\hline & Non-Senegalese & $\begin{array}{l}151.65 \\
247.92)\end{array}$ & $50.93(24.46,160.41)$ & $5.33(2.18,13.21)$ \\
\hline & Other & $\begin{array}{l}45.90 \quad(28.05, \\
74.25)\end{array}$ & $13.06(6.08,40.25)$ & $4.67(2.08,11.54)$ \\
\hline & Poular & $\begin{array}{l}102.44 \\
164.47)\end{array}$ & $35.15(18.26,102.64)$ & $3.79(1.82,7.95)$ \\
\hline & Serer & $1.28(0.52,2.86)$ & $1.81(0.76,4.82)$ & $1.57(0.42,6.17)$ \\
\hline & Soninke & $\begin{array}{ll}117.6 & (64.1, \\
208.72)\end{array}$ & $38.5(17.1,85.37)$ & $11.8(3.97,35.83)$ \\
\hline SOCIAL NORMS & & & & \\
\hline
\end{tabular}




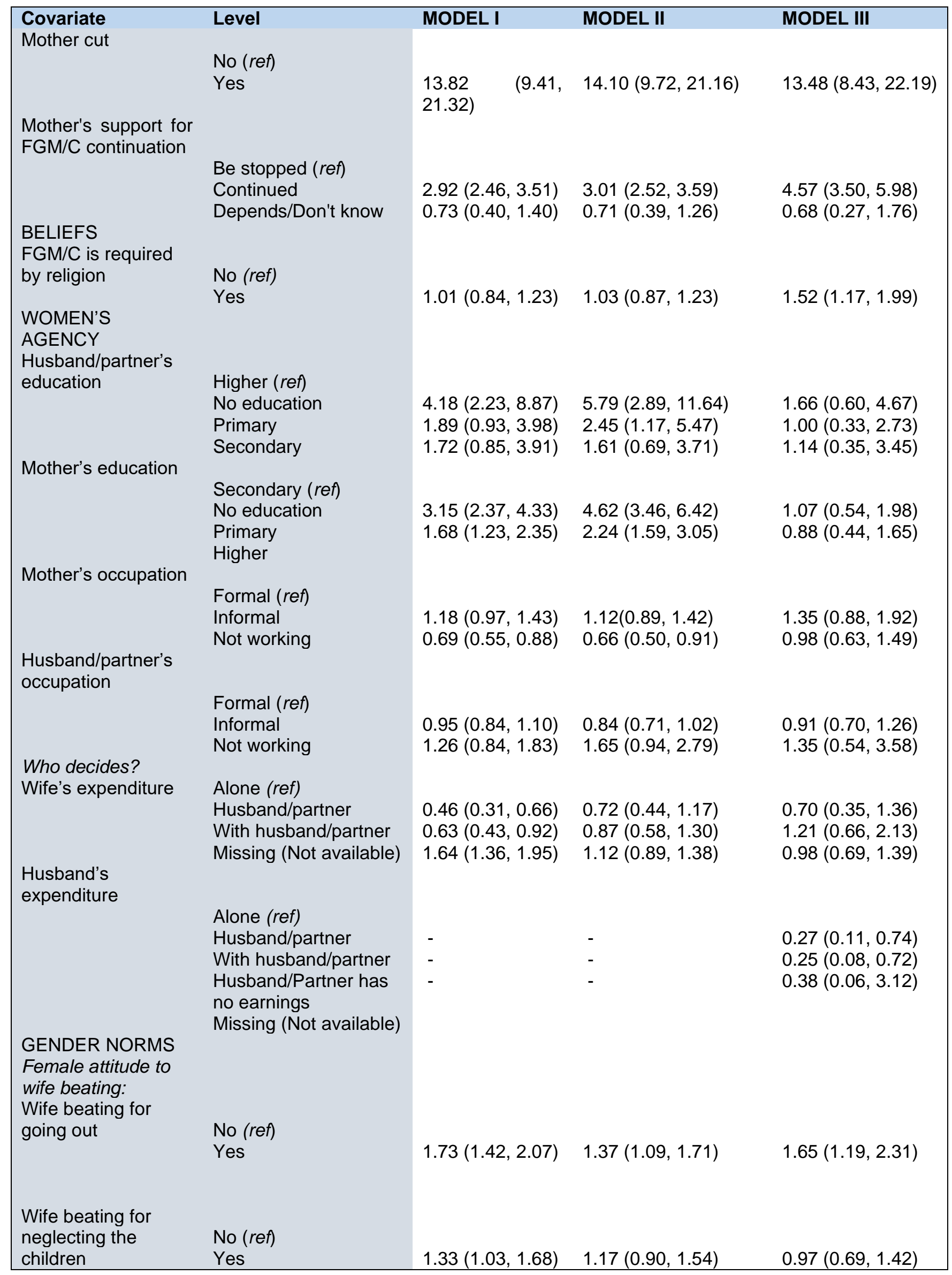




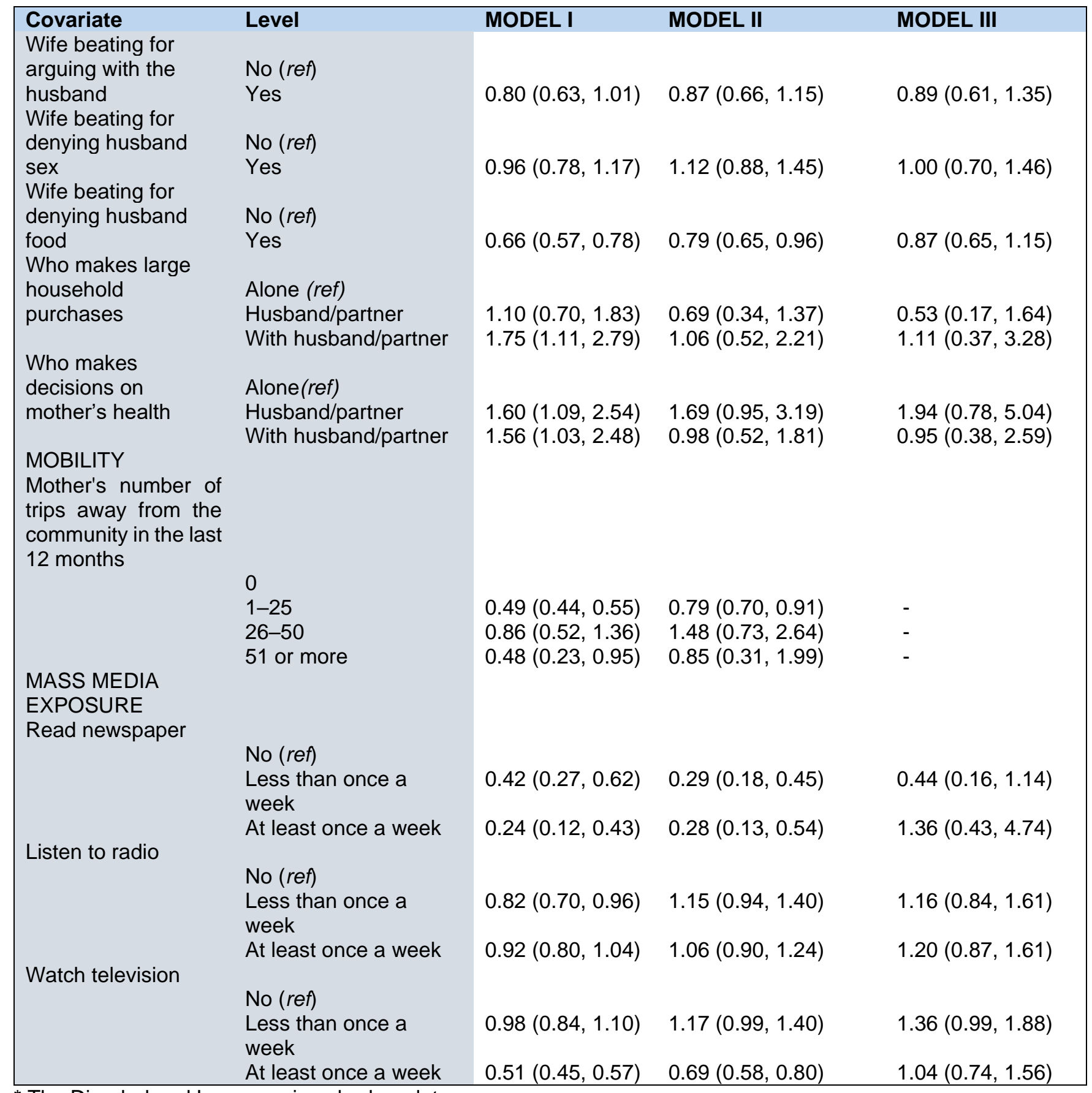

* The Diourbel and Louga regions had no data. 
Table A4. Unadjusted and adjusted posterior odds ratios (POR) and associated $95 \%$ credible intervals $(\mathrm{Cl})$ from Bayesian geo-additive hierarchical logistic regression models, SDHS 2017

\begin{tabular}{|c|c|c|c|c|}
\hline Covariate & Level & $\begin{array}{l}\text { Model I } \\
\text { (unadjusted) }\end{array}$ & $\begin{array}{l}\text { Model II } \\
\text { (Space-adjusted) }\end{array}$ & $\begin{array}{l}\text { Model III } \\
\text { (Fully adjusted) }\end{array}$ \\
\hline \multicolumn{5}{|l|}{$\begin{array}{l}\text { DEMOGRAPHIC } \\
\text { Place of residence }\end{array}$} \\
\hline & Rural (ref) & & & \\
\hline \multirow{15}{*}{ Region } & Urban & $0.32(0.29,0.35)$ & $0.3(0.26,0.33)$ & $0.50(0.39,0.66)$ \\
\hline & Dakar (ref) & & & \\
\hline & Diourbel & $0.06(0.01,0.19)$ & - & - \\
\hline & Fatick & $0.32(0.17,0.55)$ & - & - \\
\hline & Kaffrine & $0.73(0.46,1.18)$ & - & - \\
\hline & Kaolack & $0.50(0.28,0.88)$ & - & - \\
\hline & Kedougou & $\begin{array}{l}19.10 \quad(13.51, \\
28.01)\end{array}$ & - & - \\
\hline & Kolda & $\begin{array}{l}13.63 \\
19.69)\end{array} \quad(9.52$ & - & - \\
\hline & Louga & $0.25(0.11,0.49)$ & - & - \\
\hline & Matam & $\begin{array}{l}40.43 \quad(28.25, \\
57.38)\end{array}$ & - & - \\
\hline & Saint Louis & $\begin{array}{l}10.60 \quad(7.10, \\
15.39)\end{array}$ & - & -- \\
\hline & Sedhiou & $\begin{array}{l}20.83 \quad(14.49, \\
29.97) \quad\end{array}$ & - & - \\
\hline & Tambacounda & $\begin{array}{l}19.86 \quad(13.66, \\
27.93)\end{array}$ & - & - \\
\hline & Thies & $0.35(0.18,0.63)$ & - & - \\
\hline & Zuguinchor & $\begin{array}{ll}14.23 & (9.48, \\
21.05) & \end{array}$ & - & - \\
\hline \multirow[t]{3}{*}{ Religion } & & & & \\
\hline & Christian (ref) & & & \\
\hline & $\begin{array}{l}\text { Animist } \\
\text { Muslim }\end{array}$ & $3.82(2.65,5.67)$ & $\begin{array}{l}- \\
5.67(3.85,8.6)\end{array}$ & $0.78(0.35,2.02)$ \\
\hline \multirow[t]{6}{*}{ Wealth index } & & & & \\
\hline & Middle (ref) & & & \\
\hline & Poorer & $2.10(1.89,2.36)$ & $2.04(1.77,2.36)$ & $0.96(0.69,1.31)$ \\
\hline & Poorest & $1.64(1.47,1.84)$ & $1.73(1.52,1.98)$ & $0.90(0.65,1.21)$ \\
\hline & Richer & $0.47(0.40,0.55)$ & $0.62(0.51,0.76)$ & $1.41(0.90,2.19)$ \\
\hline & Richest & $0.14(0.09,0.19)$ & $0.31(0.21,0.45)$ & $0.84(0.41,1.64)$ \\
\hline \multirow[t]{3}{*}{ Married } & Currently (ref) & & & \\
\hline & Formerly & $1.14(0.93,1.37)$ & $0.96(0.77,1.16)$ & - \\
\hline & Never & $0.32(0.20,0.52)$ & $0.20(0.10,0.31)$ & - \\
\hline \multirow[t]{8}{*}{ Ethnicity } & & & & \\
\hline & $\begin{array}{l}\text { Wolof (ref) } \\
\text { Idiola }\end{array}$ & $\begin{array}{l}86.25 \\
136.35)\end{array}$ & $31.6(19.26,48.6)$ & $5.93(2.38,15.87)$ \\
\hline & Mandingue & $\begin{array}{l}176.6 \quad(119.3, \\
268.4)\end{array}$ & $55.9(35.12,84.2)$ & $3.75(1.55,9.79)$ \\
\hline & Non-Senegalese & $\begin{array}{l}53.73 \quad(35.16, \\
86.72)\end{array}$ & $21.66(14.2,33.2)$ & $2.12(0.83,5.70)$ \\
\hline & Other & $\begin{array}{l}111.7 \\
173.3)\end{array} \quad$ (71.68, & $36.12(22.9,57.29)$ & $4.16(1.77,12.19)$ \\
\hline & Poular & $\begin{array}{l}124.6 \\
194.64) \quad(84.6,\end{array}$ & $39.25(24.99,57.22)$ & $3.39(1.34,8.30)$ \\
\hline & Serer & $0.49(0.15,1.20)$ & $0.77(0.22,2.02)$ & $0.52(0.11,2.50)$ \\
\hline & Soninke & $\begin{array}{l}133.49 \\
214.48)\end{array} \quad(79.75$ & $33.84(21.59,55.44)$ & $3.67(1.30,10.23)$ \\
\hline Woman from mixed & & & & \\
\hline
\end{tabular}




\begin{tabular}{|c|c|c|c|c|}
\hline Covariate & Level & $\begin{array}{l}\text { Model I } \\
\text { (unadjusted) }\end{array}$ & $\begin{array}{l}\text { Model II } \\
\text { (Space-adjusted) }\end{array}$ & $\begin{array}{l}\text { Model III } \\
\text { (Fully adjusted) }\end{array}$ \\
\hline \multicolumn{5}{|l|}{$\begin{array}{l}\text { ethnicity household } \\
\text { (husband/partner } \\
\text { from a different } \\
\text { ethnic group; } \\
\text { currently married } \\
\text { women only) }\end{array}$} \\
\hline & No (ref) & & & \\
\hline & Yes & $1.25(1.02,1.55)$ & $1.46(1.13,1.91)$ & - \\
\hline & Missing/Not available & $1.09(0.91,1.33)$ & $1.21(0.96,1.53)$ & - \\
\hline \multicolumn{5}{|l|}{$\begin{array}{l}\text { SOCIAL NORMS } \\
\text { Mother cut }\end{array}$} \\
\hline & No (ref) & & & \\
\hline & Yes & $\begin{array}{l}13.68 \\
18.66)\end{array} \quad(10.25$, & $14.25(10.60,18.81)$ & $\begin{array}{l}14.29 \\
20.01)\end{array}$ \\
\hline \multicolumn{5}{|l|}{$\begin{array}{l}\text { Mother's support for } \\
\text { FGM/C continuation }\end{array}$} \\
\hline & Be stopped (ref) & & & \\
\hline & Continued & $3.85(3.35,4.47)$ & $3.89(3.32,4.57)$ & $5.30(4.32,6.56)$ \\
\hline & Depends/Don't know & $1.24(0.86,1.81)$ & $1.28(0.89,1.77)$ & $0.99(0.57,1.86)$ \\
\hline $\begin{array}{l}\text { BELIEFS } \\
\text { FGM/C is required } \\
\text { by religion }\end{array}$ & No (ref) & $\begin{array}{l}\text { BELIEFS } \\
\text { FGM/C is required }\end{array}$ & & \\
\hline & Yes & $1.68(1.46,1.93)$ & $1.71(1.46,2.01)$ & $1.93(1.56,2.41)$ \\
\hline \multicolumn{5}{|l|}{ WOMEN'S } \\
\hline \multicolumn{5}{|l|}{$\begin{array}{l}\text { Husband/partner's } \\
\text { education }\end{array}$} \\
\hline & No education & - & - & $2.12(1.04,4.08)$ \\
\hline & Primary & - & - & $1.23(0.64,2.38)$ \\
\hline & Secondary & - & - & $1.18(0.61,2.31)$ \\
\hline \multicolumn{5}{|l|}{ Mother's education } \\
\hline & No education & $2.40(1.98,2.86)$ & $2.62(2.18,3.21)$ & $0.61(0.39,0.92)$ \\
\hline & Primary & $1.46(1.18,1.78)$ & $1.54(1.27,1.89)$ & $0.68(0.45,1.06)$ \\
\hline & Higher & $0.08(0.02,0.27)$ & $0.11(0.02,0.37)$ & $0.72(0.09,4.33)$ \\
\hline \multicolumn{5}{|l|}{$\begin{array}{l}\text { Mother employed in } \\
\text { the last } 7 \text { days }\end{array}$} \\
\hline & No (ref) & & & \\
\hline & Yes & & & $0.60(0.42,0.89)$ \\
\hline Mother's occupation & Formal (ref) & & & \\
\hline & Informal & $1.30(1.15,1.49)$ & $1.30(1.12,1.53)$ & $1.18(0.90,1.51)$ \\
\hline & Not working & $0.87(0.75,1.03)$ & $0.79(0.64,0.95)$ & $1.51(0.93,2.38)$ \\
\hline \multicolumn{5}{|l|}{$\begin{array}{l}\text { Husband/partner's } \\
\text { occupation }\end{array}$} \\
\hline & Informal & - & - & $0.87(0.68,1.10)$ \\
\hline \multirow{2}{*}{\multicolumn{5}{|c|}{ Who decides? }} \\
\hline & & & & \\
\hline \multirow[t]{4}{*}{ Wife's expenditure } & Alone (ref) & & & \\
\hline & Husband/partner & $1.61(1.30,1.97)$ & $1.07(0.84,1.38)$ & - \\
\hline & With husband/partner & $1.16(0.84,1.54)$ & $1.22(0.89,1.65)$ & - \\
\hline & Missing (Not available) & $2.20(1.94,2.49)$ & $1.75(1.49,2.05)$ & - \\
\hline $\begin{array}{l}\text { Husband's } \\
\text { expenditure }\end{array}$ & & & & \\
\hline
\end{tabular}




\begin{tabular}{|c|c|c|c|c|}
\hline Covariate & Level & $\begin{array}{l}\text { Model I } \\
\text { (unadjusted) }\end{array}$ & $\begin{array}{l}\text { Model II } \\
\text { (Space-adjusted) }\end{array}$ & $\begin{array}{l}\text { Model III } \\
\text { (Fully adjusted) }\end{array}$ \\
\hline $\begin{array}{l}\text { GENDER NORMS } \\
\text { Female attitude to } \\
\text { wife beating: } \\
\text { Wife beating for } \\
\text { going out }\end{array}$ & $\begin{array}{l}\text { Alone (ref) } \\
\text { Husband/partner } \\
\text { With husband/partner } \\
\text { Husband/partner has } \\
\text { no earnings } \\
\text { Missing (Not available) }\end{array}$ & $\begin{array}{l}1.06(0.75,1.48) \\
0.44(0.31,0.64) \\
1.79(0.98,3.29)\end{array}$ & $\begin{array}{l}1.05(0.70,1.51) \\
0.99(0.64,1.52) \\
1.66(0.84,3.03)\end{array}$ & $\begin{array}{l}0.77(0.35,1.74) \\
1.23(0.50,3.16) \\
3.47(1.08,11.17)\end{array}$ \\
\hline $\begin{array}{l}\text { Wife beating for } \\
\text { neglecting the }\end{array}$ & Yes & $1.09(0.91,1.27)$ & $1.15(0.97,1.39)$ & $0.91(0.65,1.26)$ \\
\hline $\begin{array}{l}\text { children } \\
\text { Wife beating for } \\
\text { arguing with the }\end{array}$ & No (ref) & $0.96(0.83,1.15)$ & $1.07(0.85,1.27)$ & $1.43(1.01,2.06)$ \\
\hline $\begin{array}{l}\text { husband } \\
\text { Wife beating for } \\
\text { denying husband }\end{array}$ & No (ref) & $1.48(1.26,1.76)$ & $1.02(0.83,1.27)$ & $0.75(0.52,1.07)$ \\
\hline $\begin{array}{l}\text { Wife beating for } \\
\text { denying husband }\end{array}$ & $\begin{array}{l}\text { Yes } \\
\text { No (ref) }\end{array}$ & $1.04(0.89,1.19)$ & $1.31(1.10,1.58)$ & $1.54(1.11,2.13)$ \\
\hline $\begin{array}{l}\text { food } \\
\text { Who makes large } \\
\text { household }\end{array}$ & $\begin{array}{l}\text { Yes } \\
\text { Alone (ref) }\end{array}$ & $0.95(0.84,1.08)$ & $0.91(0.79,1.04)$ & $0.74(0.58,0.96)$ \\
\hline $\begin{array}{l}\text { purchases } \\
\text { Who makes } \\
\text { decisions on }\end{array}$ & $\begin{array}{l}\text { Husband/partner } \\
\text { With husband/partner } \\
\text { Alone(ref) }\end{array}$ & $\begin{array}{l}0.68(0.48,0.95) \\
1.21(0.82,1.79)\end{array}$ & $\begin{array}{l}0.63(0.41,0.99) \\
0.83(0.52,1.38)\end{array}$ & $\begin{array}{l}0.34(0.17,0.74) \\
0.26(0.12,0.57)\end{array}$ \\
\hline $\begin{array}{l}\text { mother's health } \\
\text { MASS MEDIA } \\
\text { EXPOSURE } \\
\text { Read newspaper }\end{array}$ & $\begin{array}{l}\text { Husband/partner } \\
\text { With husband/partner }\end{array}$ & $\begin{array}{l}3.99(2.95,5.49) \\
2.27(1.61,3.11)\end{array}$ & $\begin{array}{l}2.50(1.58,3.57) \\
1.47(0.90,2.24)\end{array}$ & $\begin{array}{l}1.88(1.00,3.45) \\
1.14(0.58,2.20)\end{array}$ \\
\hline $\operatorname{ctgn} t h r$ & $\begin{array}{l}\text { Less than once a week } \\
\text { At least once a week }\end{array}$ & $\begin{array}{l}0.39(0.31,0.51) \\
0.41(0.27,0.59)\end{array}$ & $\begin{array}{l}0.40(0.29,0.52) \\
0.40(0.26,0.64)\end{array}$ & $\begin{array}{l}0.36(0.21,0.63) \\
0.56(0.22,1.39)\end{array}$ \\
\hline & $\begin{array}{l}\text { No (ref) } \\
\text { Less than once a week } \\
\text { At least once a week }\end{array}$ & $\begin{array}{l}0.97(0.86,1.08) \\
0.73(0.66,0.81)\end{array}$ & $\begin{array}{l}1.15(0.99,1.30) \\
1.18(1.02,1.35)\end{array}$ & $\begin{array}{l}1.17(0.90,1.55) \\
1.18(0.92,1.52)\end{array}$ \\
\hline 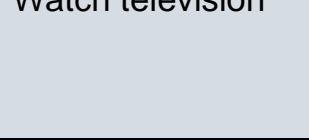 & $\begin{array}{l}\text { No (ref) } \\
\text { Less than once a week } \\
\text { At least once a week }\end{array}$ & $\begin{array}{l}0.77(0.69,0.86) \\
0.33(0.30,0.36)\end{array}$ & $\begin{array}{l}0.72(0.64,0.81) \\
0.43(0.38,0.49)\end{array}$ & $\begin{array}{l}0.77(0.61,0.98) \\
0.78(0.59,1.01)\end{array}$ \\
\hline
\end{tabular}


Table A5. Unadjusted and adjusted posterior odds ratios (POR) and associated $95 \%$ credible intervals $(\mathrm{Cl})$ from Bayesian geo-additive hierarchical logistic regression models, combined SDHS (2010, 2015 and 2017)

\begin{tabular}{|c|c|c|c|c|}
\hline Covariate & Level & Model I & Model II & Model III \\
\hline \multicolumn{5}{|l|}{$\begin{array}{l}\text { DEMOGRAPHIC } \\
\text { Place of residence }\end{array}$} \\
\hline & Rural (ref) & $065(056075)$ & $062(051 \quad 072)$ & $063(056073)$ \\
\hline \multicolumn{5}{|l|}{ Religion } \\
\hline & Christian (ref) & & & \\
\hline & Animist & $0.47(0.25,0.88)$ & $0.44(0.24,0.86)$ & $0.41(0.21,0.80)$ \\
\hline & Muslim & $0.95(0.84,1.07)$ & $0.94(0.85,1.06)$ & $0.95(0.69,1.33)$ \\
\hline \multicolumn{5}{|l|}{ Wealth index } \\
\hline & Poorer & $0.86(0.72,1.02)$ & $0.86(0.72,1.04)$ & $0.91(0.76,1.11)$ \\
\hline & Poorest & $0.91(0.77,1.07)$ & $0.93(0.80,1.11)$ & $0.93(0.79,1.12)$ \\
\hline & Richer & $1.17(0.95,1.52)$ & $1.18(0.89,1.51)$ & $1.17(0.88,1.52)$ \\
\hline & Richest & $0.80(0.54,1.16)$ & $0.87(0.58,1.32)$ & $0.84(0.56,1.20)$ \\
\hline & Wolof (ref) & \multicolumn{3}{|c|}{ Ethnicity } \\
\hline & Idiola & $3.60(2.19,5.85)$ & $3.66(2.08,6.37)$ & $3.27(1.95,5.65)$ \\
\hline & Mandingue & $2.46(1.58,4.07)$ & $3.11(2.00,5.34)$ & $2.75(1.74,4.66)$ \\
\hline & Non-Senegalese & $1.96(1.15,3.13)$ & $2.54(1.58,4.45)$ & $2.35(1.50,4.03)$ \\
\hline & Other & $2.35(1.40,3.69)$ & $3.03(1.87,5.10)$ & $2.84(1.83,4.79)$ \\
\hline & Poular & $3.05(2.02,4.76)$ & $3.46(2.18,5.88)$ & $3.19(2.08,5.21)$ \\
\hline & Serer & $0.65(0.29,1.41)$ & $0.97(0.48,2.10)$ & $0.86(0.42,1.88)$ \\
\hline & Soninke & $4.01(2.32,6.66)$ & $4.67(2.72,8.45)$ & $4.24(2.57,7.70)$ \\
\hline \multicolumn{5}{|l|}{$\begin{array}{l}\text { SOCIAL NORMS } \\
\text { Mother cut }\end{array}$} \\
\hline & $\begin{array}{l}\text { No }(r e f) \\
\text { Yes }\end{array}$ & $12.39(9.20,16.28)$ & $13.13(10.06,17.48)$ & 13.38 \\
\hline \multicolumn{5}{|l|}{$\begin{array}{l}\text { Mother's support for } \\
\text { FGM/C continuation }\end{array}$} \\
\hline & Be stopped (ref) & & & \\
\hline & Continued & $4.75(4.14,5.47)$ & $4.85(4.25,5.51)$ & $4.96(4.43,5.59)$ \\
\hline & $\begin{array}{l}\text { Depends/Don't } \\
\text { know }\end{array}$ & $1.31(0.96,1.80)$ & $1.24(0.89,1.76)$ & $1.25(0.91,1.68)$ \\
\hline \multicolumn{5}{|l|}{$\begin{array}{l}\text { BELIEFS } \\
\text { FGM/C is required by } \\
\text { religion }\end{array}$} \\
\hline religion & $\begin{array}{l}\text { No (ref) } \\
\text { Yes }\end{array}$ & $1.57(1.39,1.79)$ & $1.59(1.41,1.80)$ & $1.64(1.43,1.89)$ \\
\hline \multirow{5}{*}{$\begin{array}{l}\text { WOMEN'S AGENCY } \\
\text { Husband/partner's } \\
\text { education }\end{array}$} & & & & \\
\hline & Higher (ref) & & & \\
\hline & No education & $1.62(1.07,2.48)$ & $1.66(1.16,2.40)$ & $1.52(0.95,2.49)$ \\
\hline & Primary & $1.07(0.68,1.69)$ & $1.12(0.73,1.70)$ & $1.05(0.64,1.70)$ \\
\hline & Secondary & $1.01(0.67,1.58)$ & $1.06(0.71,1.60)$ & $0.97(0.57,1.57)$ \\
\hline & Secondary (ref) & \multicolumn{3}{|c|}{ Mother's education } \\
\hline & No education & $0.84(0.63,1.16)$ & $0.82(0.60,1.10)$ & $0.85(0.62,1.19)$ \\
\hline & Primary & $0.79(0.60,1.04)$ & $0.76(0.55,1.04)$ & $0.78(0.57,1.07)$ \\
\hline & Higher (ref) & $0.27(0.04,1.20)$ & $0.36(0.06,1.55)$ & $0.31(0.05,1.38)$ \\
\hline & $\begin{array}{l}\text { No (ref) } \\
\text { Yes }\end{array}$ & $0.79(0.66,0.94)$ & $0.76(0.63,0.91)$ & $0.75(0.63,0.90)$ \\
\hline
\end{tabular}




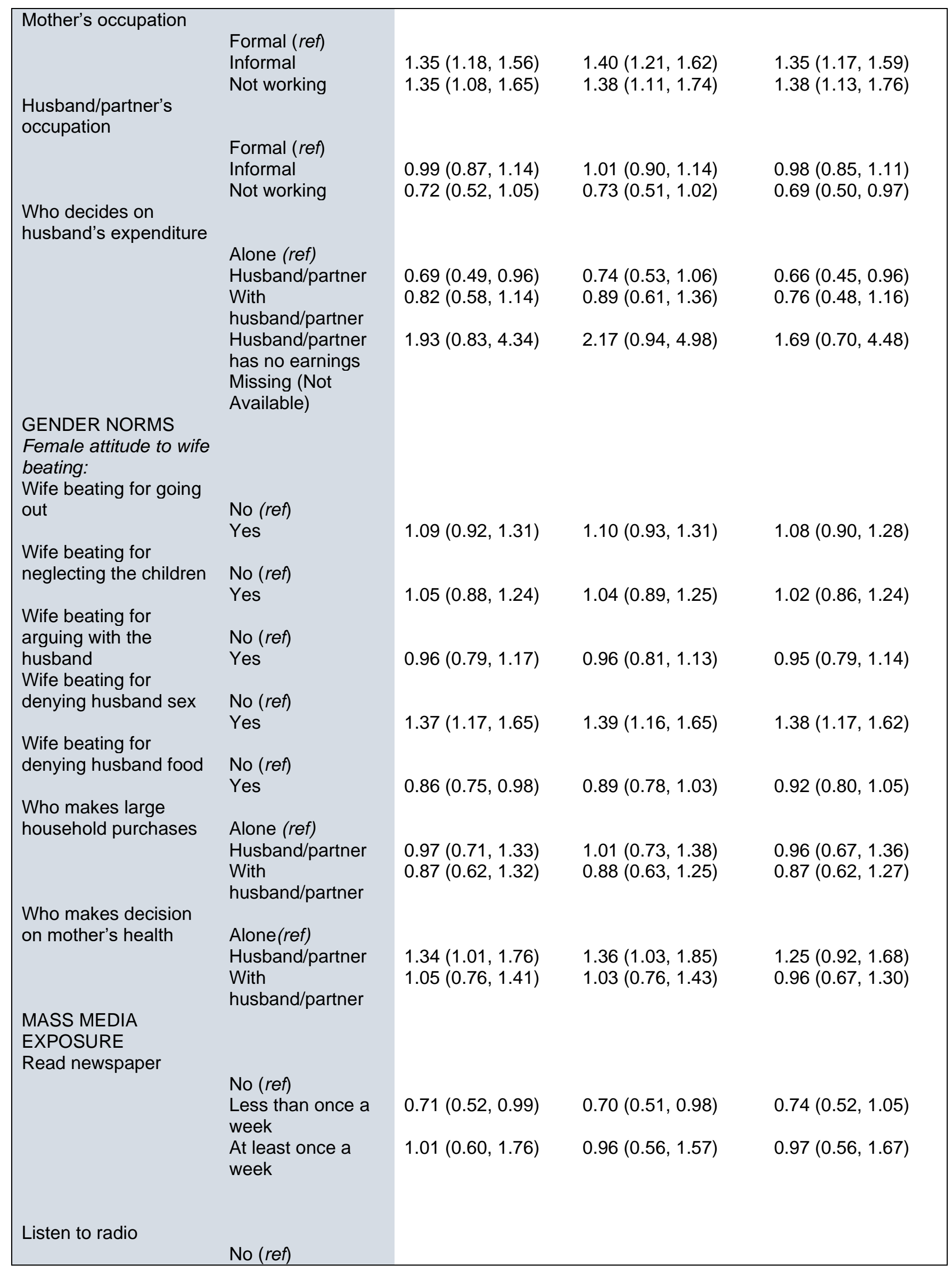




\begin{tabular}{|c|c|c|c|c|}
\hline & $\begin{array}{l}\text { Less than once a } \\
\text { week } \\
\text { At least once a } \\
\text { week }\end{array}$ & $\begin{array}{l}1.28(1.13,1.48) \\
1.33(1.17,1.52)\end{array}$ & $\begin{array}{l}1.23(1.07,1.43) \\
1.28(1.11,1.47)\end{array}$ & $\begin{array}{l}1.31(1.13,1.53) \\
1.37(1.19,1.57)\end{array}$ \\
\hline Watch television & $\begin{array}{l}\text { No }(r e f) \\
\text { Less than once a } \\
\text { week } \\
\text { At least once a } \\
\text { week }\end{array}$ & $\begin{array}{l}1.04(0.87,1.20) \\
0.95(0.80,1.11)\end{array}$ & $\begin{array}{l}1.04(0.91,1.20) \\
0.98(0.84,1.14)\end{array}$ & $\begin{array}{l}1.01(0.86,1.18) \\
0.96(0.80,1.14)\end{array}$ \\
\hline
\end{tabular}

Model I: Unadjusted model

Model II: Adjusted with unobserved spatial location effects.

Model III: Fully adjusted spatial model with all significant potential confounders.

POR = Posterior odds ratio; $95 \% \mathrm{Cl}=95 \%$ credible interval.

Table A6. Observed (DHS) and predicted FGM/C prevalence among girls aged $\mathbf{0 - 1 4}$ at region level

\begin{tabular}{|lcccccccc|}
\hline Region & Observed & Predicted & Observed & Predicted & Observed & Predicted & Observed & Predicted \\
Dakar & $\mathbf{2 0 0 5}$ & $\mathbf{2 0 0 5}$ & $\mathbf{2 0 1 0}$ & $\mathbf{2 0 1 0}$ & $\mathbf{2 0 1 5}$ & $\mathbf{2 0 1 5}$ & $\mathbf{2 0 1 7}$ & $\mathbf{2 0 1 7}$ \\
Diourbel & 7.1 & 6.9 & 5.6 & 5.4 & 2.1 & 2.7 & 3.8 & 3.8 \\
Fatick & 0.8 & 0.9 & 0.2 & 0.2 & 0.0 & 0.1 & 0.2 & 0.2 \\
Kaffrine & 2.9 & 3.3 & 0.5 & 1.1 & 2.8 & 4.0 & 1.1 & 1.8 \\
Kaolack & $\mathrm{n} / \mathrm{a}$ & $\mathrm{n} / \mathrm{a}$ & 2.7 & 2.4 & 2.6 & 3.5 & 2.4 & 2.9 \\
Kedougou & 4.0 & 4.3 & 0.2 & 0.7 & 7.1 & 6.3 & 1.6 & 1.9 \\
Kolda & $\mathrm{n} / \mathrm{a}$ & $\mathrm{n} / \mathrm{a}$ & 17.3 & 16.3 & 35.7 & 36.2 & 45.4 & 43.8 \\
Louga & 68.8 & 70.2 & 40.9 & 43.5 & 51.8 & 53.1 & 34.6 & 34.6 \\
Matam & 3.2 & 5 & 3.4 & 4.6 & 0.0 & 0.2 & 1.6 & 0.9 \\
Saint-Louis & 78.4 & 79.4 & 41.4 & 47.1 & 57.1 & 62.1 & 60.6 & 58.5 \\
Sedhiou & 41.1 & 45 & 20.6 & 25.4 & 29.6 & 34.1 & 31.8 & 31.4 \\
Tambacounda & $\mathrm{n} / \mathrm{a}$ & $\mathrm{n} / \mathrm{a}$ & 50.3 & 49.5 & 54.8 & 55.4 & 43.0 & 46.1 \\
Thios & 2.8 & 58.5 & 44.1 & 43 & 41.8 & 45.3 & 44.0 & 48.2 \\
Ziguinchor & 51.9 & 3.2 & 0.6 & 0.8 & 0.3 & 0.3 & 1.2 & 1.1 \\
Tigin & 51.5 & 19.1 & 22.4 & 42.3 & 50.3 & 38.5 & 37.8 \\
\hline
\end{tabular}

Note: $\mathrm{n} / \mathrm{a}=$ data not available (the regions of Kaffrine, Kedougou, and Sedhiou were not created until 2008). 
Figure A1 shows the Kaplan-Meier survival functions of age at cutting for girls by the educational attainment of the mother. The rate of cutting was similar among daughters of women with no education and those with secondary-level education.

Figure A1. Rate of cutting girls by mother's level of education (SDHS 2017)

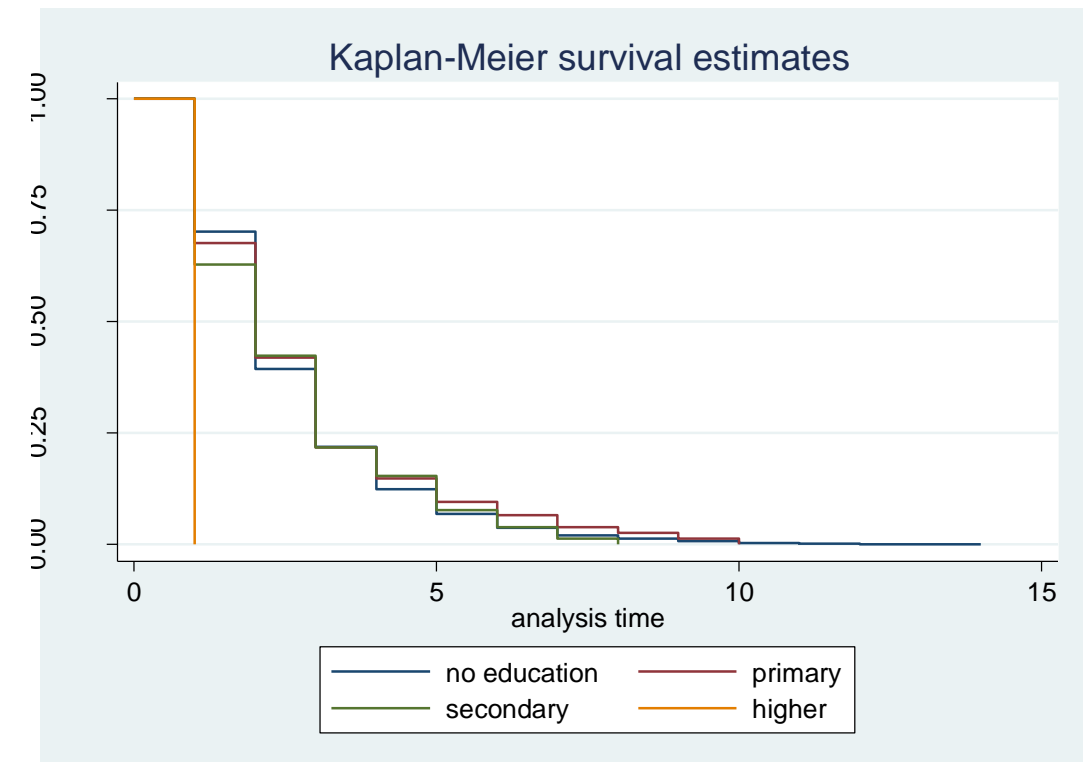

Figure A2 shows that between ages 6 and 10 years, Muslim girls are cut at a lower rate than Christian girls while there is no major difference in the rate of cutting between the two groups before age 5 (log rank test, $p=0.528$ ).

Figure A2. Rate of cutting girls by mother's religious affiliation (SDHS 2017)

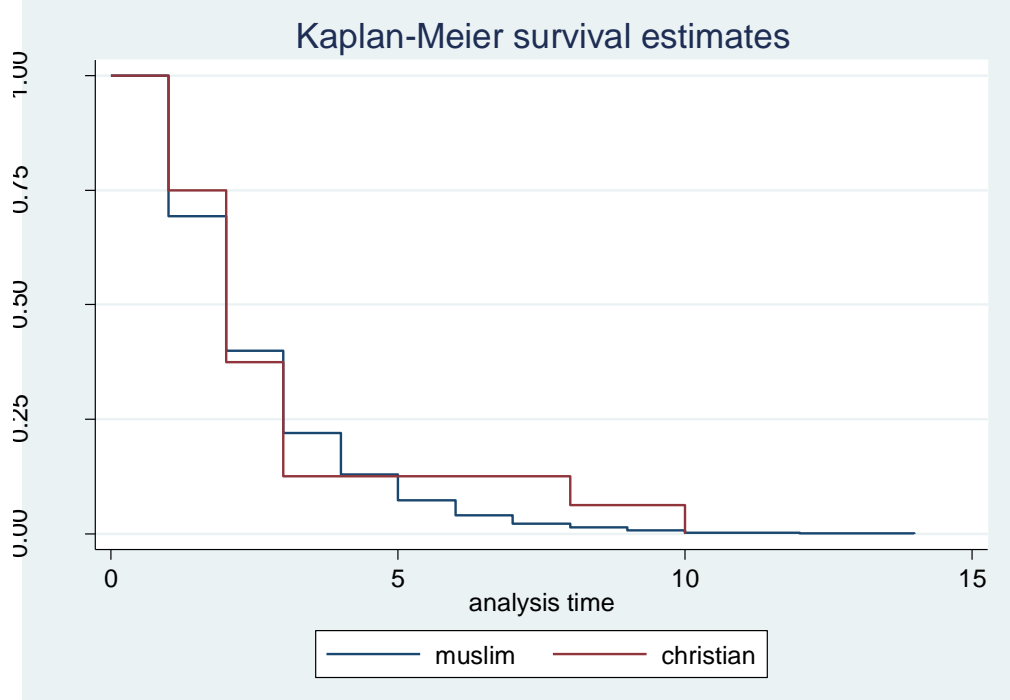


As shown in Figure A3, before age 5, Soninke mothers cut their daughters at a lower rate compared with other ethnic groups while from age 5 onwards, the rate of cutting is similar across all ethnic groups.

Figure A3. Rate of cutting girls by mother's ethnicity (SDHS 2017)

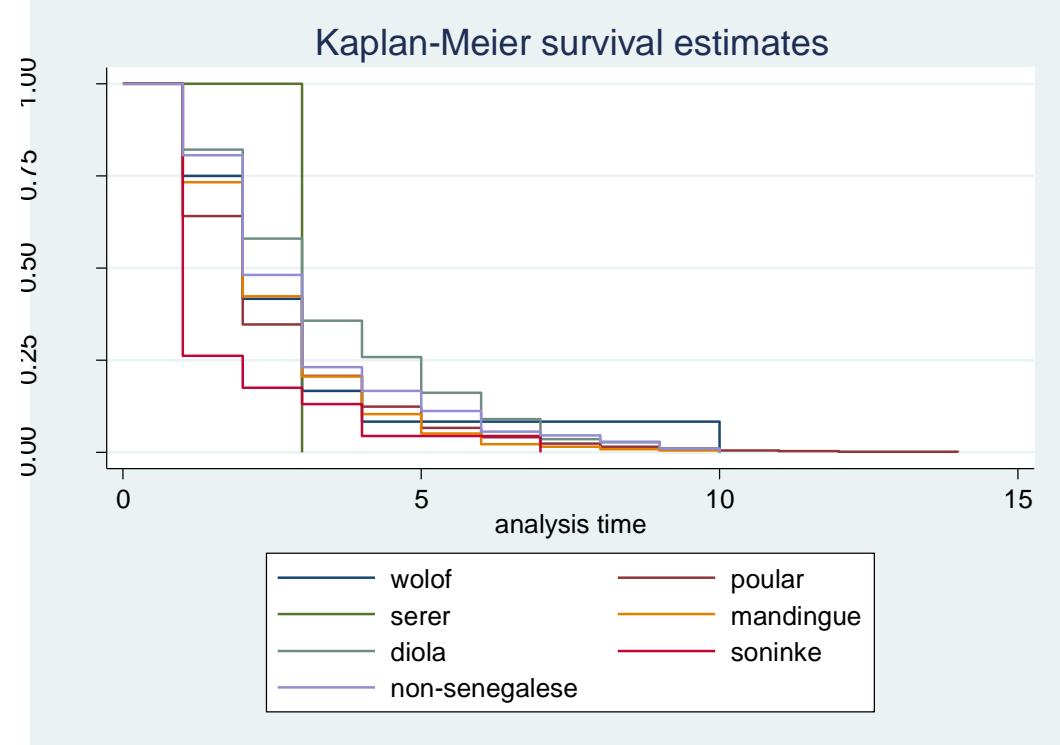

The rate of cutting at the different ages by wealth index are shown in Figure A4. The highest rate of cutting was found in girls born into the poorest household quintile but the differences by age were not statistically significant (log rank test, $\mathrm{p}=0.077$ ).

Figure A4. Rate of cutting girls by household wealth index (SDHS 2017)

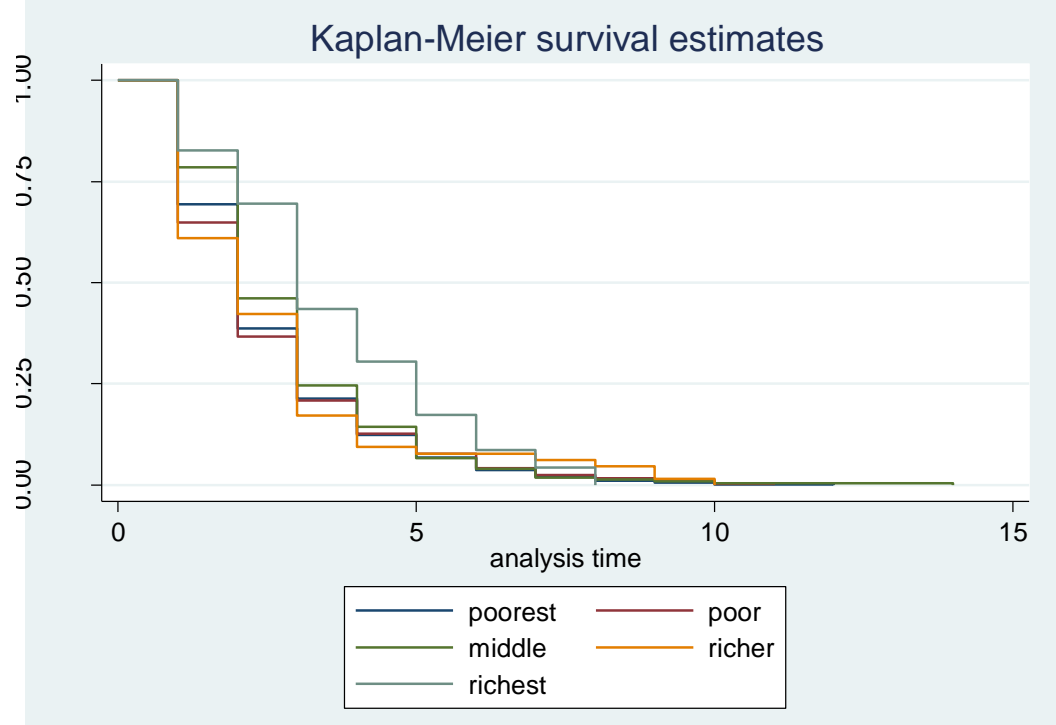


Variations in the rate of cutting by mother's support for FGM/C showed that those who supported the practice cut their daughters at a higher rate than those who did not within the first 5 years of life $(p=0.046)$. Beyond five years, the rate of cutting diminishes to near zero, with no major difference between the two groups (Figure A5).

Figure A5. Rate of cutting girls by mother's support for FGM/C (SDHS 2017)

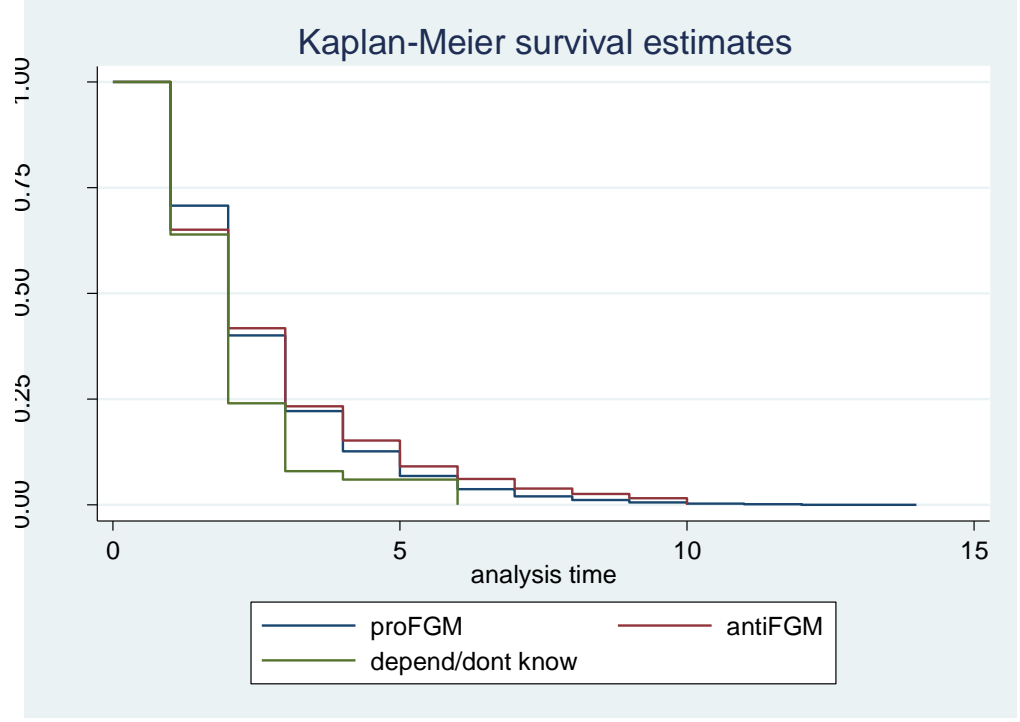

Figure A6 shows that mothers who underwent FGM/C generally cut their daughters at a higher rate than mothers who did not undergo the practice. This shows that while change may be occurring in space, time, and across, the differences in the rate of cutting by age were not statistically significant (log rank test, $\mathrm{p}=0.210$ ).

Figure A6. Rate of cutting girls by mother's FGM/C status (SDHS 2017)

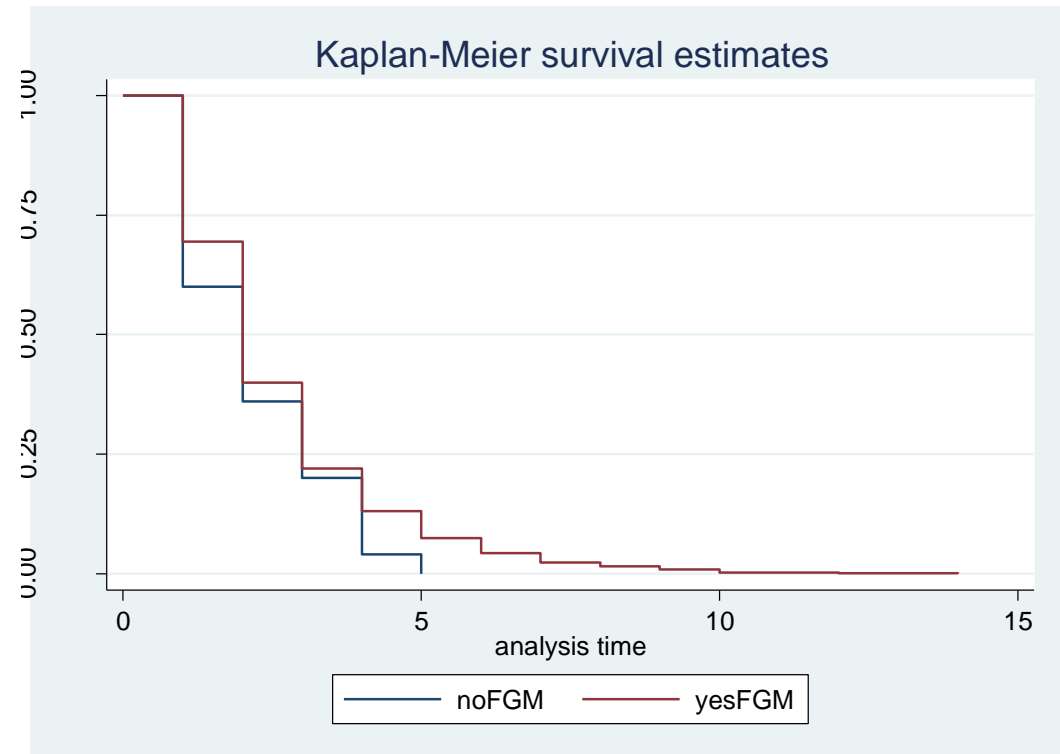

